\title{
Elucidating Solvation Structures for Rational Design of Multivalent Electrolytes-A Review
}

\author{
Nav Nidhi Rajput ${ }^{1,4} \cdot$ Trevor J. Seguin ${ }^{1,4} \cdot$ Brandon M. Wood $^{1,3,4}$. \\ Xiaohui Qu ${ }^{1,2} \cdot$ Kristin A. Persson ${ }^{1,2,4}$
}

Received: 2 August 2017 / Accepted: 23 March 2018 / Published online: 26 April 2018 (C) The Author(s) 2018

\begin{abstract}
Fundamental molecular-level understanding of functional properties of liquid solutions provides an important basis for designing optimized electrolytes for numerous applications. In particular, exhaustive knowledge of solvation structure, stability, and transport properties is critical for developing stable electrolytes for fast-charging and high-energy-density next-generation energy storage systems. Accordingly, there is growing interest in the rational design of electrolytes for beyond lithium-ion systems by tuning the molecular-level interactions of solvate species present in the electrolytes. Here we present a review of the solvation structure of multivalent electrolytes and its impact on the electrochemical performance of these batteries. A direct correlation between solvate species present in the solution and macroscopic properties of electrolytes is sparse for multivalent electrolytes and contradictory results have been reported in the literature. This review aims to illustrate the current understanding, compare results, and highlight future needs and directions to enable the deep understanding needed for the rational design of improved multivalent electrolytes.
\end{abstract}

This article is part of the Topical Collection "Modeling Electrochemical Energy Storage at the Atomic Scale"; edited by Martin Korth.

Nav Nidhi Rajput, Trevor J. Seguin, and Kristin A. Persson contributed equally to this work.

Kristin A. Persson

kapersson@1bl.gov

1 Lawrence Berkeley National Laboratory, Berkeley, CA 94720, USA

2 Department of Materials Science and Engineering, University of California, Berkeley, CA 94720-1760, USA

3 Graduate Group in Applied Science and Technology, University of California, Berkeley, CA 94720-1760, USA

4 Joint Center for Energy Storage Research (JCESR), Chicago, USA 
Keywords Multivalent electrolytes $\cdot$ Solvation structure $\cdot$ Renewable energy

\section{Introduction}

A key challenge of modern society is the sustainability of energy supply with increasing demand and depleting fossil resources. We are on the verge of a power revolution, where we desire enhanced energy storage devices with higher energy density, faster charge/discharge capability, and longer life compared to existing technologies. Access to low-cost and environmentally benign energy storage devices will not only transform the world's energy economy but also build a foundation for a carbon-free society. Li-ion batteries are considered a linchpin technology of energy storage because of their ubiquitous use in electric vehicles and electronic devices. However, current demands are pushing Li-ion technology to the limit of its capacity, which is raising serious safety concerns [1]. Even with the enhancement in energy density by $5 \%$ per year and a reduction of the cost by $8 \%$ per year, the Li-ion chemistry is perceived as incapable of meeting the high energy density, long cycle life, and low-cost requirements for future electric vehicles and electronic devices due to inherent materials limitations [2]. Hence, exploration of the vast space beyond Li-ion batteries to identify potentially safer, cheaper, and environmentally benign battery technologies is warranted.

In this context, alternative technologies such as metal-air, redox flow, and multivalent batteries are investigated. Among several proposed post-Li-ion technologies, multivalent ion batteries have spurred renewed popularity in the last two decades owing to their theoretically high volumetric capacity, improved safety, and eco-friendliness as compared to state-of-art Li-ion batteries. As multivalent cations $\left(\mathrm{Mg}^{2+}, \mathrm{Ca}^{2+}, \mathrm{Zn}^{2+}, \mathrm{Al}^{3+}, \mathrm{Y}^{3+}, \ldots\right)$ proffer more than one electron per redox center, they are capable of delivering significantly higher energy density as compared to monovalent $\mathrm{Li}$-ion and Na-ion batteries. Even though the concept of both divalent and trivalent batteries dates back to 1970 s, rechargeable trivalent batteries remain in the realm of scientific curiosities [3, 4] and greater success of divalent chemistries abated the momentum of global research efforts on trivalent batteries [5-8]. A successful secondary multivalent battery requires a metal or metal alloy negative electrode, a high-potential cathode material enabling reversible intercalation, and a non-flammable electrolyte that can provide efficient transport of ions between anode and cathode while supporting the formation of functional solid-electrolyte interphase. A practical electrolyte enables both a stable solid-electrolyte interphase (SEI), as well as facile ionic transfer through the interface. In many conventional electrolytes, divalent ion metals react with the electrolyte to form truly passivating surface films, which inhibit ionic transfer. For example, most magnesium analogues of lithium salts and typical solvents used in Li-ion batteries undergo decomposition at the $\mathrm{Mg}$ metal surface, resulting in a passivation layer that is both electronically as well as ionically insulating, hindering the cell chemistry $[5,9]$. This is in contrast to commercial Liion technology, where the graphite SEI, once formed, prohibits further reactions and supports Li-ion diffusion. 
However, the limitations and design metric of different multivalent ions are quite different from each other. For example, $\mathrm{Zn}$ exhibits a less negative electrochemical potential as compared to the standard hydrogen electrode $(-0.8 \mathrm{~V})$ than $\mathrm{Ca}(-2.9 \mathrm{~V})$ and $\mathrm{Mg}(-2.4 \mathrm{~V})$, however the volumetric capacity $(5851 \mathrm{~mA} \mathrm{~h} / \mathrm{ml})$ of the $\mathrm{Zn}$ metal anode is larger than that of the more popularly studied $\mathrm{Mg}$ (3833 $\mathrm{mA} \mathrm{h} / \mathrm{ml}$ ). Additionally, $\mathrm{Zn}$ metal is prone to dendrite formation upon cycling, limiting the lifetime and safety of a $\mathrm{Zn}$-ion battery. This was reported early in the reversible plating/stripping of zinc metal with aqueous electrolytes in which limited cycle life was observed [10]. However, more recent reports have shown markedly improved cycling performance, poising aqueous $\mathrm{Zn}$-ion batteries as promising candidates for grid applications due to lifetime, cost, and durability considerations [11]. Good compatibility of $\mathrm{Zn}$, particularly with conventional non-aqueous electrolytes, has also been observed [12]. Mg metal is less prone to dendrite formation, which makes it a potentially safer candidate system as compared to $\mathrm{Li}$ and $\mathrm{Zn}$ [13]. One of the main advantages in multivalent systems originates from volumetric energy gains on both electrodes, which directly impacts the resulting size of the battery and hence cost/kWh [14]. However, reversible multivalent chemistry is fraught with challenges; the major obstacles in the commercialization of $\mathrm{Ca}$-ion and $\mathrm{Mg}$-ion battery are the lack of suitable electrode materials in which ions can be inserted and extracted reversibly and supporting electrolytes that demonstrate the optimal conductivity, electrochemical stability window, and chemical compatibility with both electrode materials. While multivalent cations generally exhibit sluggish solid-state diffusion in most closepacked structures, recent investigations point to host structures with non-preferred coordination landscapes to achieve optimal mobility $[15,16]$. Furthermore, while $\mathrm{Zn}$ exhibits good cyclability in several electrolytes [12, 17, 18], and a few electrolytes show reversible plating and stripping of $\mathrm{Mg}$ metal [19-22], Ca has been proclaimed impossible for rechargeable energy storage applications [23]. However, recently, electrolyte formulations of $\mathrm{Ca}\left(\mathrm{ClO}_{4}\right)_{2}$ and $\mathrm{Ca}\left(\mathrm{BF}_{4}\right)_{2}$ in ethylene carbonate and propylene carbonate were demonstrated on $\mathrm{Ca}$ metal, albeit exhibiting approximately a $2-\mathrm{V}$ overpotential at elevated temperatures $\left(50-100{ }^{\circ} \mathrm{C}\right)$ [24].

Recently, the solvation structure and local dynamics of the electrolyte, as a function of the liquid components and concentrations thereof, has garnered increased attention in order to elucidate critically important phenomena for battery performance. For example, equilibrium ion association constants and diffusion coefficients impact ionic conductivity [25], as well as the formation and stability of the electrode-electrolyte interface [26], which in turn influences electrode stability and kinetics. In spite of the effort devoted to developing future electrolytes for multivalent batteries, there are still many unanswered questions regarding the intricate relationship between the electrolyte composition, structure, and dynamics, and the nature of the passivation layer formed at the metal interface. A desirable, rational designer approach to functional electrolytes requires a fundamental understanding of the local inter-molecular interactions, e.g., the solvation structure of the liquid solution and its impact on properties such as conductivity, viscosity, stability of the solution species, and resulting SEI. The term "outer sphere ion pair or ion pair" in liquid solutions is described for the oppositely charged species bonded together by 
simple electrostatic interactions, while species bound through short-range or covalent interactions in which a ligand temporarily donate a pair of electrons to fill an unoccupied orbital in the other atom (of neutral solvent molecule or negative ions) are described as "inner-sphere ion pair or complex" [27]. However, most methods of determining the association fail to distinguish between ion pair and complex formation. Also, since the solvated species are present in the solution through a series of equilibria, it is possible to observe simultaneous existence of different solvate species and complexes [27]. The outer sphere ion pairs are generally classified into four categories: (1) free ions, (2) solvent separated ion pairs (SSIPs), (3) contact ion pairs (CIPs), and (4) aggregates (AGGs). When both ions exhibit complete first solvation shells and do not share solvents, they are defined as free ions, however, when they share one or more solvent molecules, the solvate species is termed as SSIPs. When one to two and more than two counter-charged ionic species are present in the first solvation sphere of an ionic species, the ion pair is defined as CIP and AGG, respectively [28-30]. The true nature of the bonding is generally not known and some covalent character is expected to be present when ions are in close contact with each other. Both coulombic as well as covalent interaction energies contribute to the enthalpy term in free energy and the magnitude of enthalpy determines the extent of association between ions/molecules. Hence, the denomination of CIP and complex can sometimes be used interchangeably for the same species in the solution for e.g., $\mathrm{MgCl}^{+}$; similarly, higher AGGs are also termed as oligomers. Lastly, an ion pair complex is defined for a cationic and anionic complex that form an ion pair. In particular, when transition metal ions form a CIP or AGG with electron pair donors, they can form either cationic, anionic, or neutral complex. It is worth noting that when a monovalent salt $(Z=1)$ forms an ion pair, the net charge is zero with the formation of a CIP (e.g., $\left.\left[\mathrm{Li}^{+}-\mathrm{TFSI}^{-}\right]\right)$, similarly when a multivalent salt $(Z>1)$ forms an CIP the net charge is still zero (e.g., $\left[\mathrm{Mg}^{2+}-\mathrm{SO}_{4}{ }^{2-}\right]$ ), however when a multivalent cation $(Z>1)$ forms an ion pair with a monovalent anion $\left(Z^{\prime}=1\right)$ the net charge is $\left(Z-Z^{\prime}\right)$ q (e.g., $\left.\left[\mathrm{Mg}^{2+}-\mathrm{TFSI}^{-}\right]^{-}\right)[31]$.

It is well known that the structures of the active species in solution can significantly affect the kinetics of metal deposition and dynamics of charge-carrying species. In conventional electrolytes, the formation of ion pairs and AGGs are generally assumed to negatively affect the mobility of ions and the transference number, which in turn decreases the conductivity [32]. On the other hand, there is speculation that formation of CIPs in Li salts with low dielectric solvents can increase the overall dielectric constant of the electrolyte, improve solvation of free species at higher concentration and hence enable higher conductivity [33]. Furthermore, the formation of ion pairs can shift the electrochemical window of the electrolyte and the chemical constitution of the SEI [26, 30]. Recent computational studies show the impact of the solvation structure on the stability of anions in the multivalent electrolytes [30, 34]. The solvation structure of a liquid electrolyte and formation of ion pairs are known to depend on various parameters such as the nature, charge, size of the ionic species, total concentration, the dielectric constant, as well as chelating properties of the solvent, and the temperature [35]. For example, it has been observed that larger cations have a higher tendency to form complexes [36]. Recent simulation studies of multivalent electrolytes also show that the nature and geometry 
of the solvent molecule also play an important role in determining the association of the ions in solution [30]. Approaches to design electrolytes by gaining an understanding of the solvation structure and ion pairing - and their effect on the stability of inorganic salts and organic solvent, ionic conductivity, viscosity are imperative in building metrics to identify electrolyte components and formulations with better stability, solvation, and conductivity [30]. Considering the crucial role of electrolytes in the development of high-energy-density and safer multivalent batteries, in this review article we aim to provide a comprehensive analysis of the composition and solvation structure, with a particular focus on ion association, and its impact on battery performance for a range of multivalent electrolytes, covering $\mathrm{Ca}^{2+}, \mathrm{Mg}^{2+}$, and $\mathrm{Zn}^{2+}$ systems. We also discuss key advancements, major hurdles, and possible future directions in the research of multivalent electrolytes.

\section{Magnesium Electrolytes}

$\mathrm{Mg}$ metal possesses a multitude of exceptional properties such as high volumetric capacity $(3832 \mathrm{mAh} / \mathrm{ml})$, negative reduction potential $(-2.4 \mathrm{~V}$ vs. SHE), low equivalent weight (12.15 g/eq.), low cost ( $\$ 2 / \mathrm{kg})$, high melting point $(922.15 \mathrm{~K})$, eco-friendliness, and high abundance in the earth's crust, making it a good candidate anode material for high-energy-density rechargeable batteries. However, the reductive reactivity of $\mathrm{Mg}$ metal with atmospheric gasses such as $\mathrm{O}_{2}, \mathrm{H}_{2} \mathrm{O}, \mathrm{CO}_{2}$, and traditional non-aqueous electrolytes result in the formation of a passivation layer that is both electronically and ionically insulating. Furthermore, in contrast to Liion intercalation chemistry, very few solids are known to reversibly intercalate $\mathrm{Mg}^{2+}$ ions and no electrolytes have demonstrated the stability and conductivity required to enable a $>4.0-\mathrm{V}$ electrochemical window while exhibiting reversible $\mathrm{Mg}$ metal stripping and deposition. Today's Mg electrolytes are limited by their (1) insufficient anodic stability, which makes them incompatible with high-voltage cathode materials, (2) inability for reversible electrodeposition, and (3) low conductivity. Hence, intense efforts have been devoted to developing novel electrolytes to enable high-energy-density Mg-ion batteries. The high negative potential and activity of $\mathrm{Mg}$ metal render aqueous $\mathrm{Mg}$ electrolytes impractical, resulting in a preference for non-aqueous $\mathrm{Mg}$ electrolyte solutions. The difference in bonding and coordination environment of $\mathrm{Mg}$ ions in organomagnesium salts and simple $\mathrm{Mg}$ salts such as $\mathrm{Mg}(\mathrm{TFSI})_{2}$ and $\mathrm{Mg}\left(\mathrm{BH}_{4}\right)_{2}$ impacts the performance. For example, it was observed that the electrolyte exhibiting the highest degree of covalent bonding with $\mathrm{Mg}^{2+}$ such as $\mathrm{C}_{2} \mathrm{H}_{5} \mathrm{MgCl}$ results in the formation of complex species that are capable of reversible electrodeposition at the metal anode. On the other hand, ionically bonded compounds such $\mathrm{Mg}\left(\mathrm{ClO}_{4}\right)_{2}$ and $\mathrm{Mg}\left(\mathrm{BF}_{4}\right)_{2}$ result in the formation of CIPs and AGGs, which were found to be capable of supporting intercalation in most solvents but fail to show reversible electrodeposition of $\mathrm{Mg}^{2+}$ [5]. Gregory suggested that salts with weakly covalent bonding between $\mathrm{Mg}^{2+}$ and a bulky anion, such as $\mathrm{BBh}_{2} \mathrm{Ph}_{2}$, would result in SSIPs or CIPs between covalently bonded complexes and promote both reversible electrodeposition as well as intercalation [5]. Hence, the 
partial charge on the atoms and steric hindrance of the ligand attached to the metal ions have a significant effect on the interaction between metal cation and ligands, which ultimately control the reversible electrodeposition and intercalation of $\mathrm{Mg}^{2+}$ ions.

\subsection{Simple Inorganic Mg Salts}

Conventional simple inorganic $\mathrm{Mg}$ salts, such as $\mathrm{Mg}\left(\mathrm{BF}_{4}\right)_{2}, \mathrm{Mg}\left(\mathrm{ClO}_{4}\right)_{2}$, $\mathrm{Mg}\left(\mathrm{CF}_{3} \mathrm{SO}_{3}\right)_{2}, \mathrm{Mg}\left(\mathrm{SO}_{4}\right)_{2}, \mathrm{Mg}\left(\mathrm{NO}_{3}\right)_{2}, \mathrm{MgCl}_{2}$, and $\mathrm{Mg}\left(\mathrm{PF}_{6}\right)_{2}$, suffer from poor solubility in most solvents ( $<0.5 \mathrm{M}$ in ether) such as esters, ethers, alkyl carbonates, and are found to be incompatible with reversible stripping/plating at the $\mathrm{Mg}$ metal anode [5, 37]. Early studies of $\mathrm{Mg}$ salts in conventional polar aprotic solvents, namely acetonitrile (AN), propylene carbonate (PC), and tetrahydrofuran (THF), demonstrate the formation of a passivation layer and very high impedance due to either the reduction of solvent molecules (AN, PC) or inactivity of the solvent (THF), which leads to the reduction of salt anions and the deposit of electronically insulting species on the metal surface [37-39]. This passivation film, which is formed as a result of reactions between the active metal and solution species, does not allow conduction of $\mathrm{Mg}^{2+}$ ions in contrast to the functional surface films (solid-electrolyte interface, SEI) that form on negative electrodes in commercially available Li-ion batteries. The solvation structure of multivalent ions is likely to play a crucial role in determining both the formation of passivation film at the negative electrode as well as intercalation of ions at the positive electrode. It has been established that divalent ions such as $\mathrm{Mg}^{2+}, \mathrm{Zn}^{2+}$, and $\mathrm{Ca}^{2+}$ tend to form more stable ion pairs in solution as compared to monovalent alkali metal ions [40, 41]. A systematic theoretical study of the binding energy between different mono- as well as multivalent ions with a gas-phase solvent molecule by Okoshi et al. [41] shows remarkably larger binding energies for multivalent ions as compared to monovalent ions (Fig. 1). Assuming

Fig. 1 Relationships between de-solvation energies of $\mathrm{Li}$ ion and monovalent (Na: blue circle) ion and multivalent ion (Mg: red square) ions, as well as $\mathrm{SbCl}_{5}$ : green triangle). The dashed line corresponds to the energies of Li ion. Republished with permission of Journal of the Electrochemical Society from ref 41 ; permission conveyed through Copyright Clearance Center, Inc

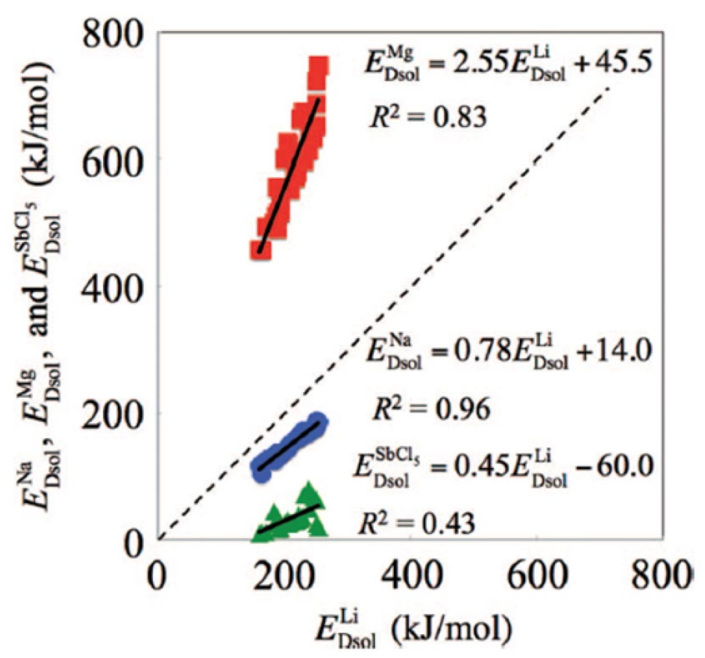


that higher molecular binding energies correlate with larger de-solvation energies in the liquid phase, it is suggested that the kinetics of charge transfer in multivalent systems would be more sluggish.

Even though $\mathrm{Mg}^{2+}\left(0.65 \AA\right.$ [42]) exhibits approximately the same size as $\mathrm{Li}^{+}$ (0.6 $\AA$ [42]), due to high charge density of magnesium, $\mathrm{Mg}$ electrolytes are highly prone to ion pair and complex formation, even at modest concentrations for a wide range of solvents [30, 32, 34, 43, 44]. Early work by Minofer et al. using MD simulations reported strong ion pair formation and even clustering in $0.5 \mathrm{M}$ aqueous solution of $\mathrm{Mg}(\mathrm{OAc})_{2}$ [6]. However, only recently the detailed solvation structure of non-aqueous $\mathrm{Mg}$ electrolytes was explored, where Rajput et al. examined the impact of bulk $\mathrm{Mg}$ electrolyte properties on the performance of $\mathrm{Mg}$-ion batteries using a high-throughput computational approach $[7,8] . \mathrm{Mg}(\mathrm{TFSI})_{2}$ is one of the few simple salts known that can be easily dissolved in many organic solvents and ionic liquids and show very high anodic stability. However, its compatibility with the $\mathrm{Mg}$ metal anode is still in question and often high overpotential and low coulombic efficiency have been observed for deposition and dissolution [44, 45]. The bulky size and highly delocalized charges of $\mathrm{TFSI}^{-}$typically result in better dissociation and lesser tendency to form ion pairs. Also, the connected $p$-orbitals in the TFSI ${ }^{-}$anion lower the total energy of the molecule and contributes to its stability. However, an analysis of the solvation structure of $\mathrm{Mg}(\mathrm{TFSI})_{2}$ in diglyme using MD simulations and X-ray total scattering by Saul et al. reveal formation of CIPs even at a moderate concentration of $0.4 \mathrm{M}$, where $\mathrm{Mg}^{2+}$ is sixfold coordinated by oxygen atoms including both a TFSI $^{-}$anion, and diglyme solvent molecules (Fig. 2), to form octahedral or distorted octahedral geometry in solution [43]. Recently, Raman spectroscopy also observed such sixfold coordination of $\mathrm{Mg}^{2+}$ ions in $\mathrm{Mg}(\mathrm{TFSI})_{2} /$ glyme solution in which two ether oxygen atoms originate from monoglyme and four oxygen atoms from the $\mathrm{TFSI}^{-}$anion [43]. However, due to the high flexibility of glymes and different conformers of the $\mathrm{TFSI}^{-}$anion, the number of oxygen atoms donated by glymes and $\mathrm{TFSI}^{-}$anion can vary based on salt concentration. Both simulation and

Fig. 2 Solvation structure of $\mathrm{Mg}(\mathrm{TFSI})_{2} /$ diglyme solution from $\mathrm{r}$-weighted form of the d-PDFs, rG(r), highlights the well-defined inner sphere features and broader solvation shells at longer distances (top). $\mathrm{Mg}-\mathrm{X}$ radial distribution functions from MD simulations (O: red, N: blue, C: grey, S: yellow). The corresponding simulation showing $\mathrm{Mg}^{2+}$ in space-filling format (magenta), TFSI- and diglyme in stick format (bottom). Reproduced from Ref. 43 by permission of the PCCP Owner Societies

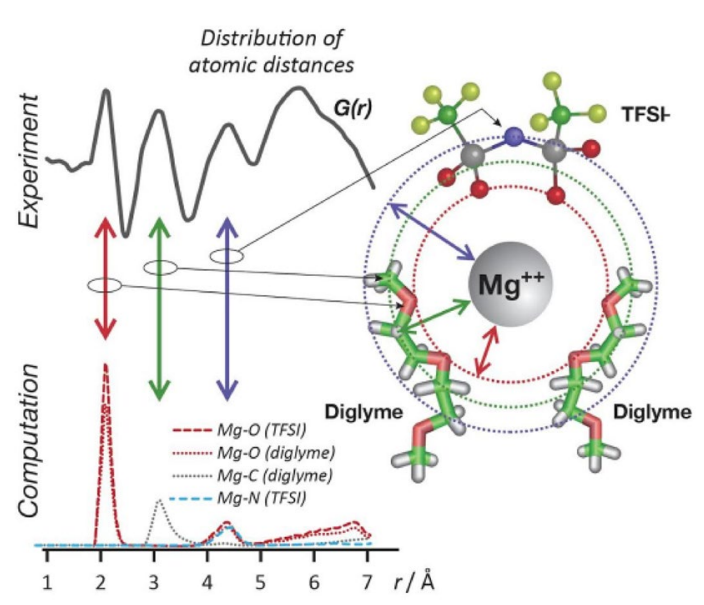


experiment validate that the TFSI ${ }^{-}$anion coordinates with metal cations $\left(\mathrm{Li}^{+}, \mathrm{Mg}^{2+}\right.$, $\mathrm{Zn}^{2+}$ ) through the oxygen atoms and not the nitrogen or fluorine $[8,43] . \mathrm{Mg}^{2+}$ is also known to form larger complexes through bridge formation including two or more cations, especially at high concentrations $[13,15]$. In electrolytes based on ionic liquids, such as $\mathrm{Pyr}_{14}$-TFSI or BMPyr-TFSI with $\mathrm{Mg}(\mathrm{TFSI})_{2}$, the $\mathrm{Mg}^{2+}$ cation is surrounded by three to four $\mathrm{TFSI}^{-}$anions with more bidentate and bridging $\mathrm{TFSI}^{-}$anions due to a higher population of TFSI $^{-}$in the solution [44]. Such ion association not only alters the effective charge of the solvated ions $\left(\left[\mathrm{Mg}_{\mathrm{n}}(\mathrm{TFSI})_{\mathrm{m}}\right]^{(\mathrm{m}-2 \mathrm{n})-}\right)$ but also affects the dynamics of ionic species in the solution as well as kinetics/energetics for desolvation at an electrode-electrolyte interface [43].

The concentration of the solute is a critical parameter in determining the formation of different ionic species in the solution, which in turn control the electrochemical performance of the electrolyte. High-concentration $(>1 \mathrm{M})$ electrolytes are often preferred, as they can potentially provide high ionic conductivity that in turn lowers the system's internal resistance [45]. Cyclic voltammograms of $\mathrm{Mg}(\mathrm{TFSI})_{2} /$ diglyme suggest an increase in current density of magnesium deposition/dissolution with an increase in salt concentration from $0.1 \mathrm{M}$ to $1.0 \mathrm{M}$ and a decrease with further
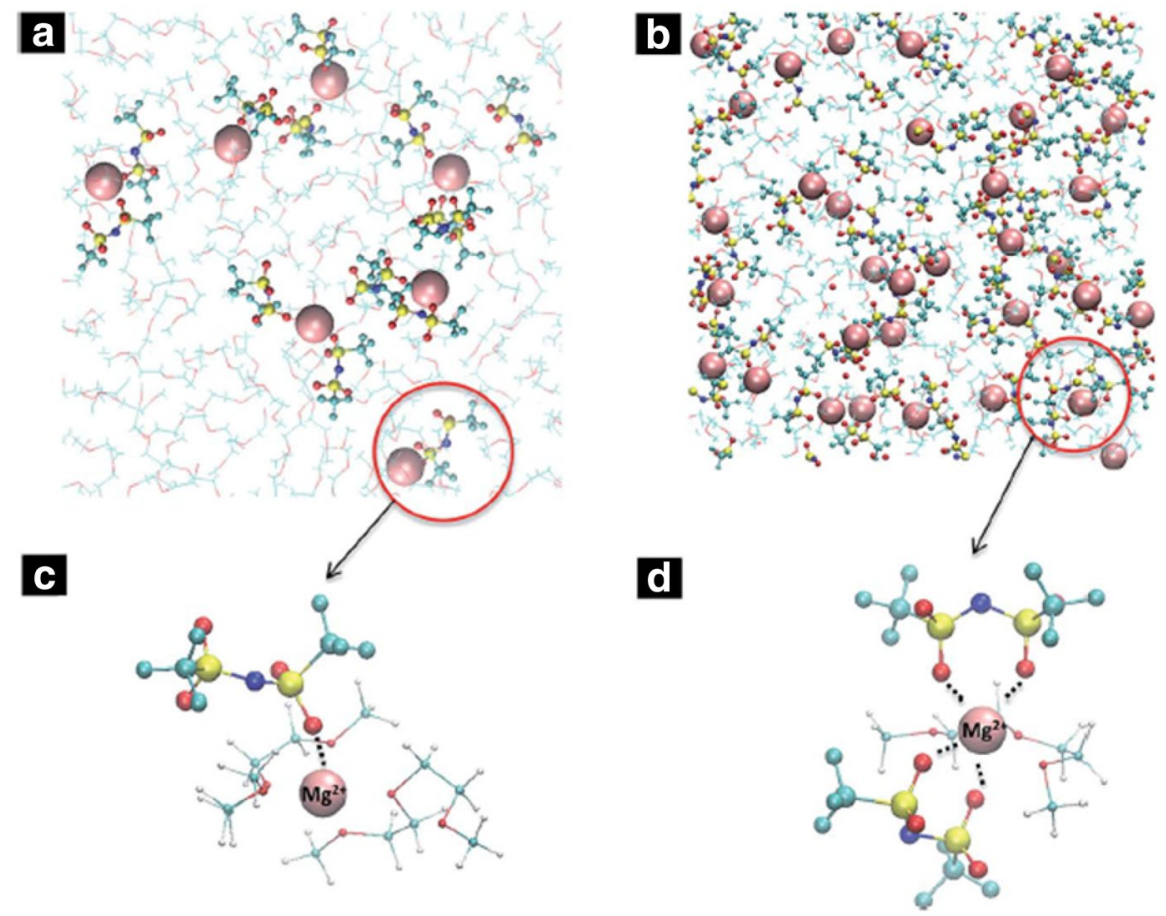

Fig. 3 Representative simulation snapshot of a $0.1 \mathrm{M}$; b $1.5 \mathrm{M} \mathrm{Mg}$ (TFSI) 2 /diglyme at $298 \mathrm{~K} . \mathrm{Mg}$ depicted in pink in space-filling format, TFSI in licorice, and diglyme in line format; $\mathbf{c}$ and $\mathbf{d}$ show the zoomed image of solvation structure around an $\mathrm{Mg}$ ion in $0.1 \mathrm{M}$ and $1.5 \mathrm{M}$ concentrations, respectively. Reproduced from Ref. 45 by permission of The Royal Society of Chemistry 
increase in concentration [45]. For $\mathrm{Mg}(\mathrm{TFSI})_{2} /$ diglyme classical MD simulations show the formation of SSIPs at low concentrations $(<0.4 \mathrm{M})$ and CIPs at higher concentrations, but no AGGs are observed even at $1.5 \mathrm{M}$ due to the non-coordinating nature of TFSI$^{-}$(Fig. 3a) [30]. However, higher numbers of monodentate coordination were observed at lower concentrations, whereas TFSI' ${ }^{-}$anions show more bidentate coordination at higher concentrations (Fig. 3b). The latter could significantly increase the desolvation energy, resulting in higher overpotential. Such increase in bidentate coordination, which increases the oxygen atom coordination with $\mathrm{Mg}^{2+}$, and CIP formation at higher concentration also negatively affects the ionic conductivity and transference number. Raman spectroscopy studies of the solvation environment of $\mathrm{Mg}(\mathrm{TFSI})_{2}$-ionic liquid also suggest the formation of both cis- and trans- conformer of TFSI $^{-}$in the solution, with predominantly monodentate interactions between $\mathrm{TFSI}^{-}$and $\mathrm{Mg}^{2+}$ at low concentrations and bidentate interactions at high concentrations [46]. Hence, it likely that at low concentrations TFSI $^{-}$anions which exist as CIPs are in the minimum energy transoid $\left(\mathrm{CF}_{3}\right.$ groups on the opposite side of the $\mathrm{S}-\mathrm{N}-\mathrm{S}$ plane) state, while at higher concentrations, a slightly higher local minima cisoid $\left(\mathrm{CF}_{3}\right.$ groups on the same side of the $\mathrm{S}-\mathrm{N}-\mathrm{S}$ plane) with $\sim 3.5 \mathrm{~kJ} /$ mol energy barrier compared to trans- conformer exists [28, 46]. Such increase in bi-dentate and bridging TFSI $^{-}$affects the dynamical properties as well as the desolvation energy of ions in the solution. Different solvates of varying sizes, including free TFSI', CIPs with mono and bidentate coordination and bridging aggregates with several metal centers have also been observed in the solution as a function of concentration [44-46].

The solvation structure depends strongly on the nature of the ligand, its geometry, and the concentration of the solute. Using MD simulations, Rajput et al. reported that for most $\mathrm{Mg}$ salts, SSIPs are observed in high-donor-number solvents such as DMSO and in long-chain glymes (e.g., tetraglyme) due to their high oxygendonor denticity and flexibility to chelate around the $\mathrm{Mg}^{2+}$ [30]. Glymes are known to enhance the solvation of metal ions via ion-dipole interaction with the oxygen atoms exhibiting high electron donicity [20]. Kimura et al. [47] also reported formation of SSIPs for $\mathrm{Mg}(\mathrm{TFSI})_{2} /$ triglyme(G3) by forming an $\left[\mathrm{Mg}(\mathrm{G} 3)_{2}\right]^{2+}$ cationic species for a concentration range of 0-1.6 M using Raman spectroscopy and DFT at the B3LYP/6-311+ $\mathrm{G}^{* *}$ level. The strong chelating effect of neutral glyme molecules on metal cations reduces the cation-anion interaction, which promotes SSIPs, as observed previously for Li salts [48]. Contrary to organic electrolytes such as $\mathrm{Li}$ salts in PC, Kimura et al. [47] observed an increase in ionicity (dissociativity) for $\mathrm{Mg}(\mathrm{TFSI})_{2}$ /triglyme electrolyte with an increase in salt concentration. A systematic study by Watanabe et al. using impedance and pulsed-filed gradient spin-echo NMR also reported a similar increase in ionicity for $\mathrm{Li}(\mathrm{TFSI})_{2} /$ triglyme in concentrated solutions $(\sim 3 \mathrm{M})[49,50]$. On the other hand, the MD simulations of $\mathrm{Mg}(\mathrm{TFSI})_{2}$ in short-chain glymes such as diglyme $(\mathrm{G} 2)$ and dimethoxyethane (G1) reported formation of CIPs and AGGs, respectively [30]. From both MD simulations and Fourier-transform infrared (FTIR) analysis, it was inferred that the tendency of $\mathrm{Mg}$ salts to form ion pairs in glymes monotonically decreases with an increase in chain length of glymes [20, 30, 51]. Similar to Watanabe's work on Li salt/glyme solution $[49,50]$, Watkins et al. [46] also reported an alternative class of ionic liquids known 
as "solvate" ionic liquids for $\mathrm{Mg}$ salts/glyme solutions with a general formula of $\mathrm{M}(\text { Glyme })_{\mathrm{m}}(\mathrm{X})_{\mathrm{n}}[\mathrm{M}=\mathrm{Li}, \mathrm{Mg} ; X=$ counter ion $]$. For a weakly Lewis basis anion such as TFSI $^{-}, \mathrm{M}(\text { Glyme })_{\mathrm{m}}(\mathrm{TFSI})_{\mathrm{n}}$ solutions behave as a typical ionic liquid with $\left[\mathrm{M}(\text { Glyme })_{\mathrm{m}}\right]^{+}$as the cationic species and exhibit properties similar to those of ionic liquids such as high oxidative stability, high thermal conductivity, high ionic conductivity, etc. [46, 50]. Solvated ionic liquid studies have primarily been performed for Li salts, and obtaining a detailed understanding of the properties of solvated ionic liquids for $\mathrm{Mg}$ electrolytes will be extremely beneficial.

Some widely used solvents such as high dielectric constant nitrogen chelating acetonitrile (AN) $(\varepsilon=37)$ and tetrahydrofuran (THF) shows formation of AGGs for most $\mathrm{Mg}$ salts resulting in very low solubility [20, 30]. Significant ion pairing of the $\mathrm{TFSI}^{-}$anions with $\mathrm{Li}^{+}$has also been observed in solvents such as glymes and acetonitrile, even at dilute concentrations [28, 52]. However, Raman spectroscopy results show a stronger interaction between Mg-TFSI than Li-TFSI due to the higher charge density and hardness of $\mathrm{Mg}^{2+}$ as compared to $\mathrm{Li}^{+}$[46]. The size of the anions and charge distribution also play an important role in forming CIPs and AGGs, for example, the steric effects and delocalization of negative charge in TFSI ${ }^{-}$ anions reduce the tendency to form ion pair compared to the small-sized $\mathrm{BH}_{4}^{-}$and $\mathrm{BF}_{4}^{-}$anions. Hence, not just the dielectric constant of the solvent but also the size of the solvent and anions, donor number and denticity of solvents, and coordination property of the chelating ligands play a crucial role in determining the speciation of the solution. Even though numerous species have been reported in the literature for simple $\mathrm{Mg}$ salts, understanding the relationship between the solvation structure and the electrochemical properties of the electrolytes is still in its infancy. Mohtadi et al. [53] suggested that one possible reason for the failure of salts such as $\mathrm{Mg}(\mathrm{TFSI})_{2}$ in organic solvents could be the thermodynamic potential of $\mathrm{Mg}$ ion insertion into the host matrices. However, recent computational study suggests that intermediate reduced $\mathrm{Mg}^{1+}$ species can activate new decomposition modes for the species coordinated to the $\mathrm{Mg}$ ion in an ion paired configuration. Specifically, at $\mathrm{Mg}$ metal potentials, the ion pair undergoes partial reduction at the $\mathrm{Mg}$ cation center
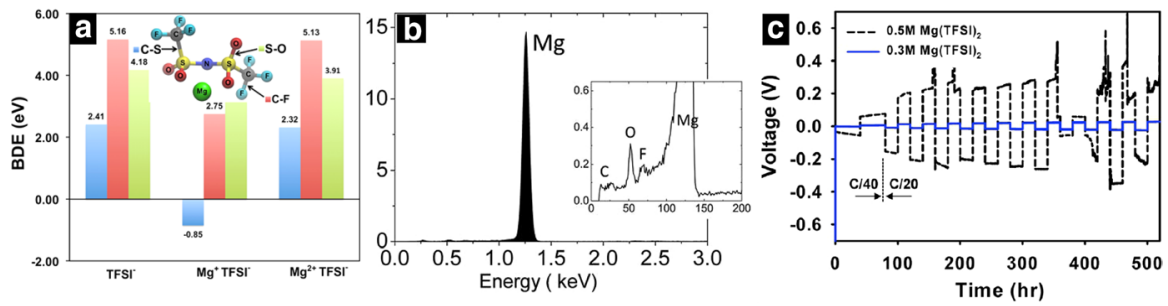

Fig. 4 a Bond dissociation energy (BDE) of TFSI ${ }^{-}$anion in different chemical environments corresponding to well-solvated, $\mathrm{Mg}^{1+}$ ion paired and $\mathrm{Mg}^{2+}$ ion paired configurations from DFT calculations. Adapted with permission from Ref 30. Copyright 2015 American Chemical Society. b Energy-dispersive X-ray spectroscopy analysis of deposited $\mathrm{Mg}$ metal from a $\mathrm{Mg}(\mathrm{TFSI})_{2}$ /diglyme electrolyte. Inset shows zoomed image at low energy. Reproduced from Ref. 45 by permission of The Royal Society of Chemistry. c Galvanostatic cycling of $\mathrm{Mg} / \mathrm{Mg}$ cells at a rate of $\mathrm{C} / 20$ after the first cycle at $\mathrm{C} / 40$. Adapted with permission from Ref. 20. Copyright 2014 American Chemical Society 
$\left(\mathrm{Mg}^{2+} \rightarrow \mathrm{Mg}^{1+}\right)$, which competes with the charge transfer mechanism and activates the anion to render it susceptible to decomposition, thereby limiting the cathodic stability of the electrolyte (Fig. 4a) [30]. Recent scanning electron microscopy study [45] of $\mathrm{Mg}(\mathrm{TFSI})_{2} /$ diglyme solution for a concentration range from 0.1 to $1.5 \mathrm{M}$ also observed trace signal of elements $\mathrm{C}, \mathrm{O}$, and $\mathrm{F}$, confirming decomposition of anions possibly by initiation with $\mathrm{C}-\mathrm{S}$ bond breaking or solvent molecules during cycling as observed in simulations (Fig. 4b), [30, 45]. Ha et al. [20] also observed a difference in cathodic stability behavior of $\mathrm{Mg}(\mathrm{TFSI})_{2} /$ glymes electrolyte as a function of salt concentration (Fig. 4c), which is possibly due to an increase in ion pair formation as a function of increased concentration ultimately leading to enhanced decomposition of $\mathrm{TFSI}^{-}$as mentioned above. Conversely, anions that are known to support reversible plating/stripping of $\mathrm{Mg}$ metal, such as $\mathrm{BH}_{4}{ }^{-}$, exhibit stable bonds even when ion paired with the transient, highly reactive $\mathrm{Mg}^{+}$species [30].

As discussed above, an increase in salt concentration is often known to lead to the formation of CIPs or AGGs, which in turn decreases the conductivity and increases the viscosity of the solution and is also likely to put a penalty on the stability of the delivery vehicle. It should also be noted that CIPs with multivalent ions, $\left[\mathrm{Mg}(\mathrm{TFSI})_{n}\right]^{(2-n)}$, are cationic complexes, unlike the neutral CIPs, $\left[\mathrm{Li}(\mathrm{TFSI})_{n}\right]^{(1-n)}$, formed with monovalent ions. Similarly, the AGGs that form, $\left[\mathrm{Mg}_{z}(\mathrm{TFSI})_{n}\right]^{(2 z-n)}$, can exhibit neutral or anionic composite charges [30]. Hence the effect of CIPs and AGGs on the ionic conductivity and transference number in divalent cation electrolytes are likely quite different than for monovalent systems. At concentrations where CIPs and AGGs form, the conductivity in divalent systems can decrease due to the formation of neutral ion pairs or due to a decrease in the mobility of large chargecarrying species (Fig. 5a, b). Classical MD simulation studies of Mg(TFSI) 2 demonstrate the formation of $\mathrm{AGGs}$ for $\mathrm{Mg}(\mathrm{TFSI})_{2}$ in short-chain glymes and acetonitrile and SSIPs in DMSO and tetraglyme, but the diffusion constant of ionic species was found to be faster in AN and short-chain glymes (Fig. 5c) [30]. The faster dynamics observed is likely due to lower viscosity in case of AN and weaker interaction between the ions and the solvent molecules in case of glymes. Hence, interestingly,
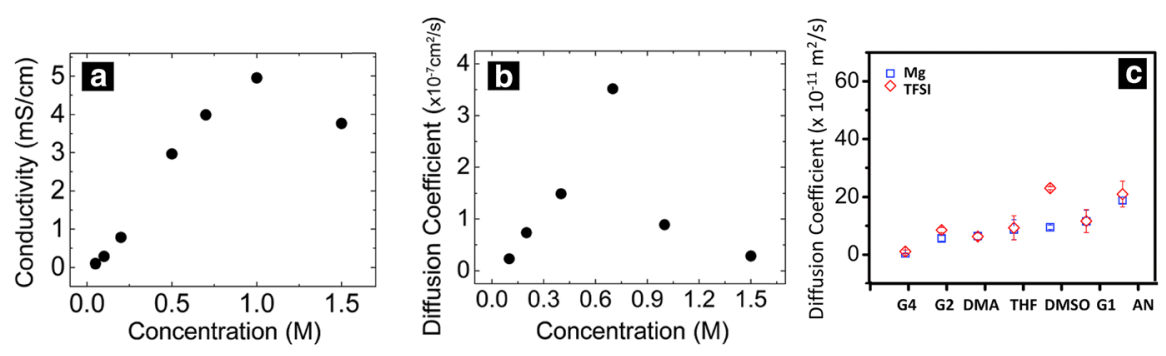

Fig. 5 a Concentration-dependent ionic conductivity and $\mathbf{b}$ diffusion coefficient of $\mathrm{Mg}(\mathrm{TFSI})_{2} /$ diglyme electrolyte at a concentration range from 0.1 to $1.5 \mathrm{M}$. Reproduced from Ref. 45 by permission of The Royal Society of Chemistry. c Self-diffusion coefficients of $\mathrm{Mg}^{2+}$ and $\mathrm{TFSI}^{-}$in seven different solvents (shown on x-axis) displayed with error bars. Adapted with permission from Ref 30. Copyright 2015 American Chemical Society 
depending on the properties of solvent molecules and the mechanism of diffusion, it is possible to have a faster mobility of large-size AGGs compared to smaller CIPs.

Two modes of ion transport often discussed in the literature are structural and vehicular ion diffusion. Structural diffusion is defined as the exchange of counterion or solvent molecules in the first solvation shell of the metal cation, whereas vehicular diffusion is the motion of metal cation along with the molecules in the first solvation shell. Experimental conductivity measurement of $\mathrm{Mg}(\mathrm{TFSI})_{2}$-IL solution observed a decrease in conductivity as a function of salt concentration. Further PFG-NMR results show a decrease in the mobility of $\mathrm{TFSI}^{-}$and an increase in the viscosity of the solution due to increase in $\mathrm{Mg}^{2+}-\mathrm{TFSI}^{-}$association as the salt concentration increases. Jeremias et al. [44] suggested the possibility of structural diffusion in $\mathrm{Mg}(\mathrm{TFSI})_{2}$-IL electrolytes by exchange of $\mathrm{TFSI}^{-}$anions between "free" TFSI $^{-}$and neighboring $\left[\mathrm{Mg}_{n}(\mathrm{TFSI})_{m}\right]^{(m-2 n)-}$ clusters (Fig. 6). Bidentate $\mathrm{TFSI}^{-}$ coordination was found to be stronger and stable as compared to bridge complexes. Hence, due to the strong interaction between bidentate $\mathrm{TFSI}^{-}$anions and $\mathrm{Mg}^{2+}$, the mobility of $\mathrm{Mg}$ clusters can be higher than the exchange rate of bidentate TFSI- anions. Such hopping of ions explains the non-linear trend of conductivity as a function

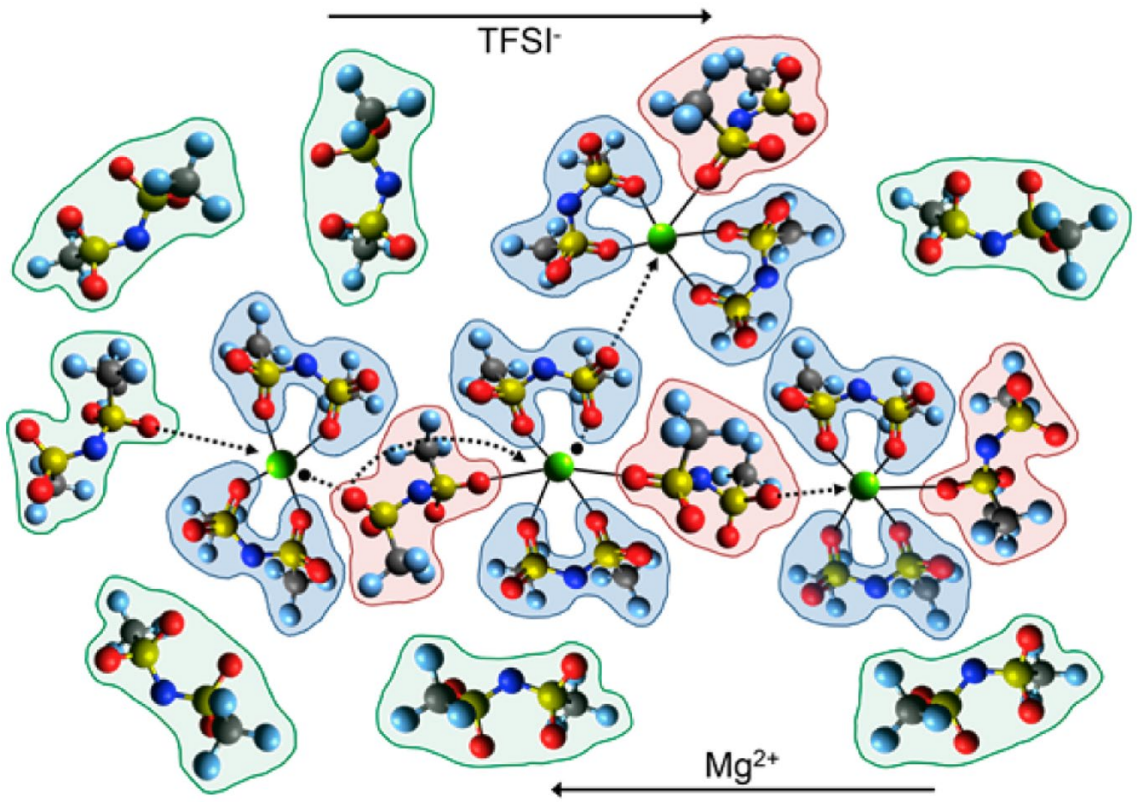

Fig. 6 Proposed mechanisms of structural diffusion in the $\mathrm{Mg}^{2+}-\mathrm{IL}$ electrolytes, where the dashed lines indicate interactions being formed $(\bullet)$ and broken $(\bullet)$. The weakly coordinating monodentate and bridging TFSI $^{-}$anions tend to rapidly exchange between different ionic clusters, resulting in a faster process. On the other hand, strong coordination of bidentate TFSI $^{-}$anions results in a vehicular diffusion of the cluster followed by a slower process, which involves exchange of the bidentate anions via a bidentate to bridging mechanism. The Pyr $1 \mathrm{x}^{+}$cations are omitted for simplicity. Reprinted with permission from Ref 44. Copyright 2014 American Chemical Society 
of concentration observed by Jeremias et al. and the faster diffusion observed for $\mathrm{Mg}(\mathrm{TFSI})_{2}$ from MD simulations by Rajput et al. in acetonitrile and monoglyme solutions where AGGs were observed [30]. However, a deeper, detailed understanding of the effect of the molecular organization of the electrolyte and modes of ion transport on the diffusion coefficient, conductivity, and viscosity is desirable.

Salama et al. [54] combined DFT, NMR, and single-crystal X-ray diffraction (SCXRD) to explore the solvation structure of $\mathrm{Mg}(\mathrm{TFSI})_{2}$ in dimethoxyethane (DME). DME was found to be a promising solvent in both Li-oxygen and Li-sulfur chemistries and results in higher conductivity of the ionic species, while TFSI ${ }^{-}$ -based salts are highly soluble due the delocalized charge and larger size of the TFSI $^{-}$anion as discussed above. At all concentrations studied $(0.05-1.3 \mathrm{M})$, the dissolution of $\mathrm{Mg}(\mathrm{TFSI})_{2}$ results in $\mathrm{Mg} .3 \mathrm{DME}$ as a stable moiety, where $\mathrm{Mg}^{2+}$ ions are encaged by three DME molecules (Fig. 7a). The Raman spectra results for $\mathrm{Mg}(\mathrm{TFSI})_{2} / \mathrm{DME}$ solution indicate the formation of either SSIPs or free TFSI' ions irrespective of the concentration $(0.05-1.3 \mathrm{M})$ (Fig. $7 \mathrm{~b}$ ). These results are in disagreement with the previous simulation and experimental studies of $\mathrm{Mg}$ salt in glymes, which suggests the formation of CIPs and AGGs in short-chain glymes such as DME and diglyme [20, 30, 34, 44]. Indeed, the experimental conductivity measurements by Salama et al. show a decrease in conductivity after $0.9 \mathrm{M}$, indicating the formation of AGGs and increase in viscosity (Fig. 7c). Hence, it is surprising that Salama et al. observed SSIPs and free anions for $\mathrm{Mg}(\mathrm{TFSI})_{2} / \mathrm{DME}$ irrespective of the salt concentration. Even though spectroscopy techniques such as NMR and Raman are powerful techniques, they have been reported to be inadequate to provide reliable information about ion association equilibria [55]. As the detection limit of NMR [1] $\mathrm{H}$ and [13] $\mathrm{C}$ is typically low, it is possible that some minority species were not detected by the NMR studies performed by Salama et al.

Several recent studies have reported enhancement in electrochemical performance through the current density and coulombic efficiency for reversible $\mathrm{Mg}$ deposition with the addition of $\mathrm{MgCl}_{2}$ to $\mathrm{Mg}$ salts such as $\mathrm{Mg}(\mathrm{TFSI})_{2}$ [56]. Although, while a detailed understanding of the species present in the solution in the mixed salt system is pending, a single-crystal diffraction and electrospray ionization mass
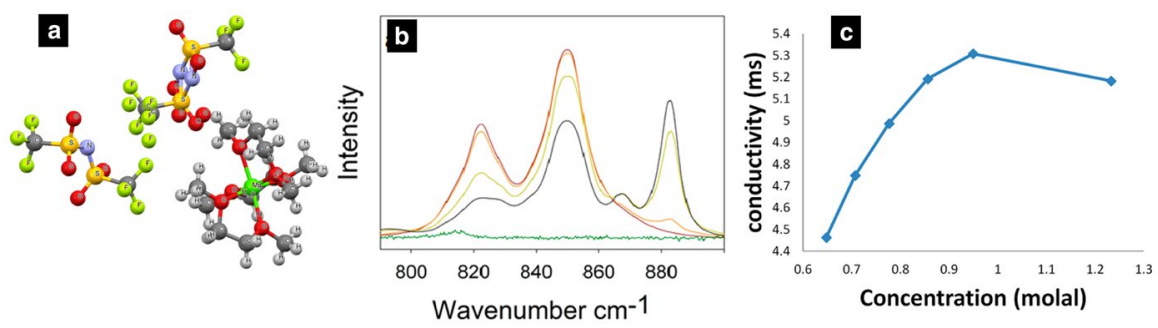

Fig. 7 a Refined SCXRD structure for $\mathrm{MgTFSI}_{2}$ single crystal, recrystallized from $\mathrm{MgTFSI}_{2} / \mathrm{DME}$ solution. b Raman spectra of pure DME (brown line), U-phase (orange line), L-phase (yellow line), 1.25 $\mathrm{M} \mathrm{MgTFSI}_{2}$ solution in DME, and powder pure $\mathrm{MgTFSI}_{2}: 750-900 \mathrm{~cm}^{-1}$ spectral region. c Conductivity measurements of $\mathrm{MgTFSI}_{2} / \mathrm{DME}$ solutions at various salt concentrations. Adapted with permission from Ref 54. Copyright 2016 American Chemical Society 


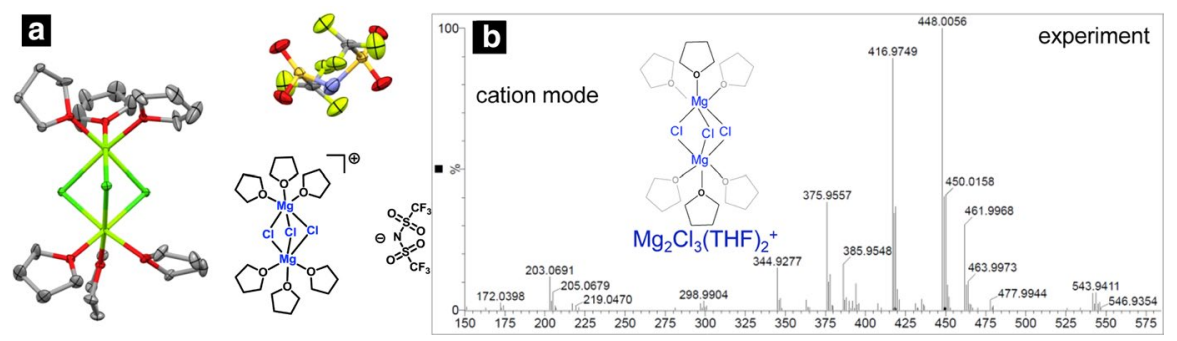

Fig. 8 a Displacement of ellipsoid representation of $\left[\mathrm{Mg}_{2} \mathrm{Cl}_{3}(\mathrm{THF})_{6}\right]^{+}[\mathrm{TFSI}]^{-}$. b ESI-MS spectrum of $0.5 \mathrm{M} \mathrm{Mg}(\mathrm{TFSI})_{2}-\mathrm{MgCl}_{2}$ at the ratio of 1:(0.5) in THF (experimental measurement in positive mode). Adapted with permission from Ref 56. Copyright 2016 American Chemical Society

spectroscopy (ESI-MS) study by Sa et al. reveal formation of an ion pair complex composed of a cation $\left[\mathrm{Mg}_{2} \mathrm{Cl}_{3}(\mathrm{THF})_{6}\right]^{+}$and the [TFSI]- anion (Fig. 8) in the solution [56]. The cationic species reported here is the widely accepted electroactive species present in the magnesium organohaloaluminate or organomagnesium electrolytes in THF responsible for the reversible magnesium deposition/dissolution. This suggests that irrespective of anions such as $\mathrm{TFSI}^{-}$, magnesium and chlorine have a strong tendency to form a bridge complex where chloride ions are shared by more than one magnesium ion. As previous simulation results suggested formation of AGGs in $\mathrm{Mg}$ (TFSI) $)_{2}$ THF solution [30], it is likely that the addition of $\mathrm{MgCl}_{2}$ results in a competing interaction between $\mathrm{TFSI}^{-}$and $\mathrm{Cl}^{-}$anions, where the strong electrostatic interactions between $\mathrm{Mg}^{2+}-\mathrm{Cl}^{-}$results in formation of a cationic complex species while the weaker ionic interaction between $\mathrm{Mg}^{2+}-\mathrm{TFSI}^{-}$results in formation of CIPs of $\mathrm{TFSI}^{-}$anion with the $\left[\mathrm{Mg}_{\mathrm{x}} \mathrm{Cl}_{\mathrm{y}}\right]^{+}$complex.

$\mathrm{Mg}\left(\mathrm{BH}_{4}\right)_{2}$ is an example of another simple and non-corrosive inorganic $\mathrm{Mg}$ salt that has gained much popularity over the last few years due to its compatibility with a Mg metal anode [57, 58]. Both Mohtadi et al. [53] and Shao et al. [57] reported significant ion pair and aggregate formation of $\mathrm{Mg}\left(\mathrm{BH}_{4}\right)_{2}$ in diglyme, dimethoxyethane, and THF solvents using IR and NMR spectroscopy analyses [53, 57]. Later MD simulations confirmed a strong tendency of $\mathrm{Mg}\left(\mathrm{BH}_{4}\right)_{2}$ to form CIPs and AGGs in most solvents except DMSO and tetraglyme [30]. Also, stronger interaction between $\mathrm{Mg}^{2+}$ and $\mathrm{BH}_{4}^{-}$was observed in THF as compared to DME in agreement with previous experimental results reported by Mohtadi et al. The interaction between $\mathrm{Mg}^{2+}$ and $\mathrm{BH}_{4}^{-}$was observed to be mediated through the $\mathrm{Mg}-\mathrm{H}$ bond instead of the $\mathrm{Mg}-\mathrm{B}$ bond, which results in a strong covalent bonding between $\mathrm{Mg}^{2+}-\mathrm{BH}_{4}^{-}$, especially in weakly coordinating solvents $[51,57,58]$. Yuyan et al. investigated the effect of ligands on the electrochemical properties of $\mathrm{Mg}\left(\mathrm{BH}_{4}\right)_{2} /$ glyme electrolytes [51]. They observed that the electrochemical performance (coulombic efficiency, overpotential, and current density) of $\mathrm{Mg}\left(\mathrm{BH}_{4}\right)_{2}$ is enhanced with an increase in the chain length of glyme from DME (G1) to tetraglyme (G4) (Fig. 9a). Classical MD simulations demonstrate that the $\mathrm{Mg}-\mathrm{O}($ Glyme $)$ distance decreases and the coordination number of $\mathrm{Mg}-\mathrm{BH}_{4}$ decreases monotonically with an increase in chain length of glymes from DME to tetraglyme, indicating stronger coordination between $\mathrm{Mg}^{2+}$ 

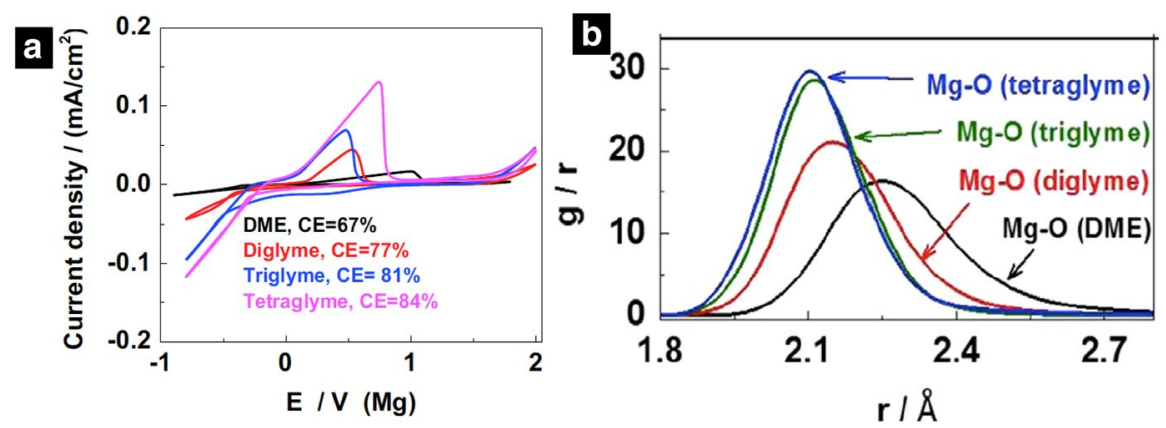

Fig. 9 a Cyclic voltammograms $\left(20 \mathrm{mVs}^{-}{ }^{1}\right)$ of $0.01 \mathrm{M} \mathrm{Mg}\left(\mathrm{BH}_{4}\right)_{2}$ in glymes on a Pt electrode. b Radial distribution function of $\mathrm{Mg}-\mathrm{O}$ (solvent) of $\mathrm{Mg}\left(\mathrm{BH}_{4}\right)_{2}$ in $\mathrm{DME}$, diglyme, triglyme, and tetraglyme from MD simulations. Reprinted from Ref. 51 with permission from Elsevier

and longer chain glymes (Fig. 9b). Similar trends of decreasing cation-anion coordination number with an increase in chain length of glymes were also reported for other Mg salts using MD simulations [30]. It should be noted that the donor number (DN), which is commonly referred to as an index of the Lewis base character of solvent, follows the order DME/monoglyme (24.0) $>$ diglyme (19.5) $>$ triglyme $(-)>$ tetraglyme (16.6) [20] while their dielectric constant is very similar; approximately 7 . However, the high oxygen donor denticity and flexibility with an increase in chain length improves the solvation of the metal cation with an increase in chain length. On the other hand, such improved solvation comes at the cost of slow mobility of ionic species, as suggested by the diffusion coefficient results from MD simulation, showing that the mobility of both cation and anion decreases monotonically with an increase in chain length of glymes [30]. Hence, a mixture of glymes is often used to obtain an optimal combination of dissociation and conductivity.

Few studies have suggested that the addition of additives such as $\mathrm{LiBH}_{4}$ or other $\mathrm{Mg}$ salts reduces the strong interaction between $\mathrm{Mg}^{2+}$ and $\mathrm{BH}_{4}{ }^{-}$, resulting in an enhancement of the electrochemical performance. However, it is worth noticing that any addition of other electrochemically active species such as $\mathrm{Li}$ convolutes the evaluation of the role of the $\mathrm{Mg}$ electrochemical response [59]. Recently, $\mathrm{Hu}$ et al. investigated the solvation structures and dynamics of $\mathrm{Mg}\left(\mathrm{BH}_{4}\right)_{2}$ and $\mathrm{Mg}(\mathrm{TFSI})_{2}$ dissolved in diglyme (DGM) at various concentrations and ratios of $\mathrm{Mg}\left(\mathrm{BH}_{4}\right)_{2} /$ $\mathrm{Mg}(\mathrm{TFSI})_{2}$ using a combination of natural abundance ${ }^{25} \mathrm{Mg} \mathrm{NMR}$, quantum chemistry calculations of ${ }^{25} \mathrm{Mg}$ NMR chemical shifts, classical MD calculations, and electrochemical performance tests [60]. They observed that for $0.01 \mathrm{M} \mathrm{Mg}\left(\mathrm{BH}_{4}\right)_{2}$ (which is the saturated concentration in DGM), the first solvation shell of $\mathrm{a} \mathrm{Mg}^{2+}$ ion contains two $\mathrm{BH}_{4}^{-}$anions and one DGM molecule as a tridentate chelating the $\mathrm{Mg}^{2+}$, while the second solvation shell consists of five DGM molecules (Fig. 10a Structure-A). In contrast, for the system of $\mathrm{Mg}(\mathrm{TFSI})_{2}$ in DGM, at dilute concentrations, TFSI ${ }^{-}$is fully dissociated from $\mathrm{Mg}^{2+}$ while at high concentration $\mathrm{Mg}^{2+}$ and TFSI $^{-}$are only partially dissociated with CIPs formed between $\mathrm{Mg}^{2+}$ and $\mathrm{TFSI}^{-}$ (Fig. 10a Structure-B). An exchange mechanism between solvation structures in the 
a

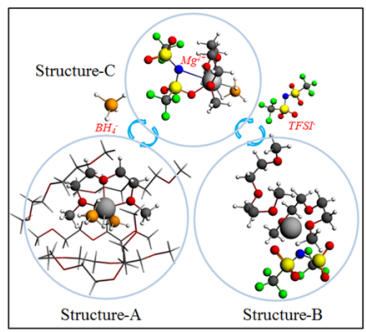

b

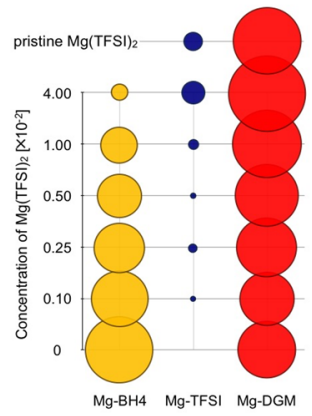

C

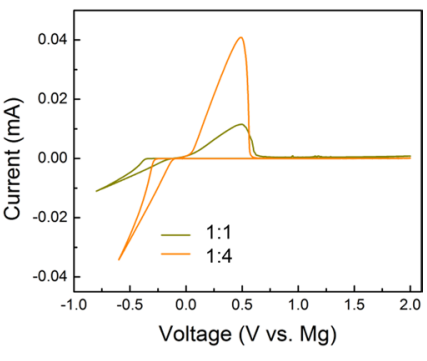

Fig. 10 a The exchange mechanisms and solvation structures in the combined electrolyte containing both $\mathrm{Mg}\left(\mathrm{BH}_{4}\right)_{2}$ and $\mathrm{Mg}(\mathrm{TFSI})_{2}$ in diglyme (DGM), highlighting that Structure-A is changed to Structure- $\mathrm{B}$ via intermediate Structure-C. b Coordination number of $\mathrm{Mg}^{-\mathrm{BH}_{4}}, \mathrm{Mg}$-TFSI and Mg-DGM in mixed solutions of $\mathrm{Mg}\left(\mathrm{BH}_{4}\right)_{2}$ and $\mathrm{Mg}(\mathrm{TFSI})_{2}$ (b) cyclic voltammetry of electrolyte solutions prepared in diglyme with different concentrations of $\operatorname{Mg}(\mathrm{BH} 4) 2$ and $\operatorname{Mg}(\mathrm{TFSI}) 2$ as labeled. The scan rate was $20 \mathrm{mV} / \mathrm{s}$. Reprinted from Ref. 60 with permission from Nano Energy

combined electrolyte containing both $\mathrm{Mg}\left(\mathrm{BH}_{4}\right)_{2}$ and $\mathrm{Mg}(\mathrm{TFSI})_{2}$ in DGM was found to result in a single observed ${ }^{25} \mathrm{Mg}$ NMR peak. Such solvent exchange is responsible for the more uncoordinated anions, improved stability, and ionic conductivity of the mixed anion composition as compared to each single anion solution. For the solvent exchange mechanism, an intermediate Structure-C (Fig. 10a) with its first solvation shell similar to Structure-A but with one $\mathrm{BH}_{4}^{-}$replaced by a TFSI ${ }^{-}$anion was found to be responsible for facilitating the process. Such stable $\mathrm{Mg}$ species in mixed $\mathrm{Mg}$ electrolytes $\left[\mathrm{Mg}-\mathrm{BH}_{4}-\mathrm{TFSI}\right] /$ solvent, potentially reduce the possibility of the $\mathrm{TFSI}^{-}$anion decomposition that was observed in $\mathrm{Mg}(\mathrm{TFSI})_{2} / \mathrm{DGM}$ solutions in previous simulation results. By mixing two competing $\mathrm{Mg}$ salts, they were able to reduce the strong covalent interactions between $\mathrm{Mg}^{2+}$ and $\mathrm{BH}_{4}^{-}$anions. A small increase is observed in the coordination number of Mg-TFSI and a significant increase in the interaction of $\mathrm{Mg}^{2+}$ ions with glymes (Fig. 10b). The weakest interaction between $\mathrm{Mg}^{2+}$ ions with $\mathrm{BH}_{4}{ }^{-}$and $\mathrm{TFSI}^{-}$anions were observed when the ratio of $\mathrm{Mg}\left(\mathrm{BH}_{4}\right)_{2}$ and $\mathrm{Mg}(\mathrm{TFSI})_{2}$ is 1:4. Battery performance tests indicated that the efficiency of reversible plating/stripping of $\mathrm{Mg}$ strongly depends on the concentration and the ratios of $\mathrm{Mg}\left(\mathrm{BH}_{4}\right)_{2}$ and $\mathrm{Mg}(\mathrm{TFSI})_{2}$ in DGM that is optimal at the $\mathrm{Mg}\left(\mathrm{BH}_{4}\right)_{2}$ and $\mathrm{Mg}(\mathrm{TFSI})_{2}$ ratio of approximately 1:4, owing to both the enhanced molecular dynamics and the stability of the TFSI ${ }^{-}$anion (Fig. 10c).

Excitingly, Mohtadi et al. recently introduced 3-D boron clusters as potential anions for $\mathrm{Mg}$ batteries. Monocarborane, $\mathrm{CB}_{11} \mathrm{H}_{12}{ }^{-}$, in an $\mathrm{Mg}\left(\mathrm{CB}_{11} \mathrm{H}_{12}\right)$ /tetraglyme electrolyte, was reported to be compatible with $\mathrm{Mg}$ metal and possess a high anodic stability $\left(3.8 \mathrm{~V}\right.$ vs. $\left.\mathrm{Mg} / \mathrm{Mg}^{2+}\right)$ as well as relatively high conductivity $\left(1.8 \mathrm{mS} \mathrm{cm}^{-1}\right)$, marking a significant development in practical electrolytes for $\mathrm{Mg}$ batteries [61]. In the same study, X-ray diffraction analyses on crystallized $\mathrm{Mg}\left(\mathrm{CB}_{11} \mathrm{H}_{12}\right)_{2} /$ dimethoxyethane and $\operatorname{Mg}\left(\mathrm{CB}_{11} \mathrm{H}_{12}\right)_{2}$ /diglyme solutions showed the presence of SSIPs containing $\mathrm{Mg}^{2+}$ cations bound to solvent molecules in a hexacoordinate configuration. Following Mohtadi's work, McArthur et al. [62] reported a smaller ten-vertex 
carborane anion-based $\mathrm{Mg}$ salt, $\left[\mathrm{Mg}^{2+}\right]\left[\mathrm{HCB}_{9} \mathrm{H}_{9}{ }^{1-}\right]_{2}$ which form SSIPs as observed from ${ }^{11} \mathrm{~B}$ NMR spectrum and X-ray diffraction study with three DME molecules coordinated with $\mathrm{Mg}^{2+}$ in the solid state. Monocarborane is known to be chemically inert and weakly coordinating $[61,63]$, but further detailed examination of the solvation structure involving this salt from e.g., MD simulations or first-principles calculations is not yet available. Crystal structures and solution NMR data of various carborane salts show the preferred site of interaction for cations at boron atoms opposite the carbon atom of the anion, despite the carbon calculated to be the most negatively charged atom of the cage [64].

\subsection{Organometallic Compounds (Complex Salts)}

Organometallic complex electrolytes in ether solvents comprise some of the few $\mathrm{Mg}$ electrolytes known to demonstrate highly reversible electrodeposition due to the stability of the ethers, the $\mathrm{RMgX}$ compound, and the $\operatorname{Mg}\left(\mathrm{AR}_{2} \mathrm{R}_{2}{ }_{2}\right)_{2}$ with respect to the metal anode. These electrolytes are highly corrosive [65-67] and the metal deposition process is found to occur by complex adsorption phenomena. The first evidence demonstrating reversible electrodeposition of magnesium from solutions of Grignard reagents in ether solvents was provided by Gaddum back in 1927 [68]. Unfortunately, despite the high stability of organo-magnesium salts against the metallic magnesium surface, the strong reducing character, extremely poor ionic conductivity (few $\mu \mathrm{S} / \mathrm{cm}$ ), and insufficient anodic stability $(<1 \mathrm{~V})$ curbed their practical applicability in $\mathrm{Mg}$ batteries [19, 65, 66]. Through the seminal work of Gregory et al., it was established that the addition of electron-withdrawing Lewis acids such as aluminum chlorides $\left(\mathrm{AlCl}_{3}\right)$ with Lewis bases such as Grignard reagents $(\mathrm{RMgCl})$ and dibutylmagnesium $\left(\mathrm{Bu}_{2} \mathrm{Mg}\right)$ can significantly enhance the oxidative stability by stabilizing the R-Mg bond in Grignard solutions [5]. In the last three decades, there have been continuous efforts in enhancing the anodic stability and conductivity of Grignard solutions by Lewis acid (aluminum or organoboron) neutralization while at the same time developing suitable cathode materials that can intercalate $\mathrm{Mg}$ ions in nonaqueous media. A breakthrough was made in 2000 when Aurbach et al. demonstrated the first successful prototype of a rechargeable $\mathrm{Mg}$ battery consisting of an $\mathrm{Mg}$ anode, a Chevrel phase molybdenum sulfide $\left(\mathrm{Mo}_{6} \mathrm{~S}_{8}\right)$ cathode, and a magnesium organohaloaluminate electrolyte solution. From meticulous screening of several electrolytes synthesized by the acid-base $\left(\mathrm{R}_{m} \mathrm{MgCl}_{2-m}-\mathrm{R}_{n}^{\prime} \mathrm{AlCl}_{3-n}\right)$ reactions, a complex obtained from the reaction of $\mathrm{EtAlCl}_{2}$ and $\mathrm{Bu}_{2} \mathrm{Mg}$ with a molar ratio of 2:1, namely the dichloro complex (DCC) dissolved in THF exhibited the highest anodic stability ( $2.4 \mathrm{~V}$ vs. $\left.\mathrm{Mg} / \mathrm{Mg}^{2+}\right)$, an impressive cycle life ( $>2000$ cycles), improved ionic conductivity of $1.4 \mathrm{mS} / \mathrm{cm}$ and an energy density of $\sim 60 \mathrm{Wh} / \mathrm{kg}$ [19]. The question of which electroactive species governs the enhanced oxidative stability and highly reversible $\mathrm{Mg}$ deposition/dissolution in Grignard electrolytes has intrigued the scientific community. Figure 11 a shows the widely accepted single-crystal structure observed in the DCC electrolytes, which was obtained by the addition of a nonpolar cosolvent such as hexane or by precipitation at low temperature $[65,66]$. It was observed that Grignard solutions are composed of chloride-bridged species, 
a

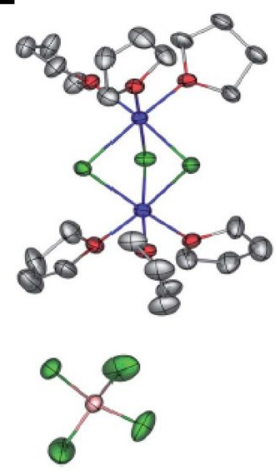

b

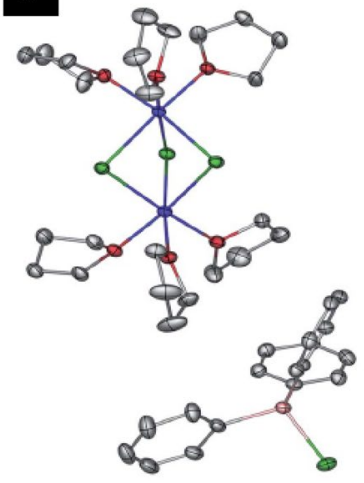

c
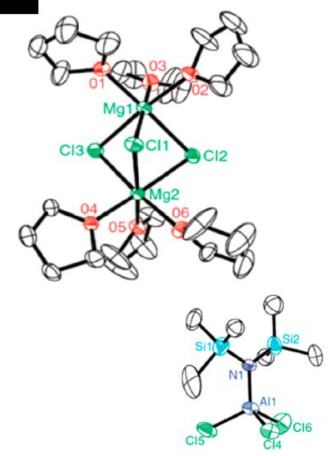

Fig. 11 a ORTEP plot of $\left[(\mu-\mathrm{Cl})_{3} \mathrm{Mg}_{2}(\mathrm{THF})_{6}\right] \mathrm{AlCl}_{4}$. b $\left[(\mu-\mathrm{Cl})_{3} \mathrm{Mg}_{2}(\mathrm{THF})_{6}\right] \mathrm{AlPh}_{3} \mathrm{Cl}\left[(\mu-\mathrm{Cl})_{3} \mathrm{Mg}_{2}(\mathrm{THF})_{6}\right]$ $\mathrm{AlCl}_{4}(\mathrm{Mg}$, blue; $\mathrm{Cl}$, green; $\mathrm{Al}$, pink; $\mathrm{C}$, gray; $\mathrm{O}$, red $)$. Reproduced from Ref. 75 with permission from The Royal Society of Chemistry. c ORTEP plot $\left(25 \%\right.$ thermal probability ellipsoids) of $\left(\mathrm{Mg}_{2}(\mu-\right.$ $\mathrm{Cl})_{3} 6 \mathrm{THF}$ ) ( $\mathrm{HMDSAlCl}_{3}$ ). Reproduced from Ref. 67 with permission from The Royal Society of Chemistry

where the active cation may include more than one $\mathrm{Mg}$ ion and exhibit a general structure of $\mathrm{Mg}_{2} \mathrm{R}_{3-n} \mathrm{Cl}_{n}^{+} \mathrm{ROR}$ while the aluminium-chloro-organo anions likely exhibit the general structure of $\mathrm{AlCl}_{4-n} \mathrm{R}_{n}^{-}[66,69]$. However, the accurate structures of the different electroactive species present in the solution in dynamic multiple equilibria as a result of transmetallation reaction cannot be revealed by crystallographic analysis [66]. The structure of the cationic and anionic species in the complex solution is dependent on the nature and ratio of the Lewis acid and base, the solvent, concentration, temperature, and nature of the ligand. For example, the electrochemical window of DCC electrolytes is known to be governed by the Lewis acidity of aluminum compounds and complex ionic species formed in the solution [70]. A comprehensive understanding of the effect of different parameters, such as acid-base ratio and nature of ligands on the formation of species in the solution, which controls the chemical and electrochemical properties, is found in the review article by Yoo et al. [69]. Most literature work on Mg organometallic salts refers to the $\mathrm{Mg}$ solvates as complexes and not ion pairs, possibly due to high tendency of the $\mathrm{Cl}^{-}$anion to donate a lone pair electron and form a chemical bond with $\mathrm{Mg}^{2+}$. Even though we have been unable to locate detailed analyses to confirm if the ligands are present in the inner or outer sphere of $\mathrm{Mg}^{2+}$, we refer to $\mathrm{Mg}$ species in organometallic solutions as complexes, consistent with available literature. Conversely, when a cation and anion complex is bound through electrostatic interaction, they are defined as an ion pair complex. NMR analysis by Gizbar et al. identified charged complexes formed by chlorine bridges, $\left[\mathrm{Et}_{2} \mathrm{ClAl}-\mathrm{Cl}-\mathrm{AlClEt}_{2}\right]^{-}$and $[\mathrm{MgCl}]^{+}$as the possible electroactive species present in the DCC electrolytes [71]. They suggested that the high conductivity observed at 2:1 acid:base ratio is a result of the formation of charged complexes $\left[\mathrm{Et}_{2} \mathrm{ClAl}-\mathrm{Cl}-\mathrm{AlClEt}_{2}\right]^{-}$and $[\mathrm{MgCl}]^{+}$, while neutral complexes $\left[\mathrm{MgCl}_{2}\right]$ formed at 1:1 ratio decrease the conductivity of the electrolyte solution. 
Many experimental studies including Raman spectroscopy, nuclear magnetic resonance (NMR) in solution phase, and X-ray diffraction (XRD) on the crystallized samples, Mg K-edge near X-ray absorption fine structure (NEXAFS) identified various species in multiple equilibria. These species include charged complexes such as $\left[\mathrm{Mg}_{2} \mathrm{Cl}_{3}\right]^{+}$and $[\mathrm{MgCl}]^{+}$as the most general cation species where the inorganic ligand bonds directly to $\mathrm{Mg}$ and $\mathrm{Mg}$ is always found to be a hexa-coordinated. The majority anion species are of the form $\mathrm{AlCl}_{4-n} \mathrm{R}_{n}^{-}(1 \leq n \leq 3)$ and exhibit organic ligands which reside primarily bound to $\mathrm{Al}$ with tetrahedral coordination. Finally, neutral complexes, $\mathrm{MgCl}_{2}$ and $\mathrm{AlCl}_{3-n} \mathrm{R}_{n}(1 \leq n \leq 3)$, are also evidenced [69, 71-73]. It is often suggested that the dimer cation $\left[\mathrm{Mg}_{2} \mathrm{Cl}_{3}\right]^{+}$exist in the solution through an equilibrium between $\mathrm{MgCl}^{+}$, and $\mathrm{MgCl}_{2}$. DFT calculations suggest that since the charged complex $\left[\mathrm{AlCl}_{4}\right]^{-}$possess a low-lying $\mathrm{HOMO}$ frontier orbitals, the ion pair complex between $\left[\mathrm{Mg}_{2}\left(\mu-\mathrm{Cl}_{3}\right) \mathrm{THF}_{6}\right]^{+}$and $\left[\mathrm{AlCl}_{4}\right]^{-}$should have high anodic stability $[67,74]$. The cationic complex $\left[\mathrm{Mg}_{2}\left(\mu-\mathrm{Cl}_{3}\right) \mathrm{THF}_{6}\right]^{+}$adopts a pseudo- $\mathrm{D}_{3 \mathrm{~h}}$ symmetry where two magnesium atoms share three chlorine atoms and each magnesium has three THF ligands attached (Fig. 11a) [75].

Recently, Liu et al. suggested a simple synthesis to form cationic complexes $\mathrm{Mg}_{2} \mathrm{Cl}_{3}{ }^{+}$and $\mathrm{MgCl}^{+}$in solution by using $\mathrm{MgCl}_{2}$ as a non-nucleophilic source of $\mathrm{Mg}^{2+}$ with an aluminum Lewis acid such as $\left(\mathrm{AlEtCl}_{2}, \mathrm{AlPh}_{3}\right.$, and $\left.\mathrm{AlCl}_{3}\right)(\mathrm{Fig}$. 11a, b) [75]. They provided the first evidence of the THF-solvated $\mathrm{MgCl}^{+}$complex present in the solution using SPIN-MS as traditionally used ESI-MS fails to detect weaker interactions such as Mg-THF [73]. However, contradictory results have been reported in the literature about the species present in solution and the exact solvation structure of $\mathrm{Mg}$ ions. Most experimental and simulation studies suggest hexa-coordinated Mg ions, whereas a few experimental studies using NEXAFS and Fouriertransformed extended X-ray absorption fine structure (EXAFS) and first-principlebased simulations reported a tetrahedral coordination for $\mathrm{Mg}^{2+}$ ions [70, 76]. A detailed study of the solvation structure of ionic species present in DCC solution was performed by Nakayama et al. [70] using X-ray absorption fine structure (XAFS) and Fourier-transformed extended X-ray absorption fine structure (EXAFS). By comparing the coordination environment of $\mathrm{Mg}\left(\mathrm{AlCl}_{2} \mathrm{EtBu}\right)_{2} / \mathrm{THF}$ with $\mathrm{BuMgCl} /$ THF and $\mathrm{Mg}\left(\mathrm{ClO}_{4}\right)_{2} / \mathrm{H}_{2} \mathrm{O}$, it was concluded that the coordination number of $\mathrm{Mg}$ and $\mathrm{Al}$ are $2 / 3$ in $\mathrm{Mg}\left(\mathrm{AlCl}_{2} \mathrm{EtBu}\right)_{2} / \mathrm{THF}$ and $\mathrm{BuMgCl} / \mathrm{THF}$ compared to those in aqueous $\mathrm{Mg}\left(\mathrm{ClO}_{4}\right)_{2} / \mathrm{H}_{2} \mathrm{O}$ and $\mathrm{Al}\left(\mathrm{NO}_{3}\right)_{2}$ solutions. The presence of second and third solvation shell for $\mathrm{Mg}$ indicated the formation of oligomers while monomers were observed for $\mathrm{Al}$ complexes. Contrary to previous reports, they observed tetrahedral coordination for both $\mathrm{Mg}$ and $\mathrm{Al}$, where the coordination number of $\mathrm{Al}$ varies between 4 and 6 depending on the $\mathrm{pH}$ of the solution within the range of $3<\mathrm{pH}<7$ (Fig. 12a). They reported $\left(\mathrm{Mg}_{2} \mathrm{Cl}_{2} \mathrm{THF}_{4}\right)^{2+},\left(\mathrm{R}_{2} \mathrm{AlCl}_{2}\right)^{-}$, and $\left(\mathrm{R}_{2} \mathrm{AlCl}_{3}\right)^{-}$as the active ionic species present in the solution responsible for the electrochemical performance of the DCC electrolytes. The first-principle molecular dynamics (FPMD) simulations based studies using DFT (PBE-GGA) by Wan et al. also found the sixfold coordination $\mathrm{Mg}$ structures energetically unstable (Fig. 13b below) [76]. They reported tetrahedral coordination of $\mathrm{Mg}$ and occasional observation of fivefold coordination in the cationic complexes often known as dimer structures in the electrolyte. They concluded that six-fold $\mathrm{Mg}$ species can only be established in the solid phase. However, 


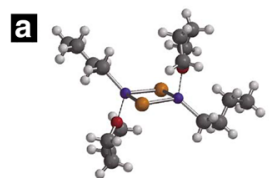

b

e
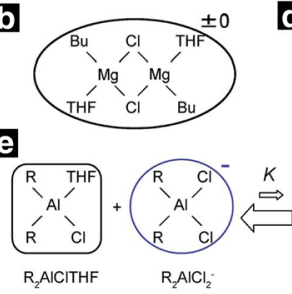

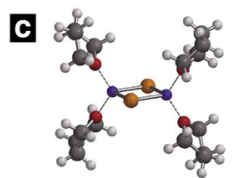

d

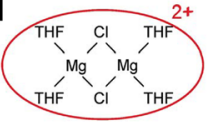

$\mathbf{f}$

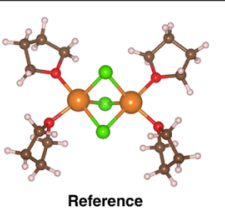

Reference

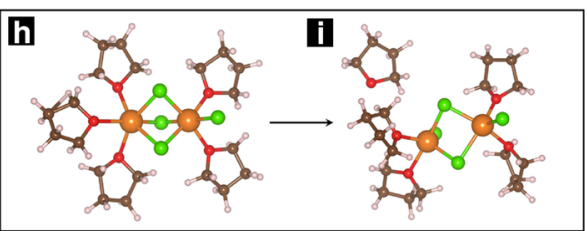

Fig. 12 Complex structures of $\mathrm{Mg}$ electrolytes. a, b Tetrahedral dimer structure of neutral Mg complex in $0.25 \mathrm{M} \mathrm{BuMgCl} / \mathrm{THF}: \mathrm{Mg}_{2} \mathrm{Cl}_{2} \mathrm{Bu}_{2} \mathrm{THF}_{2}$. $\mathbf{c}, \mathbf{d}$ Tetrahedral dimer structure of dicationic $\mathrm{Mg}$ complex in $0.25 \mathrm{M} \mathrm{MgAlCl}_{2} \mathrm{EtBu}_{2} / \mathrm{THF}: \mathrm{Mg}_{2} \mathrm{Cl}_{2} \mathrm{THF}_{4}{ }^{2+}$. e Tetrahedral monomer structures of $\mathrm{Al}$ complexes in $0.25 \mathrm{M} \mathrm{MgAlCl}_{2} \mathrm{EtBu}_{2} / \mathrm{THF}$, and their equilibrium, where $\mathrm{R}=\mathrm{Et}$ or $\mathrm{Bu}$. Republished with permission of Journal of the Electrochemical Society from Ref 70; permission conveyed through Copyright Clearance Center, Inc. DFT-PBE optimized solvation structures for $\mathrm{Mg}_{2} \mathrm{Cl}^{3+}$.4THF in approximate (f) $\mathrm{C}_{3 \mathrm{v}}$ and (g) $\mathrm{D}_{2 \mathrm{~h}}$ symmetry and $\mathrm{Mg}_{2} \mathrm{Cl}_{4} \cdot 5 \mathrm{THF}$ in approximate (h) $\mathrm{C}_{3 \mathrm{v}}$ and (i) $\mathrm{D}_{2 \mathrm{~h}}$ symmetry. Reprinted with permission from Ref 76. Copyright 2014 American Chemical Society

Fig. 13 ORTEP plot (50\% thermal probability ellipsoids) of $\left[\mathrm{Mg}_{2}(\mu-\mathrm{Cl})_{3} \mathrm{THF}_{6}\right]$ $\left[\mathrm{HMDSAlCl}{ }_{3}\right]$ THF. Hydrogen atoms are omitted for clarity. Reproduced from Ref. 86 with permission from The Royal Society of Chemistry
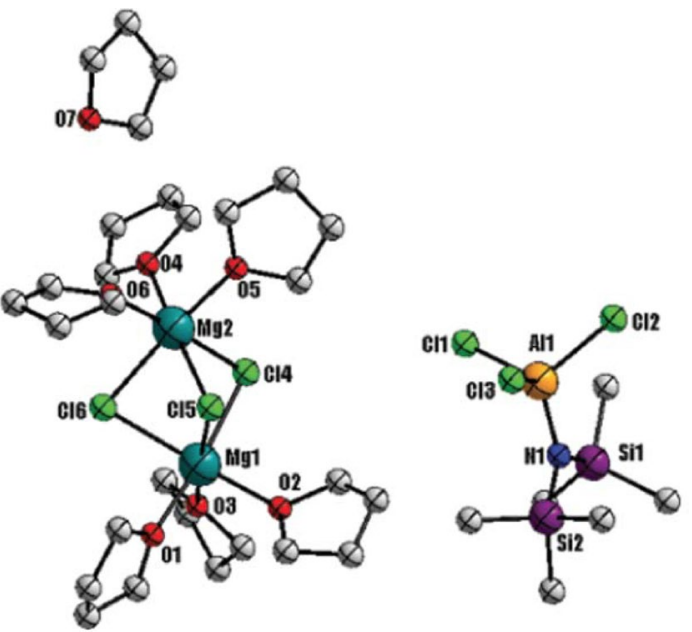

as previously noted, this is clearly not the case for aqueous solutions. Furthermore, classical molecular dynamics simulations results by Wan et al. using optimized potential for liquid simulations (OPLS) force field parameters failed to reproduce the tetrahedral solvation structure and instead demonstrated sixfold coordination. Cheng et al. pointed out the importance of the nature of the solvent in determining the solvation structure. Using Raman spectroscopy, NMR and single-crystal XRD, they identified a tetra-coordinated doubly charged cation complex, $\left[\mathrm{Mg}_{2}(\mu-\mathrm{Cl})_{2} \mathrm{DME}_{4}\right]^{2+}$ when dimethoxyethane (DME) was used as a solvent instead of THF for which they 
observed six-coordinated cation complex, $\left[\mathrm{Mg}_{2}(\mu-\mathrm{Cl})_{3} \mathrm{THF}_{6}\right]^{+}$[77]. The tetra-coordinated cation complex with DME solvent was found to be highly active for reversible $\mathrm{Mg}$ electrodeposition. They suggested that the six-coordinated complexes such as $\mathrm{MgCl}^{+}$and $\mathrm{Mg}_{2} \mathrm{Cl}_{3}{ }^{+}$are unlikely to form because DME is sterically unable to fulfill the coordination number of six. However, in contrast-six-coordination of $\mathrm{Mg}^{2+}$ in simple inorganic salts such $\mathrm{Mg}(\mathrm{TFSI})_{2}$ has been observed previously in DME solution using molecular simulations [30].

The electrochemical window of the DCC electrolyte was still narrow and limited by the relatively weak Al-C bond, which breaks through a $\beta-\mathrm{H}$ elimination reaction [65, 78]. To overcome the problems of DCC electrolytes, Mizrahi et al. [79] developed the all-phenyl complex (APC) electrolyte solutions by replacing the alkyl ligands with phenyl. By using phenyl as organic ligands, an enhanced ESW of $3.3 \mathrm{~V}$ vs. $\mathrm{Mg}$ on a Pt working electrode, low overpotential, $100 \%$ cycling efficiency, and specific conductivity of $\sim 2-5 \mathrm{mS} / \mathrm{cm}$ was achieved. Raman spectroscopy, together with DFT, NMR, and single-crystal XRD suggested $\mathrm{Mg}_{x} \mathrm{Cl}_{\mathrm{y}}^{+}\left(\mathrm{MgCl}^{+}\right.$, $\mathrm{Mg}_{2} \mathrm{Cl}_{3}{ }^{+}, \mathrm{MgCl}_{2}$ ) as the majority $\mathrm{Mg}$ species, where $\mathrm{Mg}$ is always six-coordinated and $\mathrm{AlCl}_{4-n} \mathrm{Ph}_{n}^{-}(n=0-4)$ and $\mathrm{Ph}_{4} \mathrm{Al}^{-}$as the major anionic species features consistently tetra-coordinated $\mathrm{Al}[74,79]$. Neutral complexes, such as $\mathrm{MgCl}_{2}$, were not observed for the best-performing electrolyte with $2: 1$ ratio of $\mathrm{PhMgCl}$ and $\mathrm{AlCl}_{3}$, which results in better ionic conductivity [79]. Some air-sensitive nucleophilic species such as $\mathrm{Ph}_{2} \mathrm{Mg}$ and $\mathrm{PhMgCl}$ along with minor ratios of $\mathrm{PhAlCl}_{2}, \mathrm{Ph}_{4} \mathrm{Al}^{-}, \mathrm{AlCl}_{4}{ }^{-}$ were also predicted to be present in the solution. In both DCC and APC electrolytes, ether solvents are part of the actual solvation structure and play an important role in stabilizing the ionic species, but APC electrolytes form a variety of aluminum compounds unlike DCC electrolytes. Early studies reported that the highly nucleophilic and corrosive nature of APC solutions makes them incompatible with electrophilic cathode materials (such as sulfur and oxygen) and electrophilic solvents (such as esters and carbonates) and also prohibits their use with aluminum current collectors [21, 67]. However, full operation of APC electrolytes with Chevrel phase$\mathrm{Mo}_{6} \mathrm{~S}_{8}, \mathrm{TiS}_{2}$, and $\mathrm{V}_{2} \mathrm{O}_{5}$ cathodes has already been demonstrated by adding either $\mathrm{LiCl}$ or $\mathrm{MgCl}_{2}$ as additives [80, 81]. Pan et al. demonstrated enhanced electrochemical performance for APC salts in $\mathrm{Mg}-\mathrm{Mo}_{6} \mathrm{~S}_{8}$ with the addition of $\mathrm{MgCl}_{2}$ salt and they observed a typical dimer structure $\mathrm{Mg}_{2}\left(\mu-\mathrm{Cl}_{3}\right)$ from single-crystal X-ray diffraction [82]. Hence, it is likely that addition of $\mathrm{MgCl}_{2}$ does not change the active species of APC salts but rather drive the Schlenk equilibrium to generate more electroactive species. However, the addition of $\mathrm{MgCl}_{2}$ is likely to make APC salts more corrosive [54, 83]. To enhance air and moisture stability of the Lewis bases, a few groups suggested replacement of $(\mathrm{R}=\mathrm{Ph})$ with $(\mathrm{R}=\mathrm{OPh})$ and observed complex ion pair formation between $\left[\mathrm{Mg}_{2} \mathrm{Cl}_{3}\right]^{+}$and $\left[\mathrm{Al}(\mathrm{OR})_{4}\right]^{-}$, but these electrolytes still exhibit a highly corrosive nature due to the high chlorine content $[84,85]$. Nelson et al. further tried to enhance the performance by using the Lewis acid $\mathrm{Al}(\mathrm{OPh})_{3}$ to reduce the chlorine content. Using NMR and ESI-MS, they suggested two distinct active $\mathrm{Mg}^{2+}$ charged complexes in solution, $\left[\mathrm{Mg}_{2} \mathrm{Cl}_{3}(\mathrm{THF})_{4}\right]^{+}$and $\left[\mathrm{Mg}_{2}\left(\mathrm{OPh}_{3}\right)\right.$ $\left.\mathrm{Cl}(\mathrm{THF})_{2}\right]^{+}$, where magnesium is five-coordinated. The anion complex was identified as $\left[\mathrm{Al}(\mathrm{Ph})_{4}\right]^{-}$with $\mathrm{Al}$ in tetrahedral coordination. 
In 2011, Kim et al. proposed a strategy using non-nucleophilic Hauser bases salt comprising hexamethyldisilazide magnesium chloride ( $\mathrm{HMDSMgCl}$ ) electrolyte which demonstrates good compatibility with the electrophilic sulfur cathode [21]. Similar to DCC and APC the crystal structure of HMDSMgCl electrolytes show a typical dimer cation complex $\left[\mathrm{Mg}(\mu-\mathrm{Cl})_{3} \mathrm{THF}_{6}\right]^{+}$and $\left[\mathrm{HMDSAlCl}_{3}\right]^{-}$as the anion complex (Fig. 11c). The cationic species observed from single-crystal X-ray diffraction in $\mathrm{DCC}, \mathrm{APC}$, and $\mathrm{HMDSMgCl}$ in THF show a dimeric magnesium complex, where two magnesium ions share three chlorine atoms forming a bridge complex and each magnesium ion is solvated by three THF molecules [86]. $\mathrm{Mg}$ was found to be hexa-coordinated and the counter-anion $\mathrm{Al}$ species as tetra-coordinated in all three electrolytes in a majority of experimental studies. Zhao-Karger et al. confirmed the crystal structure of [HMDSMgCl] observed by Kim et al. using NMR for the ratio of 1:2 for $\mathrm{HMDSMgCl}$ and $\mathrm{AlCl}_{3}$, while other ratios studied from NMR did not yield the same crystal structure (Fig. 13) [86]. Recently, Pan et al. demonstrated that addition of ionic liquids such as $N, N$-diethyl- $N$-methyl- $N$-(2-methoxyethyl)ammonium bis(trifluoromethanesulfonyl)imide (DEME-TFSI) can enhance the ionic conductivity of $\mathrm{Mg}(\mathrm{HMDS})_{2}-\mathrm{MgCl}_{2} / \mathrm{THF}$ electrolyte [87]. The highly dissociative DEME-TFSI salt was found to form free ions up till $53.2 \mathrm{~mol} \%$ of DEMETFSI in $0.5 \mathrm{M} \mathrm{Mg}(\mathrm{HMDS})_{2}-\mathrm{MgCl}_{2} / \mathrm{THF}$. This highly dissociative ionic liquid does not affect the first coordination sphere of $\mathrm{Mg}(\mathrm{HMDS})_{2}-\mathrm{MgCl}_{2} / \mathrm{THF}$, but disrupts the second solvation shell. A single peak observed in NMR suggested a rapid exchange or dissociation in the solution by disrupting the complex ion pair formed between and $\left[\mathrm{HMDSMgCl}_{2}\right]^{-}$and forming a weak ion pair between and [TFSI] ${ }^{-}$. Such rapid exchange of ions can possibly result in structural diffusion, leading to enhanced ionic conductivity and current density of the solution. It should be noted that the structure of the cation complex observed here $\left(\left[\left\{(\mathrm{THF})_{3} \mathrm{MgCl}\right\}_{2}-\mu-\mathrm{Cl}\right]^{+}\right)$is different than the typical dimer cation complex observed in the previous study for organometallic electrolyte where three chlorine ions are shared by two magnesium ions, whereas here only one chlorine forms the bridge between two magnesium ions.

Organic boron based Mg complex (OMBCs) salts were initially studied by Gregory in 1990 and later by Aurbach in 2002, but they were found to be limited by low cycling efficiency and anodic stability [5, 66]. Recently Guo et al. [88] developed an OMBC through reaction of tri(3,5-dimethylphenyl)borane $\left(\mathrm{Mes}_{3} \mathrm{~B}\right)$ and $\mathrm{PhMgCl}$ in THF. Even though exact intermediates species present in the solution are unclear, based on the single-crystal XRD, NMR, Raman and fluorescence spectra analyses, they reported the same cation complexes $\left(\mathrm{Mg}_{2} \mathrm{Cl}^{3+}, \mathrm{MgCl}^{+}\right)$as observed in DCC, APC and $\mathrm{HMDSMgCl}$ electrolytes as the main cationic species and $\mathrm{Ph}_{2} \mathrm{Mg}$ and $\left[\mathrm{Mes}_{3} \mathrm{BPh}\right]^{-}$as anionic species present in the solution. The XRD results suggested the presence of ion paired $\left[\mathrm{Mg}_{2} \mathrm{Cl}_{3}-\mathrm{THF}_{6}\right]^{+}\left[\mathrm{Mes}_{3} \mathrm{BPh}\right]^{-}$, where the anion is tetrahedrally coordinated, while the cation shows a typical bridged structure of magnesium atoms hexa-coordinated by three chlorine and six THF molecules (Fig. 14). Further, fluorescence spectroscopy for different ratios of $\mathrm{Mes}_{3} \mathrm{~B}$ mixed with $\mathrm{PhMgCl}$ and Raman spectroscopy analysis suggested the presence of weak interactions between $\left[\mathrm{Mes}_{3} \mathrm{BPh}\right]^{-}$and $\left[\mathrm{Ph}_{2} \mathrm{Mg}\right]$ through the formation of aggregates or $\pi-\pi$ interactions, which results in high anodic stability of the $\mathrm{Mes}_{3} \mathrm{~B}-(\mathrm{PhMgCl})_{2}$ electrolyte solution. 


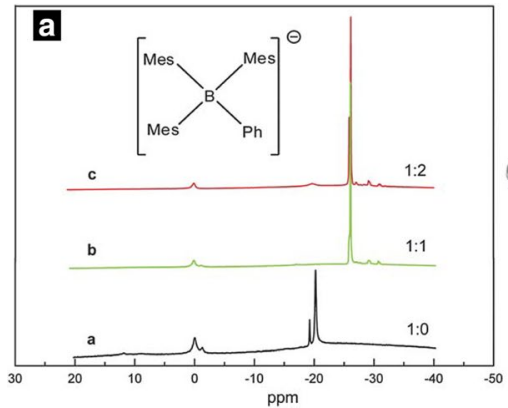

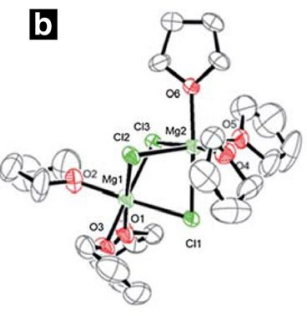

$\left[\mathrm{Mg}_{2} \mathrm{Cl}_{3}-6 \mathrm{THF}\right]^{+}$

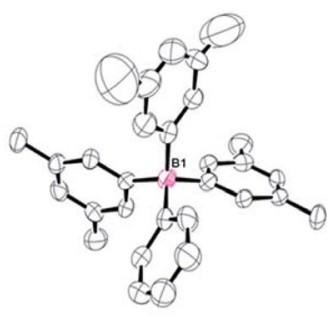

$\left[\mathrm{Mes}_{3} \mathrm{BPh}\right]^{-}$

Fig. 14 a ${ }^{11} \mathrm{~B}$ NMR spectra measured with boron-based electrolyte solutions of $\mathrm{Mes}_{3} \mathrm{~B} / \mathrm{THF}$ (a), $\mathrm{Mes}_{3} \mathrm{~B}-\mathrm{PhMgCl} / \mathrm{THF}(\mathbf{b}), \mathrm{Mes}_{3} \mathrm{~B}-(\mathrm{PhMgCl})_{2} / \mathrm{THF}(\mathbf{c}),(\mathbf{b})$ ORTEP drawing of the molecular structure of the crystallized $\mathrm{Mes}_{3} \mathrm{~B}-(\mathrm{PhMgCl})_{2}$ complex electrolyte. Hydrogen atoms have been omitted for clarity. Reproduced from Ref .88 with permission from The Royal Society of Chemistry

Doe et al. reported the first simple all-inorganic $\mathrm{Mg}$ electrolyte by in situ reaction between $\mathrm{MgCl}_{2}$ and $\mathrm{AlCl}_{3}$ in ethereal solutions, namely the magnesium aluminum chloride complex electrolytes (MACC). The MACC electrolyte shows a high anodic stability of $\sim 3.3 \mathrm{~V}$ with good reversible deposition/dissolution, however, the reported enhanced performance after conditioning remains a mystery and

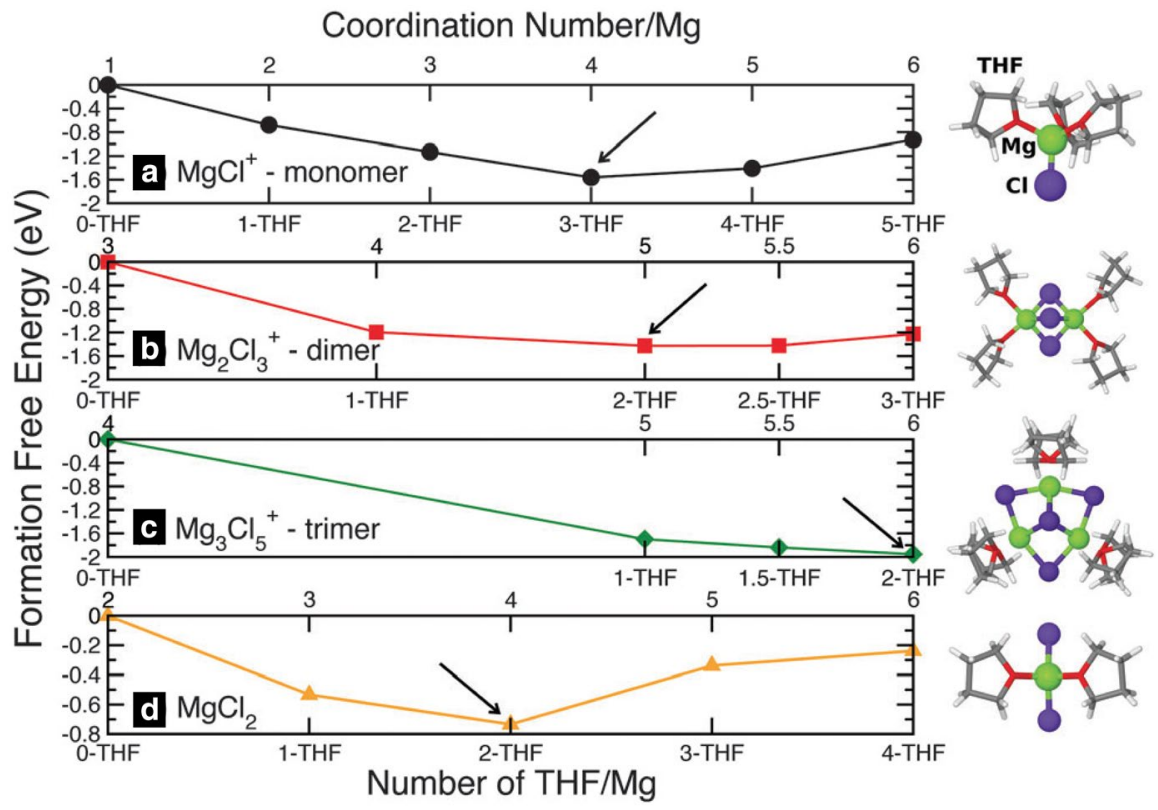

Fig. 15 Formation free energy (in eV) of magnesium-chloride complexes as a function of THF coordination for a $\mathrm{MgCl}^{+}$(monomer), $\mathbf{b ~} \mathrm{Mg}_{2} \mathrm{Cl}_{3}{ }^{+}$(dimer), $\mathbf{c ~} \mathrm{Mg}_{3} \mathrm{Cl}_{5}{ }^{+}$(trimer), and $\mathbf{d ~} \mathrm{MgCl}_{2}$. Arrows indicate the most stable THF coordination environment for each complex. Snapshots of the most stable magnesium-chloride complexes are also depicted. Ref. 90 - Published by The Royal Society of Chemistry 
the performance deteriorates after the few cycles [89]. Canepa et al. [90] coupled ab initio calculations with molecular dynamics simulations to investigate the functional species and the structural evolution during electrochemical cycling. In agreement with Wan et al. and Nakayana et al. results for DCC electrolytes, Canepa et al. observed fourfold coordination for monomers $\left(\mathrm{MgCl}^{+}\right.$and $\left.\mathrm{MgCl}_{2}\right)$ and fivefold coordination for dimers $\left(\mathrm{Mg}_{2} \mathrm{Cl}_{3}^{+}\right)$(Fig. 15). Some experimental studies suggested the formation of trimers and multimeric units in MACC electrolytes [89] and Canepa et al. reported a sixfold coordination of trimer $\left(\mathrm{Mg}_{3} \mathrm{Cl}_{5}{ }^{+}\right)$complexes [91]. However, Canepa et al. predicted dimers and trimers to be metastable under normal thermodynamic conditions, suggesting that a dimer structure might become accessible with the reduction of the THF chemical potential (e.g., drying). In contrast to these results, other experimental studies using X-ray diffraction, Raman, and NMR spectroscopy revealed hexa-coordinated structure of $\mathrm{Mg}$ ions in the MACC electrolytes for both monomer $\mathrm{MgCl}^{+}$as well as dimer $\mathrm{Mg}_{2} \mathrm{Cl}_{3}{ }^{+}$complexes. Four-fold coordination was observed in aluminum complexes, where $\left(\mathrm{AlCl}_{2}{ }^{+} \mathrm{THF}_{2}\right),\left(\mathrm{AlCl}_{2}{ }^{+}\right.$ $\mathrm{THF}_{2}$ ), $\mathrm{AlCl}_{3}$ (THF) and $\mathrm{AlCl}_{4}{ }^{-}$were suggested as the stable species in the solution while no polymeric species were observed. Contrary to experimental studies, the simulation does not report the formation of other higher-order magnesium-chloro structures, rather suggests agglomeration of $\mathrm{MgCl}^{+\ldots} \mathrm{MgCl}_{2}$, which could be interpreted as higher-order clusters in spectroscopic measurements [90,91]. We note that dimers or other higher-order complexes would be favored under drying conditions due to lack of solvent molecules or solvent polymerization. It was speculated that enhanced electrochemical performance after conditioning is due to increase in the concentration of active species $\left(\mathrm{MgCl}^{+}\right.$and $\left.\mathrm{AlCl}_{4}^{-}\right)$in the solution. Conversely, resting the electrolyte, a process known as 'aging', deteriorates the electrochemical performance of MACC electrolytes, which was correlated with the drastic decrease in the concentration of electroactive species in the solution.

\subsection{Aqueous Mg Electrolytes}

Water is an excellent solvent for the divalent cations considered here, hence aqueous electrolytes are expected to exhibit improved solubility for $\mathrm{Mg}$ salts. However, conversely, aqueous electrolytes are limited by the inherent water molecular electrochemical stability window of $1.5 \mathrm{~V}$ and passivation of the $\mathrm{Mg}$ metal anode. For reasons discussed above, there are sparse studies on aqueous $\mathrm{Mg}$ electrolytes for energy storage and those available report mainly simple salts such as $\mathrm{Mg}\left(\mathrm{SO}_{4}\right)_{2}, \mathrm{Mg}\left(\mathrm{ClO}_{4}\right)_{2}$, $\mathrm{Mg}\left(\mathrm{NO}_{3}\right)_{2}$ and $\mathrm{MgCl}_{2}$. But very recently Seoung-Bum et. al demonstrated reversible cycling of the $\mathrm{Mg} / \mathrm{V}_{2} \mathrm{O}_{5}$ full cell in a $0.5 \mathrm{M} \mathrm{Mg}(\mathrm{TFSI})_{2} / \mathrm{PC}$ electrolyte containing $3 \mathrm{M}$ water. They suggested that presence of small amount of water supports the intercalation of $\mathrm{Mg}$ ions in $\mathrm{V}_{2} \mathrm{O}_{5}$. Since water is well known to passivate the $\mathrm{Mg}$ metal anode, they employed a protective artificial polymeric interphase to suppress the electrochemical decomposition of water-containing carbonate based electrolyte. However, details of the active species present in the electrolyte is not known at this point [92]. Due to the excellent hydration of $\mathrm{Mg}$, exhibiting a preferred octahedral first-shell solvation structure [93], most simple salt aqueous solutions are reported 
not to exhibit ion pairs below $2 \mathrm{M}[94,95]$. Yagi et al. evaluated the $\mathrm{Mg}\left(\mathrm{SO}_{4}\right)_{2}$ electrolyte performance and concluded that dehydration plays an important role [96]. As aforementioned, a large desolvation energy is expected in the case of complete desolvation, and partial dehydration at the electrode interface alleviates the penalty of this process. While some hydration may benefit intercalation in oxides [97, 98], it is expected that ions with smaller hydration numbers exhibit less detrimental impact on the host structure [99]. Buchner et al. reveal the dependence of the hydration number on the concentration of $\mathrm{Mg}\left(\mathrm{SO}_{4}\right)_{2}$ [100]. It was deduced that the effective hydration number decreases from $\sim 14$ at infinite dilution to $\sim 10$ at high concentrations $(>1 \mathrm{M})$ of $\mathrm{Mg}\left(\mathrm{SO}_{4}\right)_{2}$. We note that this effective hydration number includes not only the first solvation shell but also the second solvation shell where the $\mathrm{H}_{2} \mathrm{O}$ molecule that are "irrotationally bounded" [100]. Raman spectroscopy confirmed the formation of both CIPs and AGGs in (>1 M) $\mathrm{Mg}\left(\mathrm{SO}_{4}\right)_{2}$ aqueous solutions [100, 101], which reduces the hydration numbers, in turn affecting the electrolyte electrochemical properties. The association constants of $\mathrm{Mg}\left(\mathrm{SO}_{4}\right)_{2}$ were also experimentally determined [40, 102]. However, the direct effect of ion pair formation on electrochemical performance was not investigated.

Several early reports demonstrated that additions of water can facilitate the desolvation process as well as insertion into various vanadium metal oxides as a result of the strong solvation structure between water and $\mathrm{Mg}^{2+}$ [102-110]. The highest specific charge, $170 \mathrm{Ah} / \mathrm{kg}$, was attained in a $1 \mathrm{M} \mathrm{Mg}\left(\mathrm{ClO}_{4}\right)_{2}+1 \mathrm{M} \mathrm{H}_{2} \mathrm{O}$ solution in acetonitrile, which coincides with a $1: 1$ ratio between $\mathrm{Mg}^{2+}$ and $\mathrm{H}_{2} \mathrm{O}$ [110]. Similarly, Song et al. [111] reported reversible intercalation in a $\mathrm{MnO}_{2}$ nanowire electrode with gold current collector and a water-containing $\mathrm{Mg}\left(\mathrm{ClO}_{4}\right)_{2} / \mathrm{PC}$ electrolyte where the highest performance was observed at a ratio of $\mathrm{Mg}^{2+}$ to $\mathrm{H}_{2} \mathrm{O}$ ratio of 1:6. However, co-intercalation of water, while alleviating the desolvation process, tends to compromise the structural integrity of the electrode material and hence the cycling stability.

In contrast to non-aqueous solutions, aqueous $\mathrm{MgCl}_{2}$ electrolytes have been reported to exhibit weak ion-pairing tendencies $\left(0.2 \mathrm{M} \mathrm{Cl}^{-}, 1.4 \mathrm{Mg}^{2+}, 3 \mathrm{M}\right.$ ionic strength in a $\mathrm{Mg}^{2+}-\mathrm{Na}^{+}-\mathrm{Cl}^{-}-\mathrm{ClO}_{4}{ }^{-}$system) from both potentiometric and osmometric measurements [112]. Furthermore, the association constant of $\mathrm{Mg}^{2+}-\mathrm{Cl}^{-}$is 25.6 times smaller than $\mathrm{Mg}\left(\mathrm{SO}_{4}\right)_{2}$ in aqueous solutions [102], indicating that the $\mathrm{Mg}^{2+}-\mathrm{Cl}^{-}$ion pair is significantly weaker than for $\mathrm{Mg}\left(\mathrm{SO}_{4}\right)_{2}$. For $\mathrm{Cl}^{-}$and $\mathrm{SO}$ [42] -, the ion pair stability with divalent metal ions decreases from $\mathrm{Ca}^{2+}$ to $\mathrm{Mg}^{2+}$, which supports the speculation that the hydration number of $\mathrm{Mg}^{2+}$ is larger than that of $\mathrm{Ca}^{2+}[40]$.

\subsection{Mg Polymer Electrolytes}

Polymer electrolytes hold the promise of electrochemical and thermal stability, which are important regardless of the specific chemistry. A primary challenge that remains for practical battery applications of polymer electrolytes is effectively managing the tradeoff between ion transport and other physical or chemical properties, such as mechanical or thermal stability. Solvation structure and specifically 
ion pairing impacts transport properties and is the focus of this section. Lithium poly(ethylene oxide) (PEO) electrolytes have been well characterized and provide a useful starting point for the discussion of multivalent ions.

Despite PEO having a modest dielectric constant ( 7.5) [113], it has been reported both experimentally and computationally that CIPs do not appear to form until high salt concentrations, where the number of ether oxygens (EO) per metal cation nearly matches the average coordination number for both $\mathrm{Li}(5 \mathrm{EO})$ and $\mathrm{Mg}$ (6 EO) with TFSI anion. Mao et al. [114, 115] used neutron diffraction isotopic substitution (NDIS) to identify the solvation structure of high molecular weight, amorphous PEO LiTFSI. It was found that, on average, no CIPs were present in $\mathrm{P}(\mathrm{EO})_{7.5} \mathrm{LiTFSI}$ at room temperature. Although no CIPs were present, broad peaks around 4.85 and $5.5 \AA$ in the pair distribution function were suggested to be the result of SSIPs. Conductivity data provides similar evidence. Conductivity of binary liquid electrolytes generally increases with salt concentration until a maximum is reached where the formation of neutral IPs or neutral ion AGGs lead to a reduction in conductivity [116]. This analysis is complicated for systems where charged IPs or AGGs contribute to conductivity. It was recently demonstrated that charged AGGs (i.e., triplets) are important for transport in highly concentrated PEO LiTFSI [117]. Additionally, in the case of polymers, increased ion concentration reduces segmental motion, further complicating the connection between a maximum in conductivity and the formation of neutral IPs or AGGs. Nevertheless, in the case of high molecular weight PEO ( 5 and $20 \mathrm{~kg} / \mathrm{mol}$ ) a maximum in conductivity at $363 \mathrm{~K}$ and $373 \mathrm{~K}$ is reached in the range between $\mathrm{P}(\mathrm{EO})_{15} \mathrm{LiTFSI}$ and $\mathrm{P}(\mathrm{EO}){ }_{10} \mathrm{LiTFSI}[118,119]$, which at least in part, indicates formation of neutral CIPs or AGGs at higher salt concentrations. Combining NDIS and conductivity data, it appears that SSIPs are present at EO:Li ratios between 10 and 7.5, leading to a reduction in conductivity.

Conventional spectroscopic methods such as IR or Raman, do not typically detect SSIPs, however, these methods can be advantageous for identifying CIPs [4]. IR and Raman studies of high molecular weight amorphous PEO LiTFSI seem to be in agreement that little to no CIPs are present when EO: $\mathrm{Li}$ is greater than or equal to $8[120,121]$, and a substantial fraction of CIPs $(\sim 24 \%)$ are present when EO:Li is equal to 6 [121]. It is worth noting that Edman saw little evidence of CIPs in roomtemperature samples that were not preheated to the amorphous regime at the same salt concentration [121]. This was attributed to slow recrystallization of salt-rich PEO, and is evidence that crystalline regions solvate Li salts at higher concentrations than amorphous regions.

A molecular dynamics study of $\mathrm{P}(\mathrm{EO})_{7.5} \mathrm{LiTFSI}$ at $393 \mathrm{~K}$ reported 4.6 oxygen atoms in the first coordination shell, 3.85 from EO, and 0.5 from TFSI anion (it is unclear why these do not sum to 4.6) [122]. The elevated presence of CIPs compared to experiment at this salt concentration may be due to the challenge of obtaining accurate electrostatic interactions including polarization for concentrated solutions. A few simulation snapshots are shown in Fig. 16 to help visualize the local environment around the cations in the PEO matrix. Overall, the picture that emerges for high molecular weight amorphous $\mathrm{P}(\mathrm{EO})_{\mathrm{n}}$ LiTFSI is that SSIPs are favorable between $n=15$ and $n=10$ and CIPs begin to be favorable when $n<7.5$; CIPs make up a substantial fraction when $n=6$. 


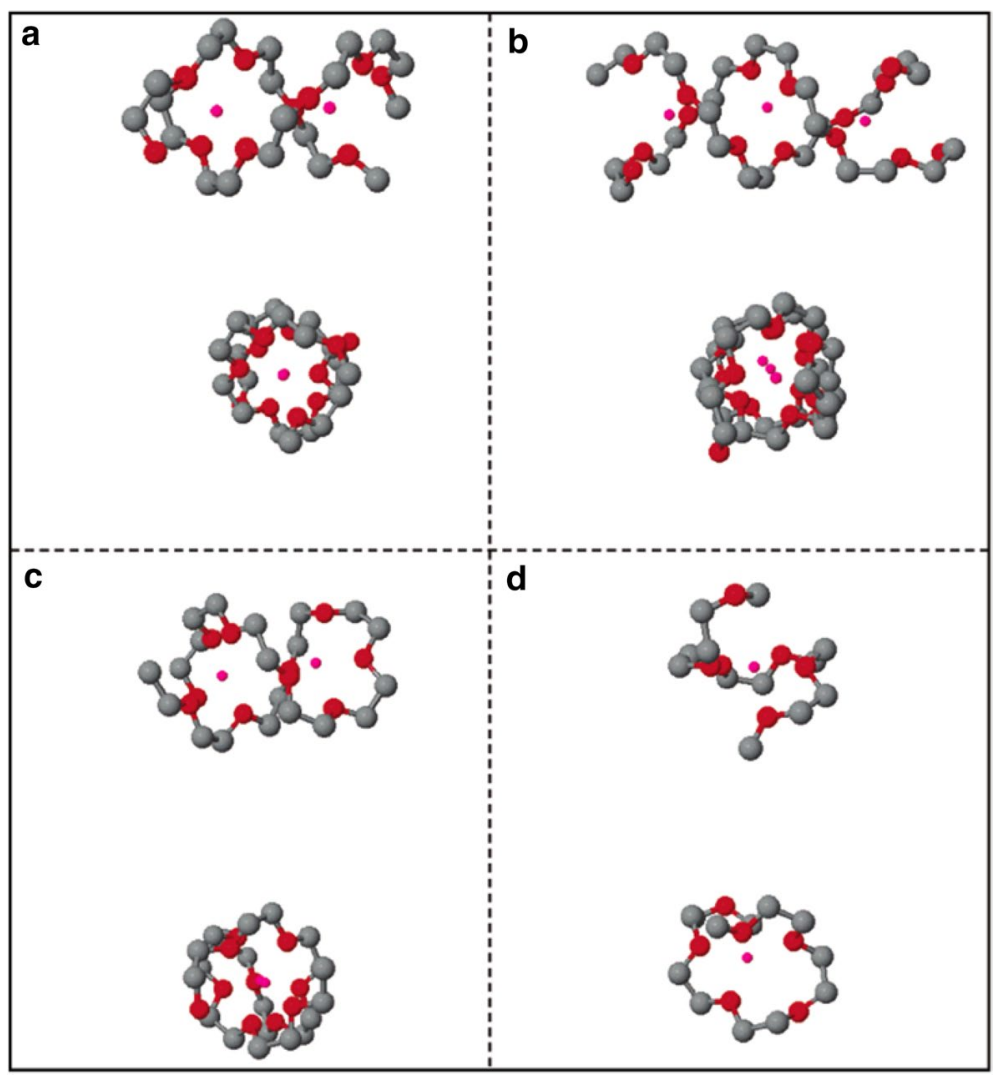

Fig. 16 Snapshots from simulations of PEO/LiTFSI at $423 \mathrm{~K}(\mathbf{a}, \mathbf{b}, \mathbf{d})$ for EO:Li=20:1 and $\mathbf{c}$ for $\mathrm{EO}: \mathrm{Li}=10: 1$. Hydrogen atoms are not shown for clarity. Only atoms within $4.0 \AA$ of each $\mathrm{Li}+$ are shown. Reprinted with permission from Ref. 112. Copyright 2006 American Chemical Society

Table 1 Comparison of the CIP regime, the point at which there are more CIPs than SSIPs and free ions, for a variety of electrolyte systems and the methods that aided in this determination

\begin{tabular}{lll}
\hline Electrolyte system & CIPs regime & Methods \\
\hline $\mathrm{P}(\mathrm{EO})_{\mathrm{n}} \mathrm{LiTFSI}$ & $n \leq 7.5$ & NDIS [114], FTIR [120, 123], Ramen \\
& & [120], Conductivity [118, 119] \\
$\mathrm{P}(\mathrm{EO})_{\mathrm{n}} \mathrm{Mg}(\mathrm{TFSI})_{2}$ & $n<9$ & FTIR, Conductivity [115] \\
$\mathrm{P}(\mathrm{EO})_{\mathrm{n}} \mathrm{Mg}\left(\mathrm{ClO}_{4}\right)_{2}$ & $n<28$ & FTIR, Conductivity [123] \\
$\mathrm{P}(\mathrm{EO})_{\mathrm{n}} \delta-\mathrm{MgCl}{ }_{2}$ & $n \leq 32$ & FTIR [124, 166] \\
$\mathrm{PEO}-\mathrm{b}-\mathrm{P}\left[(\mathrm{STFSI})_{2} \mathrm{Mg}\right]$ & Not Dissociated & Conductivity [124] \\
$\left.\mathrm{PEO} / \mathrm{B} / \mathrm{PEO} \mathrm{Mg}(\mathrm{ClO})_{4}\right)_{2}$ & N/A & Ramen, Conductivity [127] \\
$(\mathrm{MEEP})_{\mathrm{n}} \mathrm{Mg}(\mathrm{TFSI})_{2}$ & $n<8$ & Conductivity [129] \\
\hline
\end{tabular}


While there is a smaller body of work exploring PEO with Mg salts, several systems are summarized in Table 1. Bakker et al. [115] performed conductivity and FTIR experiments on a variety of divalent cations, including $\mathrm{Mg}, \mathrm{Ca}, \mathrm{Sr}$, and $\mathrm{Ba}$ with the TFSI anion. Conductivity data does not provide unambiguous results with respect to IP formation as previously mentioned. However, FTIR indicates that CIPS are not favored until $n<9$ in $\mathrm{P}(\mathrm{EO})_{n} \mathrm{MTFSI}_{2}$, which is, as excepted, higher than that of the lithium analog due to magnesium's larger average coordination number. Additionally, a larger shift in the $\mathrm{C}-\mathrm{O}-\mathrm{C}$ vibration band was observed for $\mathrm{Mg}$ relative to $\mathrm{Ca}, \mathrm{Sr}$, and $\mathrm{Ba}$, demonstrating that smaller cations interact more strongly with ether oxygens [115]. In contrast with Edman's LiTFSI study, the authors found no CIP temperature dependence in the range tested. This can be reconciled by the absence of crystalline peaks in multivalent systems at concentrations $n \leq 16$. Specifically for multivalent applications, it is interesting to note that the strong interaction between $\mathrm{Mg}^{2+}$ and ether oxygen atoms distorts crystalline regions. These observations were supported by Edman, as well as by Reddy and Chu who observed reduced PEO crystalline content with increasing salt concentration in a PEO $\mathrm{Mg}\left(\mathrm{ClO}_{4}\right)_{2}$. FTIR and conductivity measurements were combined to detect CIPs, and for $\mathrm{P}(\mathrm{EO})_{n} \mathrm{Mg}\left(\mathrm{ClO}_{4}\right)_{2}$ CIPs were observed as favorable when $n<28$ [123]. We note that although this value is considerably larger than that found by Bakker et al., it is likely due to the different anions present.

In a short-chain $\mathrm{P}(\mathrm{EO})_{n} \delta-\mathrm{MgCl}_{2}$ (referred to as poly(ethylene glycol) PEG) system it was formulated, using FTIR, that free ions dominate when $n \geq 86$, and both $\mathrm{Mg}^{2+}$ and $\mathrm{MgCl}^{+}$are present when $14 \leq n \geq 32$ [124]. Both $\mathrm{Mg}^{2+}$ and $\mathrm{MgCl}^{+}$ contribute to conductivity and using equivalent conductivity analysis a strong cation-anion interaction was demonstrated with increasing concentration [125]. Additionally, it is interesting to note that Di Noto el al. observed increased IP, either $\mathrm{MgCl}^{+}$or $\mathrm{MgCl}_{2}$, for given O:Mg ratios when the short PEO chains were linked together using diethoxydimethylsilane (DEOS) PEO/DEOS/PEOS- $\mathrm{MgCl}_{2}$ [126].

Single-ion conductors or ionomers utilizing a PEO type domain have recently gained attention as the concept introduces the possibility to have a cation transference number near unity by covalently bonding the anion to the polymer backbone [130]. A recent study tested both $\mathrm{Li}$ and $\mathrm{Mg}$ single-ion block copolymers, PEO-b$\mathrm{P}[(\mathrm{STFSI}) \mathrm{Li}]$ and PEO-b-P[(STFSI $\left.)_{2} \mathrm{Mg}\right]$ [127]. It was found that the conductivity of the magnesiated samples were about an order of magnitude lower than that of the lithiated samples. This was attributed to roughly an order of magnitude lower number of charge carriers in the $\mathrm{Mg}$ system when fitted with the Vogel-Tamman-Fulcher (VTF) equation. Additionally, there was a notable difference in the small-angle X-ray scattering (SAXS) profile. The SAXS peak present in magnesiated samples revealed local correlations between like blocks of different chains. The hypothesis put forward was that $\mathrm{Mg}^{2+}$ did not dissociate from the $\mathrm{P}\left[(\mathrm{STFSI})_{2} \mathrm{Mg}\right.$ block, remaining a CIP, causing less mixing than in the Li-containing system.

Lewis acidic polymer electrolytes or introducing Lewis acid moieties have also been investigated [131]. In PEO, strong cation-polymer interactions aid in the dissociation of ions, however as a result, conductivity is dominated by anion motion [132]. On the other hand, Lewis acid groups can interact strongly with anions, promoting cation motion and dissociation while inhibiting anion motion. Saito et al. 
cross-linked short PEG chains with boron ester (Lewis acid) groups, and tested the cross-linked system with a variety of $\mathrm{Mg}$ salts. As expected, cation transference increased with increasing boron ester concentration. Interestingly, the effect was anion-dependent, $\mathrm{ClO}_{4}{ }^{-}$being more easily immobilized than $\mathrm{TFSI}^{-}$. At both EO:Mg ratios, 64 and 32, the relative proportion of AGGs and CIPs decrease while ion dissociation increased (shown by Raman) as compared to a system with a lower concentration of borate ester group [128]. Unfortunately, the conductivity also dropped by orders of magnitude with the increased boron ester group concentration, indicating that the cation transference number increased due to immobilized anions rather than improved cation mobility in PEO-type electrolytes.

A different type of polymer that has been investigated for $\mathrm{Mg}$ electrolytes is poly(bis(2-(2-methoxyethoxy)ethoxy)phosphazene) (MEEP) [129], which has oligoether side groups similar to PEO. The behavior of both $\mathrm{Li}$ and $\mathrm{Mg}$ salts were investigated in this polymer. Impedance measurements showed that $\mathrm{MgTFSI}_{2}$ in MEEP exhibited roughly the same maximum conductivity as LiTFSI, although the maximum was reached at different concentrations MEEP: $\mathrm{Mg}=8$ and MEEP: $\mathrm{Li}=4$, respectively. In both cases, it was suggested that anion movement accounted for most of the conductivity, and the concentration difference was rationalized by the $\mathrm{Mg}$ salt having two TFSI ${ }^{-}$anions. MEEP $\mathrm{MgTf}_{2}$ exhibited low conductivity even at low concentrations (MEEP: $\mathrm{Mg} \geq 20$ ), and the authors postulated that this was due to extensive ion association.

In all of the PEO Mg examples thus far, with the exception of Reddy and Chu and Saito et al., conductivity data was interpreted with the VTF equation. Remarkably, all the data was reasonably well fit by the VTF Eq. 1;

$$
\sigma(T)=\frac{A}{\sqrt{T}} e^{-B / R\left[T-\left(T_{g}-50\right)\right]}
$$

where $A$ and $B$ are generally interpreted as the number of charge carriers and pseudo-activation barrier respectively [127]. This physical interpretation of the equation is obviously overly simplified even for $\mathrm{Li}$ [133], let alone multivalent ions where multiple types of charge carriers exist. For example, the activation barriers for a monovalent CIP, $\mathrm{Mg}^{+}$with an anion, as compared to a free $\mathrm{Mg}^{2+}$ ion are expected to be quite different. Hence, conceptualizing similar physically motivated equations that take into account multiple types of charge carries would be of interest to the community.

As previously mentioned, a major appeal of polymer electrolytes is electrochemical stability. PEO has been shown to have good stability in Li systems [134], but little work has been done to demonstrate stability with $\mathrm{Mg}$ or other chemistries. Most studies to date have not cycled $\mathrm{Mg}$ polymer electrolytes in a full cell configuration. There is one report of $\mathrm{PEO} / \mathrm{MgO} \mathrm{Mg}\left(\mathrm{BH}_{4}\right)_{2}$ where the system $(\mathrm{Mgl} \mathrm{PEO} /$ $\left.\mathrm{MgO} \mathrm{Mg}\left(\mathrm{BH}_{4}\right)_{2} \mid \mathrm{Mo}_{6} \mathrm{~S}_{8}\right)$ indicated good stability over 150 cycles [51]. Although a detailed investigation of the solvation structure for $\mathrm{Mg}\left(\mathrm{BH}_{4}\right)_{2}$ in PEO was not conducted, it was demonstrated that increasing glyme (glymes are PEO oligomers) length decreased the strong $\mathrm{Mg} \mathrm{BH}_{4}$ interaction resulting in increased ion 
dissociation. The authors extrapolated that greater dissociation could be expected in PEO [51]. One aspect of stability that has not been explored is the stability of polymer solvents in the presence of partially reduced $\mathrm{Mg}^{+}$, which is a likely transient specie during Mg plating and has been shown to be highly reactive causing anion or solvent decomposition [30].

Another difference to highlight between $\mathrm{Li}$ and less dendrite-prone multivalent metals such as $\mathrm{Mg}$ is that the polymer electrolytes may not need to provide the same amount of mechanical support to prevent dendritic growth. This allows for the use of plasticizers and inclusion of organic $[135,136]$ or ionic liquids $[137,138]$ to make polymer gel electrolytes or polyelectrolytes. An in-depth study of IP in polymer gel electrolytes or polyelectrolytes is outside the scope of this paper, however, it would be expected that this addition would increase the dielectric constant of the solvent thus reducing IP and potentially increasing the conductivity of the system. On the other hand, if a volatile or electrochemically less stable compound is added, it may negate the inherent safety benefits of polymer electrolytes and hence tradeoff effects are to be expected.

\section{Zinc Electrolytes}

Zinc has been implemented in various commercial primary battery systems, in particular, the famous "alkaline" battery with a $\mathrm{MnO}_{2}$ cathode and aqueous alkaline electrolyte. However, in the early development of secondary zinc batteries, poor cycling performance was observed for this cell configuration due to undesirable zinc morphologies such as dendrite growth, as well as zinc redistribution (shape change) on cycling, both of which are linked to the high solubility of zinc in alkaline media [7, 139]. In addition, there are safety and environmental issues associated with the corrosive nature of an alkaline electrolyte. The introduction of near-neutral $\mathrm{pH}$ electrolytes with salts such as $\mathrm{ZnSO}_{4}$ and $\mathrm{Zn}\left(\mathrm{NO}_{3}\right)_{2}$ greatly curbed cycling issues related to zinc dendrite formation and enabled nearly full capacity retention up to 100 cycles [10]. Further improvements to cycle life stemmed from cathode material development, recently leading to reports such as a vanadium bronze, $\mathrm{Zn}_{0.25} \mathrm{~V}_{2} \mathrm{O}_{5} \cdot \mathrm{nH}_{2} \mathrm{O}$ cathode demonstrating up to $80 \%$ retention over 1000 cycles [11]. Another recent report with a conversion-based $\mathrm{MnO}_{2}$ nanofiber cathode has shown a capacity retention of $92 \%$ over 5000 cycles [140]. These cell configurations, utilizing neutral aqueous electrolytes, benefit from advantages associated with water such as high conductivity and low cost; in addition, water does not suffer from the volatility and flammability of some organic solvents in non-aqueous electrolytes. The solvation structure of $\mathrm{Zn}$ aqueous electrolytes could be expected to contain little ionic association due to the excellent solvation ability of water, similar to that of $\mathrm{Mg}$ aqueous electrolytes. Raman spectroscopy of the $\mathrm{SO}_{4}{ }^{2-}$ anion, commonly used in aqueous $\mathrm{Zn}$ electrolytes, shows shifting of the $v_{1}\left(A_{1}\right)$ symmetric stretch band to higher wavenumber upon contact with $\mathrm{Zn}^{2+}$ [141]. From fitted band intensities, the population of $\mathrm{ZnSO}_{4}$ as ion pairs can be estimated as $6 \pm 2 \%$ at $0.389 \mathrm{M}$ to $13 \pm \%$ at $1.945 \mathrm{M}$ at room temperature [141]. $\mathrm{ZnSO}_{4}$ is typically used in aqueous electrolytes for secondary batteries at concentrations of $2 \mathrm{M}$ or less. 
Secondary Zn cells with non-aqueous electrolytes enable larger operating cell voltages (limited to $1.2-1.5 \mathrm{~V}$ in aqueous electrolytes, outside of which water hydrolysis and electrolyte loss occurs) as well as greater operating temperatures due to wider liquid temperature ranges. At present, research into non-aqueous secondary zinc energy storage is nascent and overshadowed by analogous $\mathrm{Mg}$ versions due to factors such as the relatively high reduction potential of $\mathrm{Zn}(-0.76 \mathrm{vs}$. $-2.4 \mathrm{~V}$ of $\mathrm{Mg}$ ). Nonetheless, zinc retains many benefits in prospective secondary energy storage such as safety, geological abundance, and cost, in addition to a large volumetric capacity (5851 vs. $3833 \mathrm{~mA} \mathrm{h/ml} \mathrm{of} \mathrm{Mg}$ ), and its development in non-aqueous systems is a compelling avenue of research, especially for grid applications. A recent study by Rajput et al. examining the solvation structure and zinc compatibility of $\mathrm{Zn}(\mathrm{TFSI})_{2}, \mathrm{Zn}\left(\mathrm{CF}_{3} \mathrm{SO}_{3}\right)_{2}, \mathrm{Zn}\left(\mathrm{BF}_{4}\right)_{2}$, and $\mathrm{Zn}\left(\mathrm{PF}_{6}\right)_{2}$ salts in diglyme (G2), acetonitrile (AN), propylene carbonate (PC), and $N, N$-dimethylformamide (DMF) solvents (0.1 $\mathrm{M}$ and $0.5 \mathrm{M}$ concentration) demonstrated reversible plating/stripping for the $\mathrm{AN}-\mathrm{Zn}(\mathrm{TFSI})_{2}, \mathrm{AN}-\mathrm{Zn}\left(\mathrm{CF}_{3} \mathrm{SO}_{3}\right)_{2}$, and $\mathrm{PC}-\mathrm{Zn}(\mathrm{TFSI})_{2}$ electrolytes, with anodic stabilities up to $3.7,3.5$, and $3.4 \mathrm{~V}$ vs. $\mathrm{Zn} / \mathrm{Zn}^{2+}$, respectively [12]. This broad assessment of non-aqueous $\mathrm{Zn}$ electrolytes with several common anions and organic solvents shows the promise of those containing the $\mathrm{TFSI}^{-}$and $\mathrm{CF}_{3} \mathrm{SO}_{3}{ }^{-}$anions in particular.

As a viable candidate for MV electrolytes, $\mathrm{TFSI}^{-}$has been studied extensively in terms of the anion's structural flexibility and manner of cation-anion binding in different electrolytes. In the free $\mathrm{TFSI}^{-}$anion, the trans conformer is more stable than the cis conformer, which can be explained by relief of repulsive steric interactions between the $\mathrm{CF}_{3}$ groups present in the cis conformer. Early theoretical work estimated the enthalpy difference between the two conformers as $3.5 \mathrm{~kJ} / \mathrm{mol}$ at the B3LYP/6-311 + G(3df) level of theory [142]. Subsequently, an experimental report put the enthalpy difference at $2.2 \mathrm{~kJ} / \mathrm{mol}$ using IR spectroscopy [143] and another in the 3.4-7.3 kJ/mol range using Raman spectroscopy [144]. Accordingly, the conformational equilibrium of non-coordinated $\mathrm{TFSI}^{-}$(e.g., in ionic liquids) generally shows preference for the trans conformer [144]. However, the cis conformation becomes favorable in the coordination sphere of metal cations [145], where an increase in binding strength is associated with an increase in the dipole moment of the anion from $0.301 \mathrm{D}$ in the trans conformer to $4.382 \mathrm{D}$ in the cis conformer [142]. Other studies detailing the structural nature of $\mathrm{Zn}$ complexes with $\mathrm{TFSI}^{-}$have shown a preference for the cis-conformer of $\mathrm{TFSI}^{-}$anions in the coordination sphere using UV-Vis, IR, and Raman spectra [146]. In addition, a recent computational study of $\left[\right.$ Emim] $\left[\mathrm{Zn}(\mathrm{TFSI})_{3}\right]($ Emim $=1$-ethyl-3-methylimidazolium) complexes at the B3LYP/6-31G(d) level of theory suggested that zinc forms a homoleptic octahedral complex with all the $\mathrm{TFSI}^{-}$anions bound to $\mathrm{Zn}$ in the cis conformation [147]. The $\mathrm{Mg}^{2+}$ cation, of similar ionic radius, shows similar coordination behavior with TFSI $^{-}$in ionic liquids, though some solvation studies which include IR/Raman spectroscopy have observed frequencies associated with bridging TFSI $^{-}$anions [32]. Similar aggregate formation could easily be expected from analogous $\mathrm{Zn}$ systems.

In non-aqueous electrolytes consisting of the $\mathrm{TFSI}^{-}$salt in some organic solvent, weakly coordinating behavior of the $\mathrm{TFSI}^{-}$anion could rationally be expected due to the flexible nature of the anion and its delocalized charge. However, theoretical 
calculations such as MD simulations have often shown this not to be the case; ion-ion association of $\mathrm{TFSI}^{-}$with $\mathrm{Mg}$ or $\mathrm{Zn}$ is prevalent in solutions with common organic solvents even in modest concentrations $(0.4 \mathrm{M}-0.5 \mathrm{M})[12,30]$. Though this ionic association increases the oxidative stability of the anion [30], the formation of multi-meric species negatively affects the dynamics of the electrolyte in terms of conductivity, viscosity, and diffusion, especially if there is a tendency toward higher-order aggregate formation. In addition, as noted in Sect. 1.1, ion-ion association between $\mathrm{Mg}^{2+}$ and $\mathrm{TFSI}^{-}$is known to render the anion susceptible to decomposition upon reduction of $\mathrm{Mg}^{2+}$ to $\mathrm{Mg}^{1+}$, which may play a role in the anode passivation observed at concentrations at or above $0.5 \mathrm{M}$ for electrolytes with this salt [30]. The extent of ion-ion association and aggregate formation can be predicted in part by first-principles calculations of cation-anion binding strength. A computational study comparing M(TFSI $)_{2}$ complexes across several metals $(\mathrm{M}=\mathrm{Mg}, \mathrm{Ca}, \mathrm{Ba}, \mathrm{Zn}$, and $\mathrm{Cu}$ ) showed that the binding energy between the metal and the TFSI ligands is stronger for $\mathrm{Zn}^{2+}$ than $\mathrm{Mg}^{2+}$ by $43.2 \mathrm{kcal} / \mathrm{mole}$ at the B3LYP/6-31G*//B3LYP/lanl2dz level of theory [148]. Thus, one may expect greater tendency for ion-ion association and decomposition of $\mathrm{TFSI}^{-}$in non-aqueous $\mathrm{Zn}$ electrolytes than the corresponding Mg ones. However, to our knowledge, no electrode passivation has been reported with an organic $\mathrm{Zn}(\mathrm{TFSI})_{2}$ electrolyte, even at $0.5 \mathrm{M}$ concentration. A closer inspection of the solvation structure and stability against decomposition is desirable to probe any relationship between $\mathrm{TFSI}^{-}$stability and the ion paired cation ( $\mathrm{Zn}$ or $\mathrm{Mg}$ ).

Zinc gel polymer electrolytes have also received considerable attention. $\mathrm{Zn}\left(\mathrm{CF}_{3} \mathrm{SO}_{3}\right)_{2}$ is a commonly employed salt in gel polymer electrolytes, perhaps to follow implementation of the $\mathrm{CF}_{3} \mathrm{SO}_{3}{ }^{-}$anion in lithium electrolytes. In addition to its high anodic stability as noted above, the $\mathrm{CF}_{3} \mathrm{SO}_{3}{ }^{-}$anion is known for its chemical stability and "weakly coordinating" nature, potentially making it another good candidate for MV electrolytes. Raman spectroscopy of the $\mathrm{CF}_{3} \mathrm{SO}_{3}{ }^{-}$anion shows splitting of the symmetric $\mathrm{SO}_{3}$ stretching mode upon coordination to a metal cation [149]. Bandshape analyses of spectra in conjunction with conductivity measurements can show the extent of ion-ion association in different salt concentrations of an electrolyte, with higher conductivity typically associated with higher populations of "free" $\mathrm{CF}_{3} \mathrm{SO}_{3}$ " ions [149-151], e.g., Fig. 17 shows the Raman spectrum and percent composition of a $\mathrm{Zn}\left(\mathrm{CF}_{3} \mathrm{SO}_{3}\right)_{2}$ gel polymer electrolyte as free ions, ion pairs, or higher aggregates at different salt concentrations. In other polymer-based electrolytes, containing e.g., PEO, ion pairing is qualitatively known to be pervasive for many salts from spectroscopic methods such as EXAFS [152, 153].

The neutral $\mathrm{Zn}\left(\mathrm{CF}_{3} \mathrm{SO}_{3}\right)_{2}$ complex exhibits four oxygen atoms, two from each $\mathrm{CF}_{3} \mathrm{SO}_{3}{ }^{-}$ion, bound tetrahedrally to the $\mathrm{Zn}^{2+}$ center [148]. In non-aqueous solutions, the coordination behavior is more complicated and also involves molecules from the solvent, which compete with or join alongside the anion(s) for $\mathrm{Zn}^{2+}$ coordination. In general, the coordination number for $\mathrm{Zn}^{2+}$ in non-aqueous $\mathrm{Zn}\left(\mathrm{CF}_{3} \mathrm{SO}_{3}\right)_{2}$ solutions exceeds four and ion-ion association is significant at $0.1 \mathrm{M}$ and $0.5 \mathrm{M}$ concentrations across a range of organic solvents [154]. It may be of interest to note that the binding energy between $\mathrm{Zn}$ and the anions in $\mathrm{Zn}\left(\mathrm{CF}_{3} \mathrm{SO}_{3}\right)_{2}$ is stronger than for $\mathrm{Zn}(\mathrm{TFSI})_{2}$ by $40.8 \mathrm{~kJ} / \mathrm{mol}$ at the B3LYP/6-31G*//B3LYP/lanl2dz level of theory [148] with possible ramifications on the relative extent of ionic association in non-aqueous solutions. 

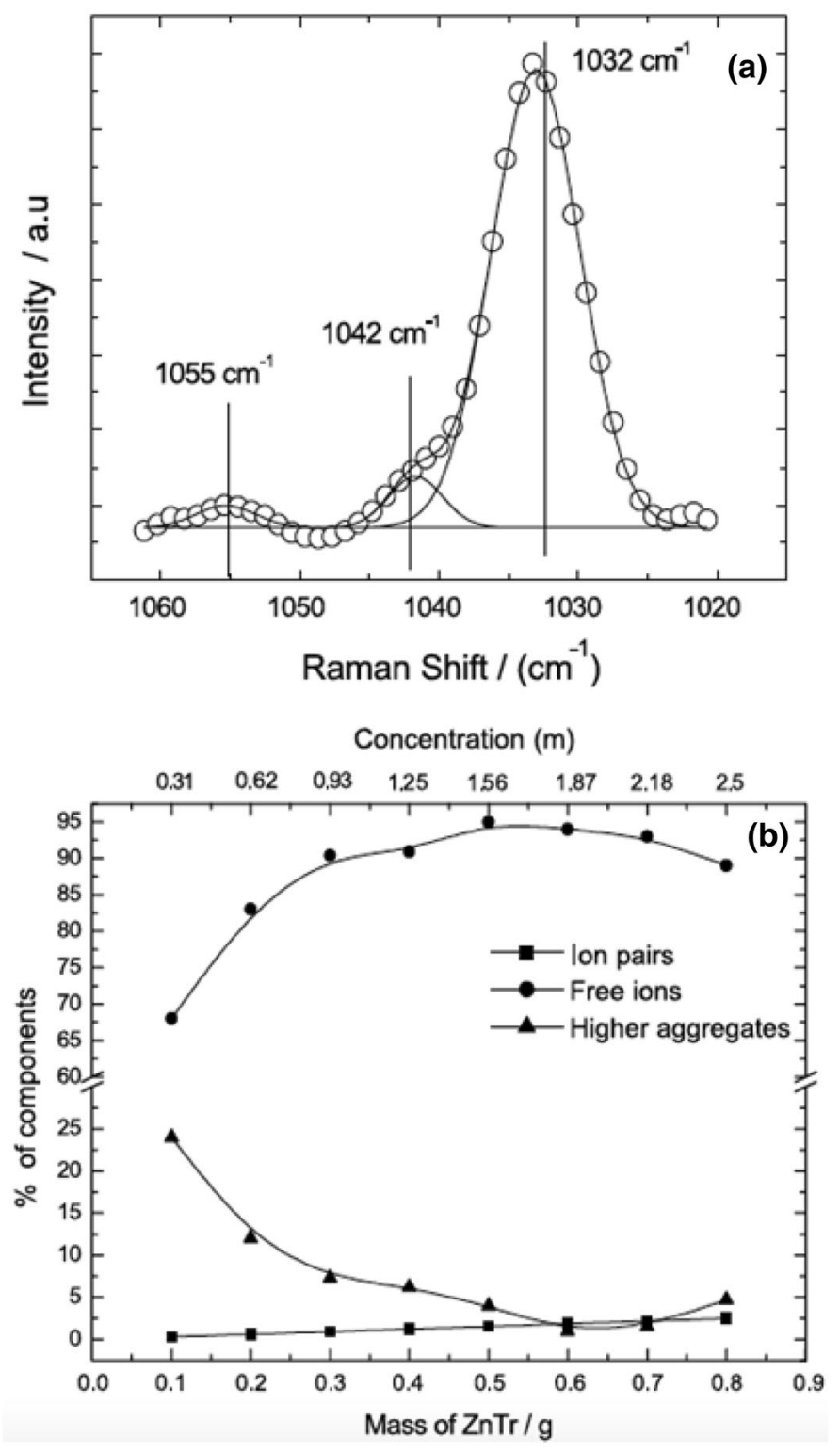

Fig. 17 a Spectrum of the symmetric $\mathrm{SO}_{3}$ stretching region of an electrolyte of polyacrylonitrile $(0.25 \mathrm{~g})$, propylene carbonate $(0.6 \mathrm{~g})$, ethylene carbonate $(0.6 \mathrm{~g})$, and $\mathrm{Zn}\left(\mathrm{CF}_{3} \mathrm{SO}_{3}\right)_{2}(1.25 \mathrm{M})$. The band at $1032 \mathrm{~cm}^{-1}$ corresponds to free $\mathrm{CF}_{3} \mathrm{SO}_{3}^{-}, 1042 \mathrm{~cm}^{-1}$ to ion pairs and $1055 \mathrm{~cm}^{-1}$ to higher aggregates. b Percent composition of free ions, ion pairs, and higher aggregates as a function of salt concentration. $\mathrm{ZnTr}=\mathrm{Zn}\left(\mathrm{CF}_{3} \mathrm{SO}_{3}\right)_{2}$. Reprinted from Ref. 148, with permission from Elsevier 

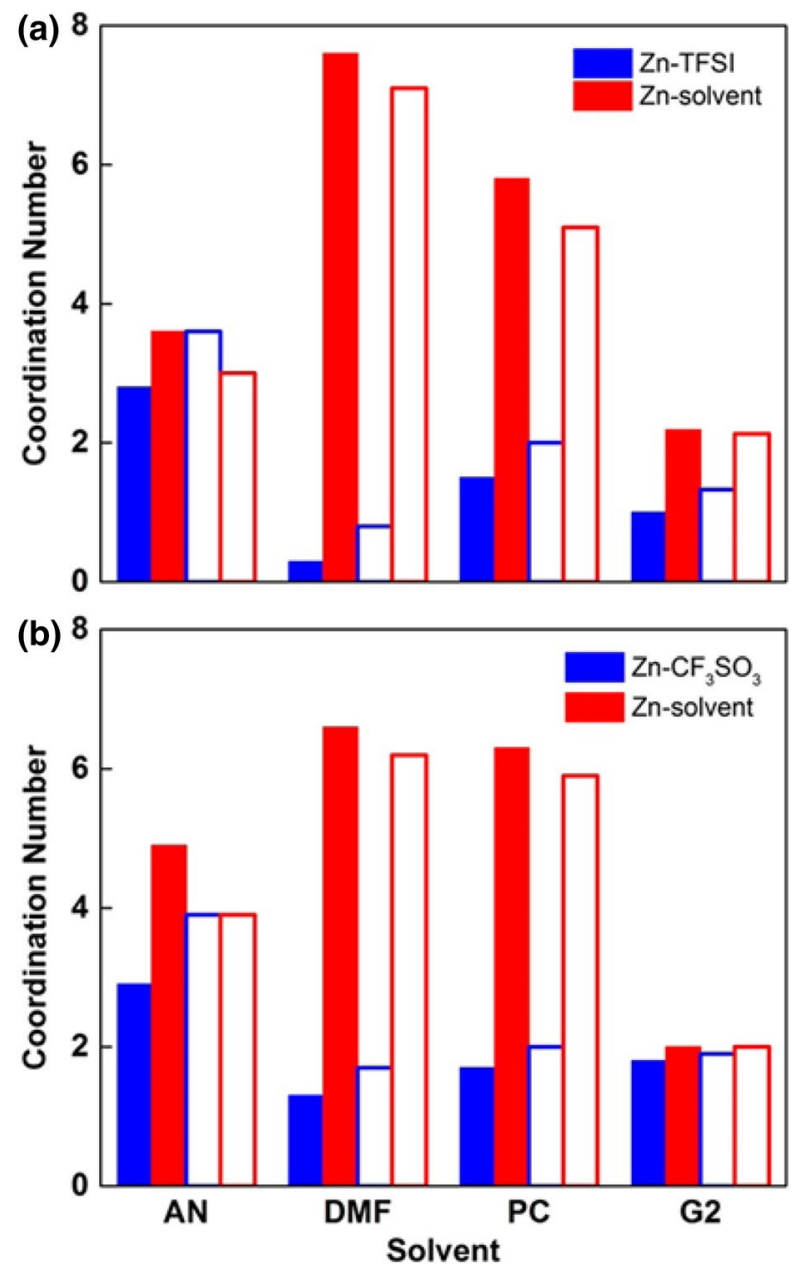

Fig. 18 Coordination numbers of $\mathrm{Zn}$-anion and $\mathrm{Zn}$-solvent for $\mathrm{TFSI}^{-}$(a) and $\mathrm{CF}_{3} \mathrm{SO}_{3}^{-}$(b) at $0.1 \mathrm{M}$ (filled bars) and $0.5 \mathrm{M}$ (hollow bars) for four different solvents. Reprinted with permission from Ref 12. Copyright 2016 American Chemical Society

A direct comparison of the solvation structure between $\mathrm{Zn}(\mathrm{TFSI})_{2}$ and $\mathrm{Zn}\left(\mathrm{CF}_{3} \mathrm{SO}_{3}\right)_{2}$ electrolytes using MD simulations [12] corroborates this finding (see Fig. 18). Of the solvents examined at $0.1 \mathrm{M}$ and $0.5 \mathrm{M}$, in the weakly coordinating solvents acetonitrile and propylene carbonate, the coordination number of $\mathrm{Zn}$ from $\mathrm{TFSI}^{-}$ligands is similar to that of $\mathrm{CF}_{3} \mathrm{SO}_{3}{ }^{-}$, whereas in the strongly coordinating solvents $N, N$-dimethylformamide and diglyme, the coordination number from $\mathrm{TFSI}^{-}$is slightly smaller. The coordination number in both $\mathrm{Zn}-\mathrm{TFSI}^{-}$and $\mathrm{Zn}-\mathrm{CF}_{3} \mathrm{SO}_{3}{ }^{-}$increases from $0.1 \mathrm{M}$ to $0.5 \mathrm{M}$, but more so for $\mathrm{TFSI}^{-}$, due to stronger solvent-anion interactions in $\mathrm{CF}_{3} \mathrm{SO}_{3}{ }^{-}$. 


\section{Calcium Electrolytes}

Among the multivalent ions, calcium faces some of the most serious hurdles in the development for practical electrochemical secondary energy storage. However, $\mathrm{Ca}$ may be gaining momentum in light of some recent exciting reports. $\mathrm{Ca}$ is an appealing component for high-voltage batteries due to its low standard reduction potential $(-2.87$ vs. $-2.38 \mathrm{~V}$ for $\mathrm{Mg}$, and almost as low as $\mathrm{Li}$ at $-3.04 \mathrm{~V})$. Other advantages of $\mathrm{Ca}$ are those shared with other multivalent metals such as geological abundance, safety, lack of toxicity, and cost.

Early assessment of nonaqueous $\mathrm{Ca}$ electrolytes with salts such as $\mathrm{Ca}\left(\mathrm{ClO}_{4}\right)_{2}$ and $\mathrm{Ca}\left(\mathrm{BF}_{4}\right)_{2}$ in some common organic solvents exposed them as incompatible with calcium metal due to formation of a oxide passivation surface layer with prohibitively low Ca transport [6]. Due to some success of Grignard reagents in early secondary $\mathrm{Mg}$ battery research, it was reasonable to explore the analogous $\mathrm{Ca}$ salts, the so-called heavy Grignards ( $\mathrm{RCaX}$, where $\mathrm{X}$ is a halide). However, no reports have been made of reversible plating/stripping of calcium metal with an electrolyte containing these salts. We also note that the synthesis of heavy Grignards can face difficulties due to the reduced reactivity of Ca metal compared to $\mathrm{Mg}$ [155].

Hence, until recently, secondary Ca battery development was impeded by the lack of electrolytes, while research on secondary $\mathrm{Mg}$ batteries has flourished in comparison. Finally, a report by Ponrouch et al. showed plating/stripping of calcium metal with electrolytes containing $\mathrm{Ca}\left(\mathrm{ClO}_{4}\right)_{2}$ and $\mathrm{Ca}\left(\mathrm{BF}_{4}\right)_{2}$ in ethylene carbonate and propylene carbonate. Successful plating/stripping took place despite formation of an anode surface layer, which was formed through electrolyte decomposition as confirmed through chemical analysis of anode surface deposits, and elevated temperatures were required to enable ionic transfer through the anode surface layer; still exhibiting with a $\sim 2$ V overpotential [139].

Assembly of a full working secondary cell requires a suitable cathode materials that enable facile intercalation/deintercalation of $\mathrm{Ca}^{2+}$ ions [156]. Some promising cathodes were developed for aqueous [157] and high water content nonaqueous (17\%) [158] electrolytes where successful intercalation/deintercalation was believed to be the result of hydrated $\mathrm{Ca}^{2+}$ ions, which reduce the electrostatic interaction between the mobile ion and the lattice of the cathode. Finally, a fully working secondary calcium battery, albeit with low voltage and capacity, was demonstrated for the first time, based on a manganese hexacyanoferrate cathode, a tin anode, and a nonaqueous electrolyte containing $\mathrm{Ca}\left(\mathrm{PF}_{6}\right)_{2}$ [159].

Concurrent with the limited research on $\mathrm{Ca}$ electrolytes, information on the solvation structure relevant to $\mathrm{Ca}$ battery applications has received little attention in the literature. A few general comments can be made based on the available studies and fundamental characteristics of coordination behavior and ion pairing with anions commonly implemented in multivalent ion electrolytes. A $\mathrm{Ca}^{2+}$ ion exhibits a larger radius $(0.99 \AA)$ as compared to $\mathrm{Mg}^{2+}(0.65 \AA)$ [160], which results in higher preferred coordination numbers in solution with longer 
metal to donor atom interaction distances. The binding energy between the metal and anions is less for $\mathrm{Ca}$ than $\mathrm{Mg}$ in $\mathrm{M}(\mathrm{TFSI})_{2}$ by $95.1 \mathrm{kcal} / \mathrm{mol}$ at the B3LYP/6$31 \mathrm{G}^{*} / / \mathrm{B} 3 \mathrm{LYP} / \mathrm{lanl} 2 \mathrm{dz}$ level of theory [148]. One explanation for the dissimilar binding strength is a different mismatch between the 'hardness' of the cation and anion, where the greater hardness of $\mathrm{Mg}^{2+}$ is a better match with the hard base character of the TFSI oxygen atoms. $\mathrm{Ca}^{2+}$ is less polarizing than $\mathrm{Mg}^{2+}$, resulting in a cation-anion interaction with less covalent character.

In summary, while examination of solvation structure in $\mathrm{Mg}$ and $\mathrm{Zn}$ electrolytes have received considerable attention, $\mathrm{Ca}$ electrolytes are less explored. The relationship between the coordination number and binding strength and properties such as conductivity, viscosity, and diffusion for $\mathrm{Ca}$ electrolytes is a topic that should be explored further in the coming years of exploratory secondary multivalent ion battery research.

\section{Rational Design of Electrolytes}

A requirement of secondary multivalent-ion battery electrolytes is compatibility with the metal anode, but properties such as high dissociation of the salt and a wide electrochemical stability window are also desirable. These properties, and their dependence on electrolyte speciation, can today exhaustively explored using computations. Depending on computational assets as well as suitable software infrastructure [161], some of these considerations can rapidly evaluated in silico prior to experimental evaluation as part of well-guided electrolyte development. For example, any chemical instability of electrolyte species affecting reversible plating/ stripping can be evaluated by first-principles calculations of possible decomposition mechanisms, in particular involving partially reduced, transient radical monocation species. Following the discovery of the decomposition mechanism for the $\mathrm{TFSI}^{-}$ anion in the presence of $\mathrm{Mg}^{+}$, stability against this and other decomposition mechanisms such as hydrolysis were criteria in the computational design of improved electrolyte anions by Qu et al. involving modifications of TFSI ${ }^{-}$[162]. The improved anions were predicted by MD simulations to engage in ion association about as much as the parent TFSI $^{-}$anion. Therefore, the primary method of rational design of electrolytes achieved in this case is enhanced chemical stability in conditions of solvation structure where ion association is prevalent.

Ideal electrolyte anions are non- or weakly coordinating. The chemical stability of anions exposed to transient $\mathrm{Mg}^{+}$would be theoretically less concerning the weaker the ion association. Ion-association strength can be predicted from first-principles calculations, bearing in mind competing ion-solvent interactions. In the absence of ion-ion interactions, the requirement for stability against $\mathrm{Mg}^{+}$-driven decomposition should instead fall on the solvent; however, detailed examination of the stability of solvents in this situation by e.g., theoretical calculations is as yet unexplored. One criteria for ion coordination strength is the size of the anion, with bulkier anions expected to be less weakly coordinating, especially if the charge is delocalized, however at the expense of increased viscosity and decreased conductivity of the electrolyte. On the other hand, computed 
ion-association strength and anion radius only exhibit strong correlation for anions up to a relatively small size [163]. Altogether, small, weakly coordinating, and chemically inert anions are ideal for multivalent battery electrolytes. The recently reported monocarborane anion [61] meets these criteria and is a significant step in the "right" direction. One could imagine that this anion could serve as a platform for further improvements. Indeed, substitution of the hydrogen atoms of this anion with halogens can raise the anodic stability quite significantly compared to the parent anion [164]. However, investigation of the practical implementation of these anions derivations in energy storage applications is premature. In general, halogenation is a common and reliable strategy for raising anodic stability of anions [163]. However, the use of chlorine may be cautioned against, as chloride ions are known to cause corrosion in stainless-steel current collectors [165].

The anodic stability of the electrolyte can be significantly affected by the solvation structure. For example, ion association raises the anodic stability of an anion as compared to the anion by itself. Similarly, cation-solvent interactions raise the anodic stability of solvent compared to the solvent alone. Conversely, anion-solvent interactions decrease the anodic stability of the solvent [166]. The electrochemical stability of an electrolyte is the result of a complex interplay of interactions in which the component having the lowest stability sets the overall limit. In further exploring improved electrolytes for multivalent ion energy storage, the current emphasis on salts of ever-increasing chemical stability, anodic stability, and dissociative behavior will inevitably call for solvent improvements. In "state-of-the-art" electrolytes such as $\mathrm{Mg}\left[\left(\mathrm{CB}_{11} \mathrm{H}_{12}\right)_{2}\right] /$ tetraglyme, the anodic limit is set by the solvent [61]. Similarly, in the recently reported $\mathrm{Mg}\left[\mathrm{B}(\mathrm{hfip})_{4}\right]_{2} /$ DME electrolyte with excellent coulombic efficiency (>98\%) and conductivity $\left(6.8 \mathrm{mS} \mathrm{cm}^{-1}\right)$ the anodic stability $(4.3 \mathrm{~V} \mathrm{vs} . \mathrm{Mg})$ is limited by the solvent [167]. Therefore, development of improved multivalent battery electrolytes may benefit from a concurrent focus towards the solvent component of the electrolyte.

\section{Conclusions}

The high charge density of multivalent ions typically results in greater tendency to form ion pairs and aggregates in most simple inorganic salts and complexes in organometallic solutions. For example, for simple inorganic $\mathrm{Mg}$ and $\mathrm{Zn}$ salts, a strong tendency of ion pairing has been observed in most solvents at moderate concentrations, however some high dielectric solvents such as DMSO and some low dielectric solvents with high oxygen donor denticity such as glymes result in solvent separated ion pairs at similar concentrations. The interaction energy between cation and anion tends to be slightly stronger for $\mathrm{Zn}$ as compared to $\mathrm{Mg}$ ion pairs, with possible ramifications on the relative extent of ion pairing and corresponding effects on conductivity and viscosity of the electrolyte. While MD simulations show significant ion pairing at $0.4 \mathrm{M}$ and $0.5 \mathrm{M}$ in many nonaqueous electrolytes for both $\mathrm{Mg}$ and $\mathrm{Zn}$, it may be beneficial to compare the solvation structure more closely in terms of the differences in interaction energies for coordination complexes formed in these 
electrolytes. Anions with bulky structure and more dispersed charge such as TFSI ${ }^{-}$ show lesser tendency towards ion pairing compared to smaller anions such as $\mathrm{BF}_{4}^{-}$ and $\mathrm{BH}_{4}{ }^{-}$for both $\mathrm{Mg}$ and $\mathrm{Zn}$. However, $\mathrm{TFSI}^{-}$was found to exhibit a structural instability during $\mathrm{Mg}$ plating, hypothesized and computationally verified as a result of contact ion-pair exposure to the transient $\mathrm{Mg}^{+}$specie. Curiously, this instability has not been reported while ion paired with $\mathrm{Zn}^{+}$. In contrast, and in agreement with experimental results, $\mathrm{BF}_{4}{ }^{-}$and $\mathrm{BH}_{4}{ }^{-}$remain stable during the same charge transfer process. Concentration also plays an important role in determining the structure of ionic species. More mono-dentate configurations of $\mathrm{TFSI}^{-}$anions were observed at lower salt concentrations, and increased bi-dentate configurations at higher concentrations. This development not only leads to an increase in ion pairs and aggregates, but also a decrease in conductivity and an increase in the viscosity of the solution. For magnesium organometallic electrolytes, it is rare to observe naked $\mathrm{Mg}^{2+}$ ions, indicating different complex species present in the solution. Most organometallic electrolytes propose a six-coordinated cation aggregate, $\left[\mathrm{Mg} 2(\mu-\mathrm{Cl})_{3} \mathrm{THF}_{6}\right]^{+}$as the active $\mathrm{Mg}^{2+}$ species and the electrochemical performance and stability varies with the choice of anion which often exists as part of an anionic aggregate in the solution. However, a few studies also reported four- and five-coordination for $\mathrm{Mg}^{2+}$ in the aggregates, but in all cases two coordinated $\mathrm{Mg}^{2+}$ ions are bridged by three chlorine atoms and form a complex ion pair with the counter anion aggregate/complex. Contradictory results in the literature regarding the coordination number of $\mathrm{Mg}$ may be due to inherent approximations in simulation methods, ex situ experimental results and interpretation. Classical molecular dynamics simulations have been widely used to study the solvation structure of ions in solution; however, the accuracy of the predicted coordination environment strongly depends on the force field parameters. For example, a +2 charge on cation in the case of $\mathrm{Mg}^{2+}$ and -1 charge on anion results in hexacoordination of $\mathrm{Mg}$ ions, while reduced charges for cations and anions obtained from ab initio calculations results in tetra-coordinated $\mathrm{Mg}$ ions [90]. Accordingly, monomers and dimers are observed in reduced charges and whole charges respectively. For aqueous $\mathrm{Mg}$ electrolytes, most simple salts do not favor ion pair formation below $2 \mathrm{M}$, although ion-pairing in $\mathrm{Mg}\left(\mathrm{SO}_{4}\right)_{2}$ and $\mathrm{MgCl}_{2}$ have been reported. Ion-pairing reduces the hydration numbers, which in turn affects the electrolyte electrochemical properties as aqueous systems often operate by cointercalation of water. While smaller hydration numbers exhibit less detrimental impact on the electrode materials, it was demonstrated that some hydration may benefit intercalation in oxides. The solvation environment of $\mathrm{Mg}$ salts in PEO-type polymer electrolytes is not only concentration dependent, but greatly influenced by the anion present, due to varying strengths of attraction between the cation and anion. When a MgTFSI 2 PEO system was compared to the analogous Li system, $\mathrm{Mg}$ was found to be more highly coordinated by oxygen, which is consistent with the higher charge density. Although PEO-type solvents are capable of solvating and at least partially dissociating multivalent salts, the conductivity remains low due to the strong ether oxygen cation attraction which limits polymer segmental motion. Similar to Li systems, anions are hypothesized to carry the majority of the current. As mentioned, classical molecular dynamics simulations and other ab initio calculations help develop a more comprehensive picture of solvation structure accessing 
spatial and temporal scales difficult to attain purely through experiment. To the best of our knowledge, there are no such studies on Mg PEO systems. Calcium secondary batteries are relatively underdeveloped, and as a result, the solvation structure of Ca nonaqueous electrolytes is relatively unexplored and should be further investigated. Nuclear magnetic resonance (NMR) has been used widely to study the solvation structure of electrolytes; however, it is limited by the temporal scale, which makes it difficult to de-convolute the peaks and assign them to specific speciation present in the solution using experiments alone, especially in novel electrolyte systems. Also, any change in the charge density localization in the complexes in the solution alters the screening effect experienced by each NMR nucleus resulting in a different NMR response [46]. NMR peaks predicted from DFT calculations can be used to complement the experimental results and distinguishing different species present in the solution. However, the NMR predicted shifts from DFT strongly depend on the reference compound peak and all the possible structures of ionic species, in principle, have to be accounted for. An in-depth understanding of the solvation structure and different species present in the solution and how these species affect the macroscopic performance of electrolyte solutions requires coupling simulations and experiments at different spatial and temporal scales.

Acknowledgements Funding for meeting the cost of this review article was supported by the Joint Center for Energy Storage Research (JCESR), an Energy Innovation Hub funded by the U.S. Department of Energy (DOE), Office of Science, Basic Energy Sciences (BES), under Contract No. DEAC0206CH11357. The Materials Project (BES DOE Grant No. KC23MP) and National Energy Research Scientific Computing Center (NERSC) (BES DOE Contract No. DE-AC02-05CH11231) are acknowledged for infrastructure, algorithmic support, and computational resources.

Open Access This article is distributed under the terms of the Creative Commons Attribution 4.0 International License (http://creativecommons.org/licenses/by/4.0/), which permits unrestricted use, distribution, and reproduction in any medium, provided you give appropriate credit to the original author(s) and the source, provide a link to the Creative Commons license, and indicate if changes were made.

\section{References}

1. Xu K (2004) Nonaqueous liquid electrolytes for lithium-based rechargeable batteries. Chem Rev 104(10):4303-4418

2. Gonzalez F (2016) Advanced and post lithium-ion batteries 2016-2026: technologies, markets, Forecasts 2016, Retrieved from http://www.idtechex.com/

3. Li Q, Bjerrum NJ (2002) Aluminum as anode for energy storage and conversion: a review. J Power Sources 110(1):1-10

4. Lin M-C, Gong M, Lu B, Wu Y, Wang D-Y, Guan M, Angell M, Chen C, Yang J, Hwang B-J, Dai $\mathrm{H}$ (2015) An ultrafast rechargeable aluminium-ion battery. Nature 520(7547):324-328

5. Gregory TD, Hoffman RJ, Winterton RC (1990) Nonaqueous electrochemistry of magnesium applications to energy storage. J Electrochem Soc 137(3):775-780

6. Aurbach D, Skaletsky R, Gofer Y (1991) The electrochemical behavior of calcium electrodes in a few organic electrolytes. J Electrochem Soc 138(12):3536-3545

7. McLarnon FR, Cairns EJ (1991) The secondary alkaline zinc electrode. J Electrochem Soc 138(2):645-656

8. Mayer A (1990) Electrodeposition of aluminum, aluminum/magnesium alloys, and magnesium from organometallic electrolytes 
9. Aurbach D, Gofer Y, Lu Z, Schechter A, Chusid O, Gizbar H, Cohen Y, Ashkenazi V, Moshkovich M, Turgeman R, Levi E (2001) A short review on the comparison between Li battery systems and rechargeable magnesium battery technology. J Power Sources 97-98:28-32

10. Xu C, Li B, Du H, Kang F (2012) Energetic zinc ion chemistry: the rechargeable zinc ion battery. Angew Chem Int Ed 51(4):933-935

11. Kundu D, Adams BD, Duffort V, Vajargah SH, Nazar LF (2016) A high-capacity and long-life aqueous rechargeable zinc battery using a metal oxide intercalation cathode. 1:16119

12. Han S-D, Rajput NN, Qu X, Pan B, He M, Ferrandon MS, Liao C, Persson KA, Burrell AK (2016) Origin of electrochemical, structural, and transport properties in nonaqueous zinc electrolytes. ACS Appl Mater Interfaces 8(5):3021-3031

13. Aurbach D, Cohen Y, Moshkovich M (2001) The study of reversible magnesium deposition by in situ scanning tunneling microscopy. Electrochem Solid State Lett 4(8):A113-A116

14. Yglesias M (2012) Electric car batteries are very expensive 2012, Retrieved from http://www.slate .com/blogs/moneybox/

15. Liu M, Jain A, Rong Z, Qu X, Canepa P, Malik R, Ceder G, Persson KA (2016) Evaluation of sulfur spinel compounds for multivalent battery cathode applications. Energy Environ Sci 9(10):3201-3209

16. Rong Z, Malik R, Canepa P, Sai Gautam G, Liu M, Jain A, Persson K, Ceder G (2015) Materials design rules for multivalent ion mobility in intercalation structures. Chem Mater 27(17):6016-6021

17. Guerfi A, Trottier J, Boyano I, De Meatza I, Blazquez JA, Brewer S, Ryder KS, Vijh A, Zaghib K (2014) High cycling stability of zinc-anode/conducting polymer rechargeable battery with nonaqueous electrolyte. J Power Sources 248:1099-1104

18. Han S-D, Kim S, Li D, Petkov V, Yoo HD, Phillips PJ, Wang H, Kim JJ, More KL, Key B, Klie RF, Cabana J, Stamenkovic VR, Fister TT, Markovic NM, Burrell AK, Tepavcevic S, Vaughey JT (2017) Mechanism of Zn insertion into nanostructured $\delta$-MnO2: a nonaqueous rechargeable Zn metal battery. Chem Mater 29(11):4874-4884

19. Aurbach D, Lu Z, Schechter A, Gofer Y, Gizbar H, Turgeman R, Cohen Y, Moshkovich M, Levi E (2000) Prototype systems for rechargeable magnesium batteries. Nature 407(6805):724-727

20. Ha S-Y, Lee Y-W, Woo SW, Koo B, Kim J-S, Cho J, Lee KT, Choi N-S (2014) Magnesium(II) Bis(trifluoromethane sulfonyl) imide-based electrolytes with wide electrochemical windows for rechargeable magnesium batteries. ACS Appl Mater Interfaces 6(6):4063-4073

21. Kim HS, Arthur TS, Allred GD, Zajicek J, Newman JG, Rodnyansky AE, Oliver AG, Boggess WC, Muldoon J (2011) Structure and compatibility of a magnesium electrolyte with a sulphur cathode. Nat Commun 2:427

22. Doe RE, Han R, Hwang J, Gmitter AJ, Shterenberg I, Yoo HD, Pour N, Aurbach D (2014) Novel, electrolyte solutions comprising fully inorganic salts with high anodic stability for rechargeable magnesium batteries. Chem Commun 50(2):243-245

23. Muldoon J, Bucur CB, Gregory T (2014) Quest for nonaqueous multivalent secondary batteries: magnesium and beyond. Chem Rev 114(23):11683-11720

24. Ponrouch A, Frontera C, Bardé F, Palacín MR (2016) Towards a calcium-based rechargeable battery. Nat Mater 15(2):169-172

25. Bruce PG, Hardgrave MT, Vincent CA (1989) Steady state current flow in solid binary electrolyte cells. J Electroanal Chem Interfacial Electrochem 271(1):27-34

26. Suo L, Borodin O, Gao T, Olguin M, Ho J, Fan X, Luo C, Wang C, Xu K (2015) "Water-in-salt" electrolyte enables high-voltage aqueous lithium-ion chemistries. Science 350(6263):938-943

27. Nancollas GH (1966) Interactions in electrolyte solutions. Elsevier, Amsterdam

28. Seo DM, Borodin O, Han S-D, Boyle PD, Henderson WA (2012) Electrolyte solvation and ionic association II. Acetonitrile-lithium salt mixtures: highly dissociated salts. J Electrochem Soc 159(9):A1489-A1500

29. Henderson WA (2006) Glyme-lithium salt phase behavior. J. Phys. Chem. B 110(26):13177-13183

30. Rajput NN, Qu X, Sa N, Burrell AK, Persson KA (2015) The coupling between stability and ion pair formation in magnesium electrolytes from first-principles quantum mechanics and classical molecular dynamics. J Am Chem Soc 137:3411-3420

31. Heilman-Miller SL, Thirumalai D, Woodson SA (2001) Role of counterion condensation in folding of the Tetrahymena ribozyme. I. Equilibrium stabilization by cations. J Mol Biol 306(5):1157-1166 
32. Giffin GA, Moretti A, Jeong S, Passerini S (2014) Complex nature of ionic coordination in magnesium ionic liquid-based electrolytes: solvates with mobile $\mathrm{Mg} 2+$ cations. J Phys Chem $\mathrm{C}$ 118(19):9966-9973

33. Doucey L, Revault M, Lautié A, Chaussé A, Messina R (1999) A study of the Li/Li+couple in DMC and PC solvents: part 1: characterization of LiAsF6/DMC and LiAsF6/PC solutions. Electrochim Acta 44(14):2371-2377

34. Baskin A, Prendergast D (2016) Exploration of the detailed conditions for reductive stability of Mg (TFSI) 2 in diglyme: implications for multivalent electrolytes. J Phys Chem C 120(7):3583-3594

35. Wright MR (2007) An introduction to aqueous electrolyte solutions. Wiley, Hoboken

36. Smithson J, Williams R (1958) A possible differentiation between ion-pairs and complexes. J Chem Soc (Resumed) 81:457-462

37. Lu Z, Schechter A, Moshkovich M, Aurbach D (1999) On the electrochemical behavior of magnesium electrodes in polar aprotic electrolyte solutions. J Electroanal Chem 466(2):203-217

38. Saha P, Datta MK, Velikokhatnyi OI, Manivannan A, Alman D, Kumta PN (2014) Rechargeable magnesium battery: current status and key challenges for the future. Prog Mater Sci 66:1-86

39. Tran TT, Lamanna W, Obrovac M (2012) Evaluation of $\mathrm{Mg}\left[\mathrm{N}\left(\mathrm{SO}_{2} \mathrm{CF}_{3}\right)\right.$ 2] 2/acetonitrile electrolyte for use in Mg-ion cells. J Electrochem Soc 159(12):A2005-A2009

40. Elgquist B, Wedborg M (1975) Stability of ion pairs from gypsum solubility degree of ion pair formation between the major constituents of seawater. Mar Chem 3(3):215-225

41. Okoshi M, Yamada Y, Yamada A, Nakai H (2013) Theoretical analysis on de-solvation of lithium, sodium, and magnesium cations to organic electrolyte solvents. J Electrochem Soc 160(11):A2160-A2165

42. Brown I (1988) What factors determine cation coordination numbers? Acta Crystallogr Sect B: Struct Sci 44(6):545-553

43. Lapidus SH, Rajput NN, Qu X, Chapman KW, Persson KA, Chupas PJ (2014) Solvation structure and energetics of electrolytes for multivalent energy storage. Phys Chem Chem Phys 16(40):21941-21945

44. Jeremias S, Giffin GA, Moretti A, Jeong S, Passerini S (2014) Mechanisms of magnesium ion transport in pyrrolidinium bis (trifluoromethanesulfonyl) imide-based ionic liquid electrolytes. J Phys Chem C 118(49):28361-28368

45. Sa N, Rajput NN, Wang H, Key B, Ferrandon M, Srinivasan V, Persson KA, Burrell AK, Vaughey JT (2016) Concentration-dependent electrochemical properties and structural analysis of a simple magnesium electrolyte: magnesium bis (trifluoromethane sulfonyl) imide in diglyme. RSC Adv 6(114):113663-113670

46. Watkins T, Buttry DA (2015) Determination of $\mathrm{Mg} 2+$ speciation in a TFSI-based ionic liquid with and without chelating ethers using Raman spectroscopy. J Phys Chem B 119(23):7003-7014

47. Kimura T, Fujii K, Sato Y, Morita M, Yoshimoto N (2015) Solvation of magnesium ion in triglyme-based electrolyte solutions. J Phys Chem C 119(33):18911-18917

48. Brouillette D, Irish DE, Taylor NJ, Perron G, Odziemkowski M, Desnoyers JE (2002) Stable solvates in solution of lithium bis (trifluoromethylsulfone) imide in glymes and other aprotic solvents: phase diagrams, crystallography and Raman spectroscopy. Phys Chem Chem Phys 4(24):6063-6071

49. Yoshida K, Tsuchiya M, Tachikawa N, Dokko K, Watanabe M (2011) Change from glyme solutions to quasi-ionic liquids for binary mixtures consisting of lithium bis (trifluoromethanesulfonyl) amide and glymes. J Phys Chem C 115(37):18384-18394

50. Ueno K, Yoshida K, Tsuchiya M, Tachikawa N, Dokko K, Watanabe M (2012) Glyme-lithium salt equimolar molten mixtures: concentrated solutions or solvate ionic liquids? J Phys Chem B 116(36):11323-11331

51. Shao Y, Rajput NN, Hu J, Hu M, Liu T, Wei Z, Gu M, Deng X, Xu S, Han KS (2014) Nanocomposite polymer electrolyte for rechargeable magnesium batteries. Nano Energy 12:750-759

52. Seo DM, Boyle PD, Sommer RD, Daubert JS, Borodin O, Henderson WA (2014) Solvate structures and spectroscopic characterization of LiTFSI electrolytes. J Phys Chem B 118(47):13601-13608

53. Mohtadi R, Mizuno F (2014) Magnesium batteries: current state of the art, issues and future perspectives. Beilstein Journal of Nanotechnology 5(1):1291-1311

54. Salama M, Shterenberg I, Gizbar H, Nitoker Eliaz N, Kosa M, Keinan-Adamsky K, Afri M, Shimon LJ, Gottlieb HE, Major DT (2016) Unique behavior of dimethoxyethane (DME)/Mg (N $\left.\left(\mathrm{SO}_{2} \mathrm{CF}_{3}\right) 2\right) 2$ solutions. J Phys Chem C 120:19586-19594 
55. Hefter G (2006) When spectroscopy fails: the measurement of ion pairing. Pure Appl Chem 78(8):1571-1586

56. Sa N, Pan B, Saha-Shah A, Hubaud AA, Vaughey JT, Baker LA, Liao C, Burrell AK (2016) Role of chloride for a simple, non-Grignard Mg electrolyte in ether-based solvents. ACS Appl Mater Interfaces 8(25):16002-16008

57. Shao Y, Liu T, Li G, Gu M, Nie Z, Engelhard M, Xiao J, Lv D, Wang C, Zhang JG, Liu J (2013) Coordination chemistry in magnesium battery electrolytes: how ligands affect their performance. Sci Rep 3:3130

58. Mohtadi R, Matsui M, Arthur TS, Hwang S-J (2012) Magnesium borohydride: from hydrogen storage to magnesium battery. Angew Chem Int Ed 51(39):9780-9783

59. Chang J, Haasch RT, Kim J, Spila T, Braun PV, Gewirth AA, Nuzzo RG (2015) Synergetic role of $\mathrm{Li}+$ during $\mathrm{Mg}$ electrodeposition/dissolution in borohydride diglyme electrolyte solution: voltammetric stripping behaviors on a Pt microelectrode indicative of $\mathrm{Mg}-\mathrm{Li}$ alloying and facilitated dissolution. ACS Appl Mater Interfaces 7(4):2494-2502

60. Hu JZ, Rajput NN, Wan C, Shao Y, Deng X, Jaegers NR, Hu M, Chen Y, Shin Y, Monk J, Chen Z, Qin Z, Mueller KT, Liu J, Persson KA (2018) 25 Mg NMR and computational modeling studies of the solvation structures and molecular dynamics in magnesium based liquid electrolytes. Nano Energy

61. Tutusaus O, Mohtadi R, Arthur TS, Mizuno F, Nelson EG, Sevryugina YV (2015) An efficient halogen-free electrolyte for use in rechargeable magnesium batteries. Angew Chem Int Ed 54(27):7900-7904

62. McArthur SG, Jay R, Geng L, Guo J, Lavallo V (2017) Below the 12-vertex: 10-vertex carborane anions as non-corrosive, halide free, electrolytes for rechargeable $\mathrm{Mg}$ batteries. Chem Commun 53(32):4453-4456

63. Strauss SH (1993) The search for larger and more weakly coordinating anions. Chem Rev 93(3):927-942

64. Douvris C, Michl J (2013) Update 1 of: chemistry of the carba-closo-dodecaborate(-) anion, CB11H12-. Chem Rev 113(10):PR179-PR233

65. Aurbach D, Weissman I, Gofer Y, Levi E (2003) Nonaqueous magnesium electrochemistry and its application in secondary batteries. Chem Rec 3(1):61-73

66. Aurbach D, Gizbar H, Schechter A, Chusid O, Gottlieb HE, Gofer Y, Goldberg I (2002) Electrolyte solutions for rechargeable magnesium batteries based on organomagnesium chloroaluminate complexes. J Electrochem Soc 149(2):A115-A121

67. Muldoon J, Bucur CB, Oliver AG, Sugimoto T, Matsui M, Kim HS, Allred GD, Zajicek J, Kotani Y (2012) Electrolyte roadblocks to a magnesium rechargeable battery. Energy Environ Sci 5(3):5941-5950

68. Gaddum L, French H (1927) The electrolysis of Grignard solutions. J Am Chem Soc 49(5):1295-1299

69. Yoo HD, Shterenberg I, Gofer Y, Gershinsky G, Pour N, Aurbach D (2013) Mg rechargeable batteries: an on-going challenge. Energy Environ Sci 6(8):2265-2279

70. Nakayama Y, Kudo Y, Oki H, Yamamoto K, Kitajima Y, Noda K (2008) Complex structures and electrochemical properties of magnesium electrolytes. J Electrochem Soc 155(10):A754-A759

71. Gizbar H, Vestfrid Y, Chusid O, Gofer Y, Gottlieb HE, Marks V, Aurbach D (2004) Alkyl group transmetalation reactions in electrolytic solutions studied by multinuclear NMR. Organometallics 23(16):3826-3831

72. Vestfried Y, Chusid O, Goffer Y, Aped P, Aurbach D (2007) Structural analysis of electrolyte solutions comprising magnesium-aluminate chloro-organic complexes by Raman spectroscopy. Organometallics 26(13):3130-3137

73. Liu T, Cox JT, Hu D, Deng X, Hu J, Hu MY, Xiao J, Shao Y, Tang K, Liu J (2015) A fundamental study on the $[(\mu-\mathrm{Cl}) 3 \mathrm{Mg} 2$ (THF) 6]+dimer electrolytes for rechargeable $\mathrm{Mg}$ batteries. Chem Commun 51(12):2312-2315

74. Pour N, Gofer Y, Major DT, Aurbach D (2011) Structural analysis of electrolyte solutions for rechargeable $\mathrm{Mg}$ batteries by stereoscopic means and DFT calculations. J Am Chem Soc 133(16):6270-6278

75. Liu T, Shao Y, Li G, Gu M, Hu J, Xu S, Nie Z, Chen X, Wang C, Liu J (2014) A facile approach using $\mathrm{MgCl} 2$ to formulate high performance $\mathrm{Mg} 2+$ electrolytes for rechargeable $\mathrm{Mg}$ batteries. $\mathrm{J}$ Mater Chem A 2(10):3430-3438 
76. Wan LF, Prendergast D (2014) The solvation structure of Mg ions in dichloro complex solutions from first-principles molecular dynamics and simulated X-ray absorption spectra. J Am Chem Soc 136(41):14456-14464

77. Cheng Y, Stolley RM, Han KS, Shao Y, Arey BW, Washton NM, Mueller KT, Helm ML, Sprenkle VL, Liu J (2015) Highly active electrolytes for rechargeable $\mathrm{Mg}$ batteries based on a $[\mathrm{Mg} 2(\mu-\mathrm{Cl})$ 2] 2 + cation complex in dimethoxyethane. Phys Chem Chem Phys 17(20):13307-13314

78. Shterenberg I, Salama M, Gofer Y, Levi E, Aurbach D (2014) The challenge of developing rechargeable magnesium batteries. MRS Bull 39(05):453-460

79. Mizrahi O, Amir N, Pollak E, Chusid O, Marks V, Gottlieb H, Larush L, Zinigrad E, Aurbach D (2008) Electrolyte solutions with a wide electrochemical window for rechargeable magnesium batteries. J Electrochem Soc 155(2):A103-A109

80. Cheng Y, Shao Y, Zhang J-G, Sprenkle VL, Liu J, Li G (2014) High performance batteries based on hybrid magnesium and lithium chemistry. Chem Commun 50(68):9644-9646

81. Gao T, Han F, Zhu Y, Suo L, Luo C, Xu K, Wang C (2015) Hybrid Mg2 +/Li + battery with long cycle life and high rate capability. Adv Energy Mater 5 (5)

82. Pan B, Huang J, Sa N, Brombosz SM, Vaughey JT, Zhang L, Burrell AK, Zhang Z, Liao C (2016) $\mathrm{MgCl} 2$ : the key ingredient to improve chloride containing electrolytes for rechargeable magnesium-ion batteries. J Electrochem Soc 163(8):A1672-A1677

83. Muldoon J, Bucur CB, Oliver AG, Zajicek J, Allred GD, Boggess WC (2013) Corrosion of magnesium electrolytes: chlorides-the culprit. Energy Environ Sci 6(2):482-487

84. Nelson EG, Kampf JW, Bartlett BM (2014) Enhanced oxidative stability of non-Grignard magnesium electrolytes through ligand modification. Chem Commun 50(40):5193-5195

85. Wang F-F, Guo Y-S, Yang J, Nuli Y, Hirano S-I (2012) A novel electrolyte system without a Grignard reagent for rechargeable magnesium batteries. Chem Commun 48(87):10763-10765

86. Zhao-Karger Z, Zhao X, Fuhr O, Fichtner M (2013) Bisamide-based non-nucleophilic electrolytes for rechargeable magnesium batteries. Rsc Adv 3(37):16330-16335

87. Pan B, Lau K-C, Vaughey JT, Zhang L, Zhang Z, Liao C (2017) Ionic liquid as an effective additive for rechargeable magnesium batteries. J Electrochem Soc 164(4):A902-A906

88. Guo Y-S, Zhang F, Yang J, Wang F-F, NuLi Y, Hirano S-I (2012) Boron-based electrolyte solutions with wide electrochemical windows for rechargeable magnesium batteries. Energy Environ Sci 5(10):9100-9106

89. Barile CJ, Barile EC, Zavadil KR, Nuzzo RG, Gewirth AA (2014) Electrolytic conditioning of a magnesium aluminum chloride complex for reversible magnesium deposition. J Phys Chem C 118(48):27623-27630

90. Canepa P, Jayaraman S, Cheng L, Rajput NN, Richards WD, Gautam GS, Curtiss LA, Persson KA, Ceder G (2015) Elucidating the structure of the magnesium aluminum chloride complex electrolyte for magnesium-ion batteries. Energy Environ Sci 8(12):3718-3730

91. Barile CJ, Spatney R, Zavadil KR, Gewirth AA (2014) Investigating the reversibility of in situ generated magnesium organohaloaluminates for magnesium deposition and dissolution. J Phys Chem C 118(20):10694-10699

92. Son S-B, Gao T, Harvey SP, Steirer KX, Stokes A, Norman A, Wang C, Cresce A, Xu K, Ban C (2018) An artificial interphase enables reversible magnesium chemistry in carbonate electrolytes. Nat Chem 10(5):532-539

93. Dudev T, Cowan J, Lim C (1999) Competitive binding in magnesium coordination chemistry: water versus ligands of biological interest. J Am Chem Soc 121(33):7665-7673

94. Pye CC, Rudolph W (1998) An ab initio and Raman investigation of magnesium (II) hydration. J Phys Chem A 102(48):9933-9943

95. Wahab A, Mahiuddin S, Hefter G, Kunz W, Minofar B, Jungwirth P (2005) Ultrasonic velocities, densities, viscosities, electrical conductivities, Raman spectra, and molecular dynamics simulations of aqueous solutions of $\mathrm{Mg}$ (OAc) 2 and $\mathrm{Mg}$ (NO3) 2: Hofmeister effects and ion pair formation. J Phys Chem B 109(50):24108-24120

96. Yagi S, Fukuda M, Ichitsubo T, Nitta K, Mizumaki M, Matsubara E (2015) EQCM analysis of redox behavior of $\mathrm{CuFe}$ Prussian blue analog in $\mathrm{mg}$ battery electrolytes. J Electrochem Soc 162(12):A2356-A2361

97. Bucur CB, Gregory T, Oliver AG, Muldoon J (2015) Confession of a magnesium battery. J Phys Chem Lett 6(18):3578-3591

98. Novak P, Desilvestro J (1993) Electrochemical insertion of magnesium in metal oxides and sulfides from aprotic electrolytes. J Electrochem Soc 140(1):140-144 
99. Lee C, Jeong S-K (2016) A novel superconcentrated aqueous electrolyte to improve the electrochemical performance of calcium-ion batteries. Chem Lett 45(12):1447-1449

100. Buchner R, Chen T, Hefter G (2004) Complexity in "simple" electrolyte solutions: ion pairing in $\mathrm{MgSO}_{4}$ (aq). J Phys Chem B 108(7):2365-2375

101. Zhang Y-H, Chan CK (2000) Study of contact ion pairs of supersaturated magnesium sulfate solutions using Raman scattering of levitated single droplets. J Phys Chem A 104(40):9191-9196

102. Kester DR, Pytkowicx RM (1969) Sodium, magnesium, and calcium sulfate ion-pairs in seawater at $25^{\circ} \mathrm{C}$. Limnol Oceanogr 14(5):686-692

103. Nam KW, Kim S, Lee S, Salama M, Shterenberg I, Gofer Y, Kim J-S, Yang E, Park CS, Kim J-S (2015) The high performance of crystal water containing manganese birnessite cathodes for magnesium batteries. Nano Lett 15(6):4071-4079

104. Novák P, Scheifele W, Joho F, Haas O (1995) Electrochemical insertion of magnesium into hydrated vanadium bronzes. J Electrochem Soc 142(8):2544-2550

105. Yuan W, Günter JR (1995) Insertion of bivalent cations into monoclinic $\mathrm{NbS}_{3}$ prepared under high pressure and their secondary batteries. Solid State Ionics 76(3-4):253-258

106. Novák P, Shklover V, Nesper R (1994) Magnesium insertion in vanadium oxides: a structural study. Z Phys Chem 185(1):51-68

107. Shklover V, Haibach T, Ried F, Nesper R, Novak P (1996) Crystal structure of the product of $\mathrm{Mg} 2$ + insertion into V2O5 single crystals. J Solid State Chem 123(2):317-323

108. Galy J, Pouchard M (1967) Oxygenated vanadium bronzes with divalent insertion element. V2O5VO2-MGO and V2O5-VO2-zno systems. Bull Soc Chim Fr 1:261

109. Bouhaouss A, Aldebert P, Baffier N, Livage J (1985) Ionic intercalation processes in V205 gels. Revue De Chimie Minerale 22(3):417-426

110. Novák P, Imhof R, Haas O (1999) Magnesium insertion electrodes for rechargeable nonaqueous batteries-a competitive alternative to lithium? Electrochim Acta 45(1):351-367

111. Song J, Noked M, Gillette E, Duay J, Rubloff G, Lee SB (2015) Activation of a $\mathrm{MnO}_{2}$ cathode by water-stimulated $\mathrm{Mg} 2+$ insertion for a magnesium ion battery. Phys Chem Chem Phys 17(7):5256-5264

112. Havel J, Hoegfeldt E (1974) Activities in the systems Mg (2+)-NA (+)-X (-)-CLO4 (-) WITH $\mathrm{X}=\mathrm{CL}(-)$, BR (-) AND SCN (-). The possible formation of Mgx (+) ion Pairs. ChemInform $5(15)$

113. Porter C, Boyd R (1971) A dielectric study of the effects of melting on molecular relaxation in poly(ethylene oxide) and polyoxymethylene. Macromolecules 4(5):589-594

114. Mao G, Saboungi ML, Price DL, Armand MB, Howells WS (2000) Structure of liquid PEOLiTFSI electrolyte. Phys Rev Lett 84:5536-5539

115. Bakker A, Gejji S, Lindgren J, Hermansson K, Probst MM (1995) Contact ion pair formation and ether oxygen coordination in the polymer electrolytes $\mathrm{M}\left[\mathrm{N}\left(\mathrm{CF}_{3} \mathrm{SO}_{2}\right)_{2}\right]_{2} \mathrm{PEO}_{\mathrm{n}}$ for $\mathrm{M}=\mathrm{Mg}$, Ca. Sr and Ba. Polymer 36(23):4371-4378

116. Marcus Y, Hefter G (2006) Ion pairing. Chem Rev 106:4585-4621

117. Pesko DM, Timachova K, Bhattacharya R, Smith MC, Villaluenga I, Newman J, Balsara NP (2017) Negative transference numbers in poly(ethylene oxide)-based electrolytes. J Electrochem Soc 164(11):E3569-E3575

118. Panday A, Mullin S, Gomez ED, Wanakule N, Chen VL, Hexemer A, Pople J, Balsara NP (2009) Effect of molecular weight and salt concentration on conductivity of block copolymer electrolytes. Macromolecules 42:4632-4637

119. Chintapalli M, Le TNP, Venkatesan NR, Mackay NG, Rojas AA, Thelen JL, Chen XC, Devaux D, Balsara NP (2016) Structure and Ionic Conductivity of Polystyrene-blockpoly(ethylene oxide) Electrolytes in the High Salt Concentration Limit. Macromolecules acs. macromol.5b02620

120. Rey I, Lassègues JC, Grondin J, Servant L (1998) Infrared and Raman study of the PEO-LiTFSI polymer electrolyte. Electrochim Acta 43:1505-1510

121. Edman L (2000) Ion association and ion solvation effects at the crystalline-amorphous phase transition in PEO-LiTFSI. J Phys Chem B 104:7254-7258

122. Borodin O, Smith GD (2006) Mechanism of ion transport in amorphous poly (ethylene oxide)/ LiTFSI from molecular dynamics simulations. Macromolecules 39:1620-1629

123. Reddy MJ, Chu PP (2002) Ion pair formation and its effect in PEO:Mg solid polymer electrolyte system. J Power Sources 109(2):340-346 
124. Vittadello M, Biscazzo S, Lavina S, Fauri M, Noto VD (2002) Vibrational studies of the ionpolymer interactions in a -hydro-N-oligo (oxyethylene). Solid State Ionic 147:341-347

125. Di Noto V, Vittadello M (2002) Mechanism of ionic conductivity in poly(ethylene glycol 400)/ $(\mathrm{MgCl} 2) \mathrm{x}$ polymer electrolytes: studies based on electrical spectroscopy. Solid State Ionics 147(3):309-316

126. Di Noto V (2002) Electrical spectroscopy studies of lithium and magnesium polymer electrolytes based on PEG400. J Phy Chem B 106(43):11139-11154

127. Thelen JL, Inceoglu S, Venkatesan NR, Mackay NG, Balsara NP (2016) Relationship between Ion dissociation, melt morphology, and electrochemical performance of lithium and magnesium single-ion conducting block copolymers. Macromolecules 23(2016):9139-9147

128. Saito M, Ikuta H, Uchimoto Y, Wakihara M (2003) Interaction between the Lewis acid group of a borate ester and various anion species in a polymer electrolyte containing Mg salt. J Phys ChemB 107:11608-11614

129. Lee DK, Allcock HR (2010) The effects of cations and anions on the ionic conductivity of poly[bis(2-(2-methoxyethoxy)ethoxy)phosphazene] doped with lithium and magnesium salts of trifluoromethanesulfonate and bis(trifluoromethanesulfonyl)imidate. Solid State Ionics 181:1721-1726

130. Ryu S-W, Trapa PE, Olugebefola SC, Gonzalez-Leon JA, Sadoway DR, Mayes AM (2005) Effect of counter ion placement on conductivity in single-ion conducting block copolymer electrolytes. $\mathrm{J}$ Electrochem Soc 152:A158

131. Kato Y, Yokoyama S, Ikuta H, Uchimoto Y, Wakihara M (2001) Thermally stable polymer electrolyte plasticized with PEG-borate ester for lithium secondary battery. Electrochem Commun 3:128-130

132. Savoie BM, Webb MA, Miller TF (2016) Enhancing cation diffusion and suppressing anion diffusion via Lewis-acidic polymer electrolytes. J Phys Chem Lett 8:1-26

133. Diederichsen KM, Buss HG, McCloskey BD (2017) The compensation effect in the Vogel-Tammann-Fulcher (VTF) equation for polymer-based electrolytes. Macromolecules 50(10):3831-3840

134. Zhang H, Liu C, Zheng L, Xu F, Feng W, Li H, Huang X, Armand M, Nie J, Zhou Z (2014) Lithium bis(fluorosulfonyl)imide/poly(ethylene oxide) polymer electrolyte. Electrochim Acta 133:529-538

135. Osman Z, Zainol NH, Samin SM, Chong WG, Md Isa KB, Othman L, Supa'At I, Sonsudin F (2014) Electrochemical impedance spectroscopy studies of magnesium-based polymethylmethacrylate gel polymer electrolytes. Electrochim Acta 131:148-153

136. Kumar GG, Munichandraiah N (2002) Poly (methylmethacrylate)—magnesium triflate gel polymer electrolyte for solid state magnesium battery application. Electrochim Acta 47(7):1013-1022

137. Pandey GP, Hashmi SA (2009) Experimental investigations of an ionic-liquid-based, magnesium ion conducting, polymer gel electrolyte. J Power Sources 187:627-634

138. Tang X, Muchakayala R, Song S, Zhang Z, Polu AR (2016) A study of structural, electrical and electrochemical properties of PVdF-HFP gel polymer electrolyte films for magnesium ion battery applications. J Ind Eng Chem 37:67-74

139. Ponrouch A, Frontera C, Barde F, Palacin MR (2016) Towards a calcium-based rechargeable battery. Nat Mater 15(2):169-172

140. Pan H, Shao Y, Yan P, Cheng Y, Han KS, Nie Z, Wang C, Yang J, Li X, Bhattacharya P (2016) Reversible aqueous zinc/manganese oxide energy storage from conversion reactions. Nature Energy 1:16039

141. Hayes AC, Kruus P, Adams WA (1984) Raman spectroscopic study of aqueous (NH4)2SO4 and ZnSO4 solutions. J Solution Chem 13(1):61-75

142. Fujii K, Fujimori T, Takamuku T, Kanzaki R, Umebayashi Y, Ishiguro S-I (2006) Conformational equilibrium of bis (trifluoromethanesulfonyl) imide anion of a room-temperature ionic liquid: Raman spectroscopic study and DFT calculations. J Phys Chem B 110(16):8179-8183

143. Herstedt M, Smirnov M, Johansson P, Chami M, Grondin J, Servant L, Lassegues J (2005) Spectroscopic characterization of the conformational states of the bis (trifluoromethanesulfonyl) imide anion (TFSI -). J Raman Spectrosc 36(8):762-770

144. Martinelli A, Matic A, Johansson P, Jacobsson P, Börjesson L, Fernicola A, Panero S, Scrosati B, Ohno H (2011) Conformational evolution of TFSI - in protic and aprotic ionic liquids. J Raman Spectrosc 42(3):522-528 
145. Fujii K, Nonaka T, Akimoto Y, Umebayashi Y, Ishiguro S-I (2008) Solvation structures of some transition metal (II) ions in a room-temperature ionic liquid, 1-ethyl-3-methylimidazolium bis (trifluoromethanesulfonyl) amide. Anal Sci 24(10):1377-1380

146. Fujii K, Nonaka T, Akimoto Y, Umebayashi Y, Ishiguro S-I (2008) Solvation Structures of Some Transition Metal(II) Ions in a Room-Temperature Ionic Liquid, 1-Ethyl-3-methylimidazolium Bis(trifluoromethanesulfonyl)amide. Anal Sci 24(10):1377-1380

147. Arellano IH, Huang J, Pendleton P (2016) Computational insights into the molecular interaction and ion-pair structures of a novel zinc-functionalized ionic liquid,[Emim][Zn (TFSI) 3]. Spectrochim Acta Part A Mol Biomol Spectrosc 153:6-15

148. Li XY, Nie J (2003) Density functional theory study on metal bis (trifluoromethylsulfonyl) imides: electronic structures, energies, catalysis, and predictions. J Phys Chem A 107(31):6007-6013

149. Frech R, Huang W (1993) Ionic association in poly (propylene oxide) complexed with divalent metal trifluoromethanesulfonate salts. Solid State Ionics 66(1-2):183-188

150. Kumar GG, Sampath S (2004) Spectroscopic characterization of a gel polymer electrolyte of zinc triflate and polyacrylonitrile. Polymer 45(9):2889-2895

151. Kumar GG, Sampath S (2005) Electrochemical and spectroscopic investigations of a gel polymer electrolyte of poly (methylmethacrylate) and zinc triflate. Solid State Ionics 176(7):773-780

152. Latham RJ, Linford RG, Schlindwein WS (1989) Cation-oxygen geometry in polymer electrolytes: interpretation of EXAFS results. Faraday Discuss Chem Soc 88:103-111

153. Einset A, Schlindwein W, Latham R, Linford R, Pynenburg R (1991) Investigation of ZnBr 2: PEO polymer electrolyte characteristics. J Electrochem Soc 138(6):1569-1574

154. Han S-D, Rajput NN, Qu X, Pan B, He M, Ferrandon MS, Liao C, Persson KA, Burrell AK (2016) Origin of electrochemical, structural, and transport properties in nonaqueous zinc electrolytes. ACS Appl Mater Interfaces

155. Westerhausen M, Koch A, Görls H, Krieck S (2016) Heavy Grignard Reagents: Synthesis. Chemical Behavior, and Reactivity. Chemistry-A European Journal, Physical and Structural Properties

156. Dompablo MEA-D, Krich C, Nava-Avendaño J, Biškup N, Palacín MR, Bardé F (2016) A joint computational and experimental evaluation of $\mathrm{CaMn} 2 \mathrm{O} 4$ polymorphs as cathode materials for $\mathrm{Ca}$ ion batteries. Chem Mater 28(19):6886-6893

157. Wang RY, Wessells CD, Huggins RA, Cui Y (2013) Highly Reversible Open Framework Nanoscale Electrodes for Divalent Ion Batteries. Nano Lett 13(11):5748-5752

158. Padigi P, Goncher G, Evans D, Solanki R (2015) Potassium barium hexacyanoferrate-a potential cathode material for rechargeable calcium ion batteries. J Power Sources 273:460-464

159. Lipson AL, Pan B, Lapidus SH, Liao C, Vaughey JT, Ingram BJ (2015) Rechargeable Ca-Ion Batteries: a New Energy Storage System. Chem Mater 27(24):8442-8447

160. Pauling L (1927) The sizes of ions and the structure of ionic crystals. J Am Chem Soc 49(3):765-790

161. Qu X, Jain A, Rajput NN, Cheng L, Zhang Y, Ong SP, Brafman M, Maginn E, Curtiss LA, Persson KA (2015) The Electrolyte Genome project: a big data approach in battery materials discovery. Comput Mater Sci 103:56-67

162. Qu X, Zhang Y, Rajput NN, Jain A, Maginn E, Persson KA (2017) Computational design of new magnesium electrolytes with improved properties. J Phys Chem C 121(30):16126-16136

163. Johansson P, Jacobsson P (2006) Rational design of electrolyte components by ab initio calculations. J Power Sources 153(2):336-344

164. Wahab A, Douvris C, Klíma J, Šembera F, Ugolotti J, Kaleta J, Ludvík J, Michl J (2017) Anodic Oxidation of 18 Halogenated and/or Methylated Derivatives of CB11H12-. Inorg Chem 56(1):269-276

165. Frankel GS (1998) Pitting corrosion of metals: a review of the critical factors. J Electrochem Soc 145(6):2186-2198

166. Kim DY, Park MS, Lim Y, Kang Y-S, Park J-H, Doo S-G (2015) Computational comparison of oxidation stability: solvent/salt monomers vs. solvent-solvent/salt pairs. J Power Sources 288:393-400

167. Zhao-Karger Z, Gil Bardaji ME, Fuhr O, Fichtner M (2017) A new class of non-corrosive, highly efficient electrolytes for rechargeable magnesium batteries. Journal of Materials Chemistry A 5(22):10815-10820 